\title{
WestVirginiaUniversity
}

THE RESEARCH REPOSITORY @ WVU

Graduate Theses, Dissertations, and Problem Reports

2018

\section{Chinese Elements and Influence in Tan Dun's Eight Memories in Watercolor}

Qian Xu

Follow this and additional works at: https://researchrepository.wvu.edu/etd

\section{Recommended Citation}

$\mathrm{Xu}$, Qian, "Chinese Elements and Influence in Tan Dun's Eight Memories in Watercolor" (2018). Graduate Theses, Dissertations, and Problem Reports. 6991.

https://researchrepository.wvu.edu/etd/6991

This Dissertation is protected by copyright and/or related rights. It has been brought to you by the The Research Repository @ WVU with permission from the rights-holder(s). You are free to use this Dissertation in any way that is permitted by the copyright and related rights legislation that applies to your use. For other uses you must obtain permission from the rights-holder(s) directly, unless additional rights are indicated by a Creative Commons license in the record and/ or on the work itself. This Dissertation has been accepted for inclusion in WVU Graduate Theses, Dissertations, and Problem Reports collection by an authorized administrator of The Research Repository @ WVU.

For more information, please contact researchrepository@mail.wvu.edu. 
Chinese Elements and Influence in Tan Dun's Eight Memories in Watercolor

\author{
Qian Xu \\ Doctoral Document submitted to the \\ College of Creative Arts \\ at West Virginia University \\ in partial fulfillment of the requirements \\ for the degree of \\ Doctor of Musical Arts \\ in \\ Music Performance
}
Peter Amstutz, DMA, Chair and Research Advisor
William Haller, DMA
Michael Ibrahim, DMA
Bruce S. Kang, PhD
James Miltenberger, DMA

School of Music

Morgantown, West Virginia

2018

Keywords: Piano, Piano Suite, Chinese repertoire, Tan Dun

Copyright $\mathbb{2} 2018$ by Qian Xu 


\title{
ABSTRACT \\ Chinese Elements and Influence in Tan Dun's Eight Memories in Watercolor
}

\begin{abstract}
Qian Xu
Since the second half of the twentieth century, Asian composers have formed a new force which has been highly influential in Western classical music. ChineseAmerican composer Tan Dun is undoubtedly one of the most significant figures among living Asian composers. He gave his first opus number to the piano suite Eight Memories in Watercolor, originally titled Eight Sketches in Hunan Accent, which is now regarded as one of most important pieces in the modern Chinese piano repertoire.
\end{abstract}

This study aims first to gain a deeper understanding of this piece. After an introduction, Chapter Two presents an overview of Tan Dun's biography and his works for piano. Chapter Three covers the compositional background, general information, and formal structure of Eight Memories in Watercolor. Chapters Four and Five illustrate respectively the Chinese cultural and philosophical influence on this piece and the use of Chinese musical elements in this music. Chapter Six summarizes the previous findings and concludes the paper. 
To my parents, my husband, and my son. 


\section{ACKNOWLEDGMENTS}

I would like to express my appreciation to all those who helped and supported me during my musical journey.

First of all, I would like to express my deepest gratitude to my mentor, Dr. Peter Amstutz, who has also served as the chair of my committee throughout the course of my studies at the West Virginia University. He has always inspired and encouraged my musical ideas. Without his support, I would not have achieved what I have during my time at WVU, not to mention his mentoring and the endless time he has spent advising and proofreading this document.

I am fortunate to have had such a supportive faculty committee during my time at WVU. The other members include Dr. William Haller, Dr. Michael Ibrahim, Dr. Bruce S. Kang, and Dr. James Miltenberger. Without their kind flexibility regarding my situation, I could not have finished this document.

Although neither of them received any musical training, my parents never wavered in their support throughout my musical studies. I am also fortunate that my parents-in-law also provided generous help during my doctoral study. Last, but not least, I wish to thank my beloved husband, Tak Chiu Wong, who has always been encouraging and supportive throughout my study in music. 


\section{TABLE OF CONTENTS}

CHAPTER 1 Introduction

CHAPTER 2 Tan Dun and His Piano Works ............................................................

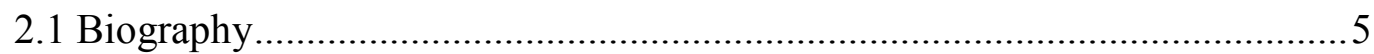

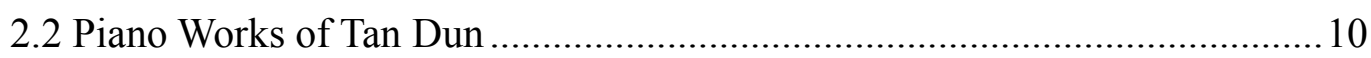

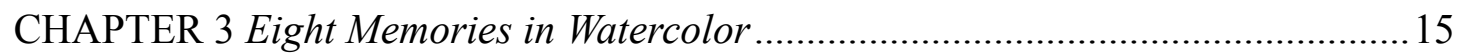

3.1 Compositional Background ....................................................................

3.2 General Information and Formal Structures ...................................................17

3.2.1. Missing Moon 《秋月》 ............................................................................... 19

3.2.2. Staccato Beans 《逗》.................................................................................20

3.2.3. Herdboy's Song 《山歌》..................................................................................21

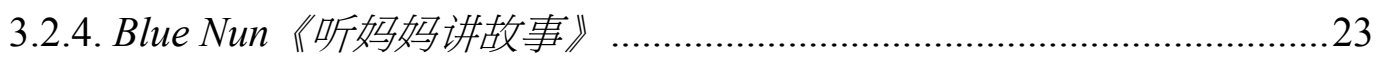

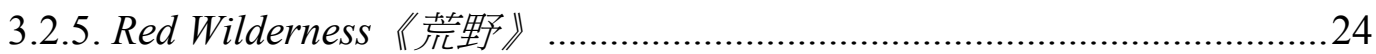

3.2.6. Ancient Burial 《古葬》 .....................................................................................25

3.2.7. Floating Clouds 《云》 ...................................................................................26

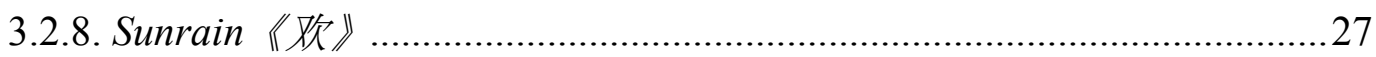

CHAPTER 4 Chinese Cultural Influence on Eight Memories in Watercolor ...............29

4.1 Influenced by Chinese Traditional Custom.................................................29

4.2 Influenced by Chinese Cultural Revolution (1966-1976)...............................29

4.3 Chinese Traditional Culture Influence in Hunan Province - Xiang-Chu

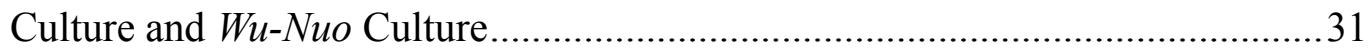

CHAPTER 5 Application of Chinese Musical Elements in Eight Memories in

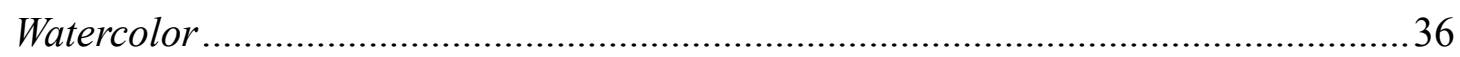

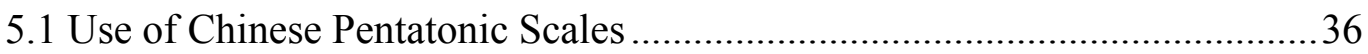

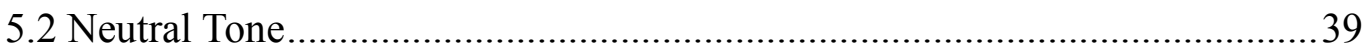

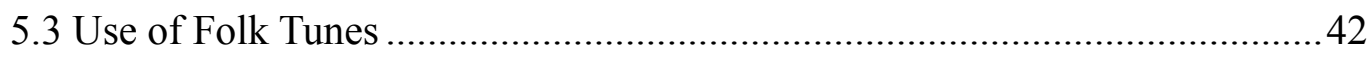

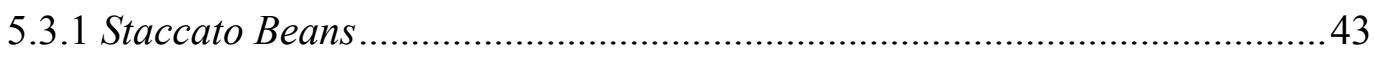

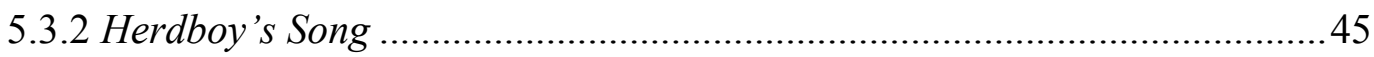

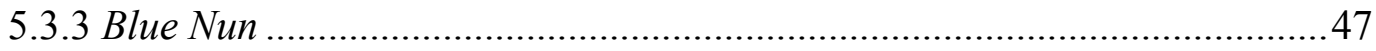

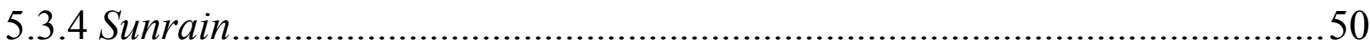

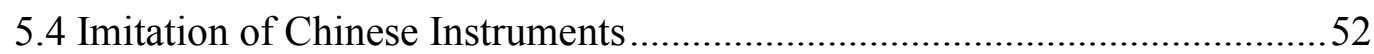

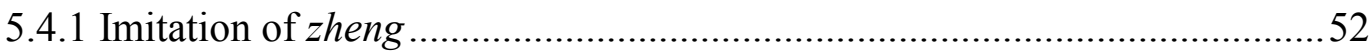

5.4.2 Imitation of Chinese gong and drums......................................................57 


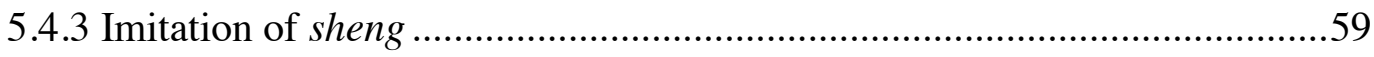

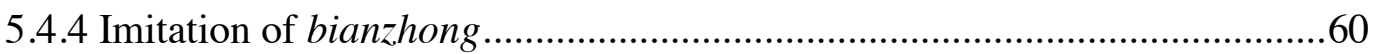

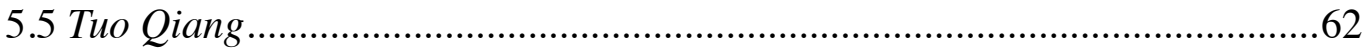

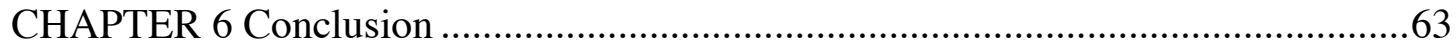

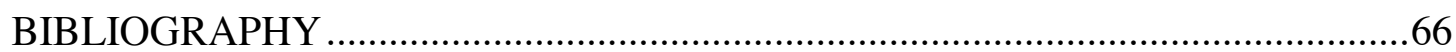

APPENDIX Score with Annotations by the Author ...................................................... 71 


\section{LIST OF FIGURES}

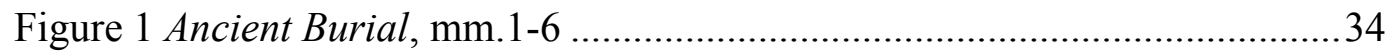

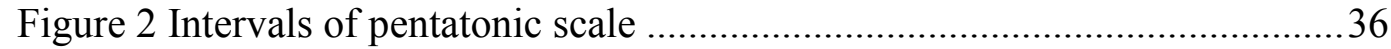

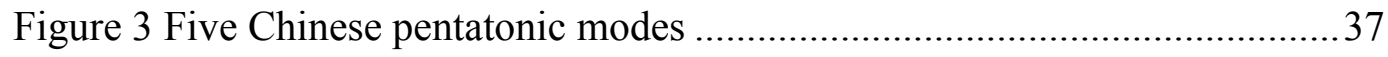

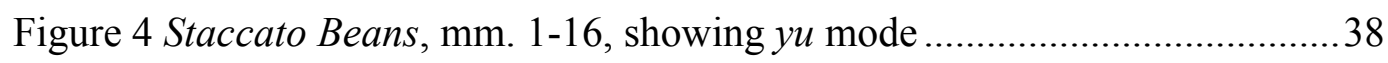

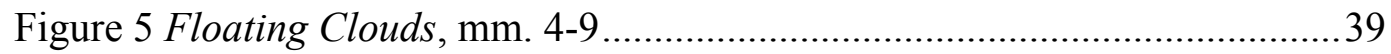

Figure 6 F-sharp replacement of neutral tone F in Staccato Beans ......................40

Figure 7 Herdboy's Song, mm. 1-2 .............................................................. 41

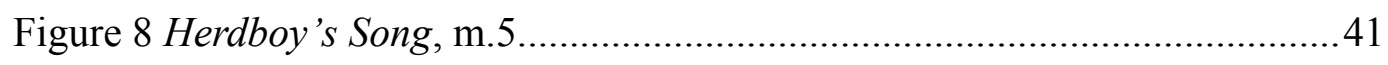

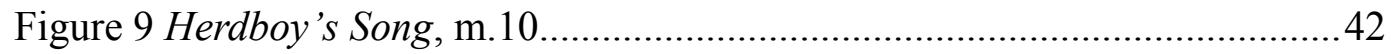

Figure 10 D-sharp and G-sharp replacements of neutral tone D and G respectively

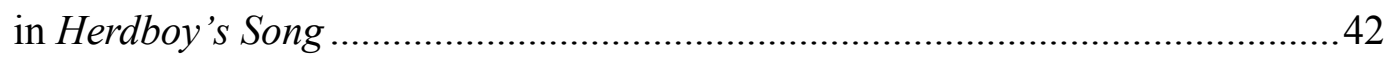

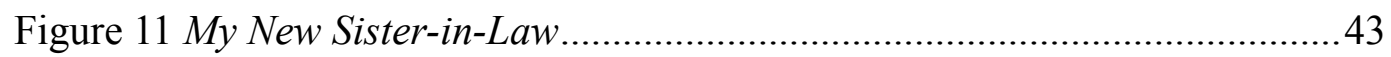

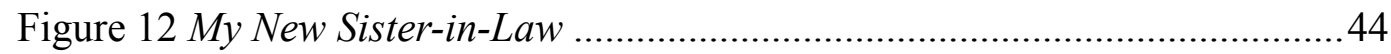

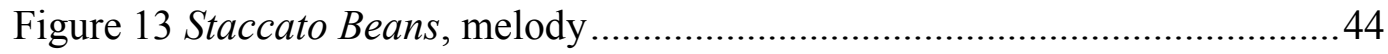

Figure 14 Staccato Beans, mm. 1-16 ...................................................................45

Figure 15 Grass is Greener on the Other Hill...................................................46

Figure 16 Grass is Greener on the Other Hill.................................................4

Figure 17 Herdboy's Song, mm. 3-4 ................................................................ 47

Figure 18 A Girl from the Country is Coming into Town ......................................4.48

Figure 19 A Girl from the Country is Coming into Town .....................................49

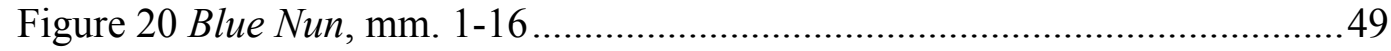

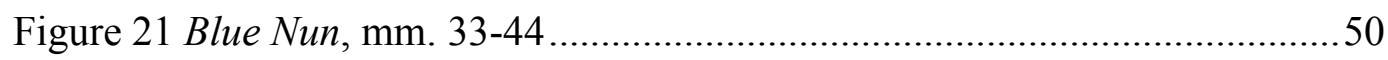

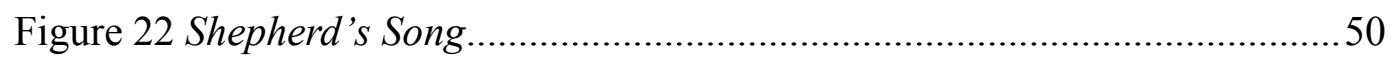

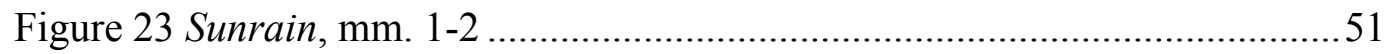

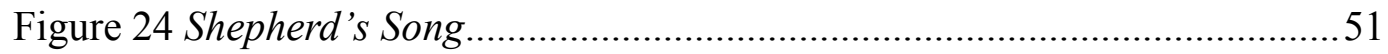

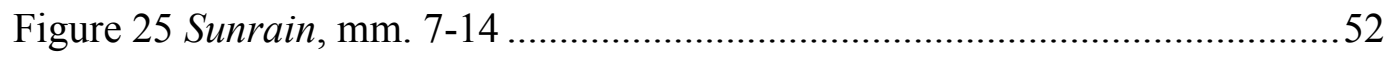

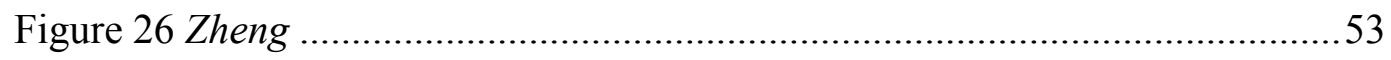

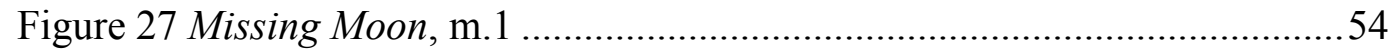

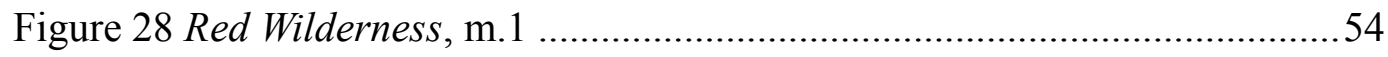

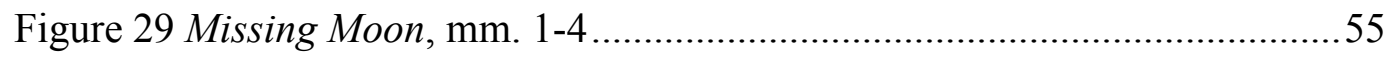

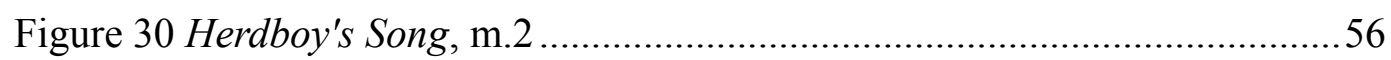

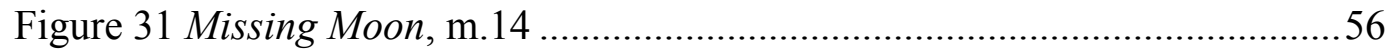

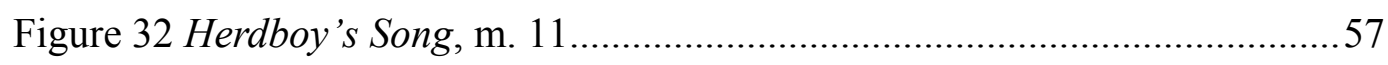

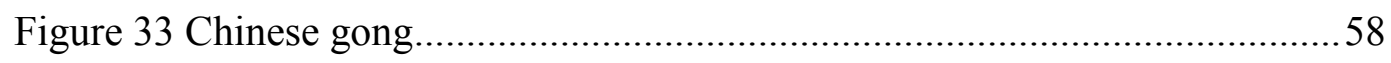

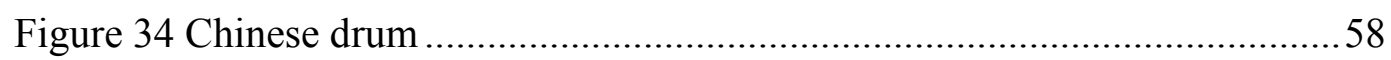

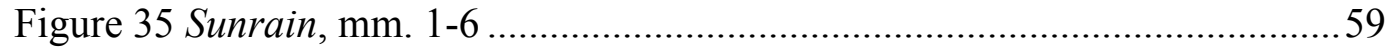

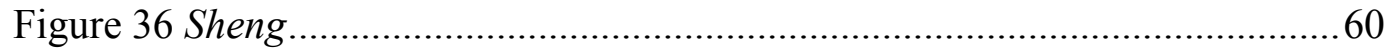




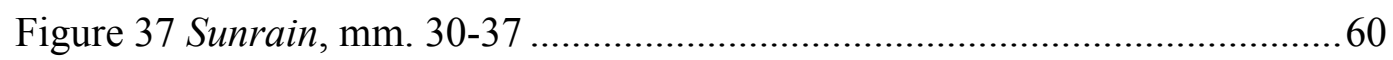

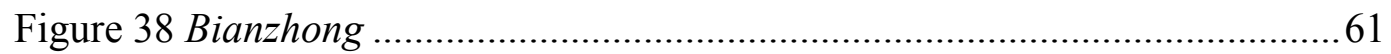

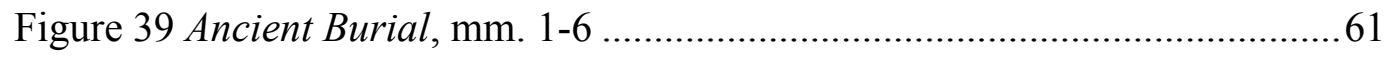

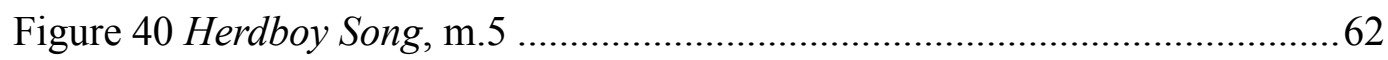




\section{CHAPTER 1}

\section{Introduction}

Since the beginning of the twentieth century, the development of Western art

music has exhibited dramatic changes which are unmatched in any previous musical history. One of the most interesting characteristics of music is the rich diversity of styles, many of which were created or inspired by different cultures. Early in the twentieth century, Oriental aesthetics and philosophy had a great impact on Western composers, including John Cage, Claude Debussy, Lou Harrison, and Maurice Ravel, influencing their works in different ways. Since the second half of the twentieth century, Asian composers (especially those from Eastern Asian countries) have formed a new force which has had an incredible impact on Western classical music. Composers such as Chou Wen-Chung, Toru Takemitsu, and Isang Yun created their own distinctive personal styles that draw upon extensive influences from both Western tradition and their own cultural backgrounds.

Chinese-American composer Tan Dun, ${ }^{1}$ who was born in 1957 , is undoubtedly one of the most influential figures among living Asian composers. In addition to his creative concert music, opera, and mixed-media productions, the general public saw his music come to a peak of fame in 2001, when he received the Academy Award for

\footnotetext{
1 "Tan" is the family name; "Dun" is the given name. The two are normally presented in the Asian way - family name first, then the given name. Thus, Tan Dun can be referred to as Dr. Tan or Mr. Tan, but not as Dr. Dun or Mr. Dun.
} 
Best Original Score for the music to the film Crouching Tiger, Hidden Dragon. Tan is enjoying praise and commissions from both China and the Western world, including the Metropolitan Opera, London Symphony Orchestra, and Berlin Philharmonic.

Tan's exceptional talent allowed him to be self-taught from an early age; in fact, he did not receive any childhood musical training at all before he entered the Central Conservatory in Beijing. He started his musical journey in a highly personal style, rooted in Chinese traditional culture with Western composition techniques learned during his undergraduate education.

Tan gave his first opus number to the piano suite Eight Memories in Watercolor, originally titled Eight Sketches in Hunan Accent. This piece was written right after the Cultural Revolution era, just as Western music began to be permitted again in China, when the young composer had just been admitted to study music in school. This special cultural background gives the music a distinctive spirit and powerful emotion. The use of Chinese musical elements is dominant throughout this piece, together with skillful Western compositional technique. The eight movements, with their differing characteristics, offer a distinctive stylistic variety within this work. Eight Memories in Watercolor is now regarded as one of most important pieces in the modern Chinese piano repertoire. This piece owes its popularity to pianists and music teachers from all over the world. The movement Blue Nun was selected for the 
syllabus of examination for piano of the Standard Grade Examination Committee of the Central Conservatory of Music in China, ${ }^{2}$ and the movement Staccato Beans was selected for the syllabus of Grade Five piano examination of the Associated Board of the Royal Schools of Music in the United Kingdom. ${ }^{3}$

This study aims first to gain a deeper understanding of this beautiful piece of music and then to share with the reader some of the ways that Tan Dun merges Western compositional technique and Eastern musical elements in his writing style. Throughout the process, we can seek a better understanding of Tan's musical language and can explore Chinese cultural influences on his music. These insights can inform interpretive decisions by pianists who want to perform this piece.

There are six chapters in this project, listed as follows:

1. Introduction

2. Tan Dun and His Piano Works

3. Eight Memories in Watercolor

4. Chinese Cultural Influence on Eight Memories in Watercolor

5. Application of Chinese musical elements in Eight Memories in Watercolor

6. Conclusion

\footnotetext{
2 "Syllabus," Standard Grade Examination Committee of the Central Conservatory of Music, accessed December 20, 2017, http://wap.kjwyh.ccom.edu.cn/index/index/textbook.

3 “Piano 2017\&2018, Grade 5 Piano," Associated Board of the Royal Schools of Music, accessed December 20, 2017, https://gb.abrsm.org/fileadmin/user_upload/syllabuses/piano0517.pdf.
} 
After the current introduction, Chapter Two presents an overview of Tan Dun's biography and his works for piano. Chapter Three covers the compositional background, general information, and formal structure of Eight Memories in Watercolor. Chapters Four and Five illustrate respectively the Chinese cultural and philosophical influence on this piece and the use of Chinese musical elements in this music. Chapter Six summarizes the previous findings and concludes the paper. 


\section{CHAPTER 2}

\section{Tan Dun and His Piano Works}

\subsection{Biography}

Tan Dun was born on August 18, 1957, in the city of Changsha, the capital of the Hunan Province, China. During his childhood, he was fascinated by the ceremonies and rituals of the Shaman, a primitive religious practice from ancient China, within which music is an inseparable part of the activities. ${ }^{4}$ During 1966 to 1976 , although he was enthusiastic about music, Tan was discouraged from pursuing music and, like many other members of the nation's younger generation at that time, he was sent to the countryside in order to labor in the fields with the farmers and learn the importance of hard work. ${ }^{5}$ Therefore, he received neither schooling nor early musical training during his teenage years. Despite his lack of formal training, Tan was called upon as a violist and arranger, following a ferry accident that resulted in the deaths of several members of a Peking opera troupe. During this period, he made arrangements of native songs and spent a significant amount of time collecting and studying folk music around the Hunan area. ${ }^{6}$

In 1976, the Cultural Revolution ended with the death of Chairman Mao; the

\footnotetext{
4 Andreas Lüderwaldt and Thomas Sebastian Köhn, "Sámi music," Grove Music Online, accessed December 21, 2017, https://doi-org.libezproxy.hkbu.edu.hk/10.1093/gmo/9781561592630.article.24461.

5 Yutong Shao, "A study on Chinese Modal Operas” (PhD diss., Northeast Normal University, 2007).

${ }^{6}$ Ibid.
} 
country's educational systems were also restored. During this period, composers

regained the freedom to create their own work without fear of punishment from the

government. Many restrictions on Western art were relaxed and the political tensions

between China and the West decreased. Tan was admitted at the age of 19 to the

newly reopened Central Conservatory of Music in Beijing, where he studied

composition with Zhao Xindao and Li Yinghai, and conducting with Li Huade. Tan

had never had the chance to encounter Western classical music before his study in the

Central Conservatory. He was soon fascinated by these styles and especially "became

a slave of [music by] Beethoven."7 He and his fellow students discovered a wide

range of formerly suppressed twentieth-century music, from Bartók and Schoenberg

to Boulez; they were also stimulated by visits from guest composers including Crumb,

Goehr, Henze, Takemitsu, and Yun. ${ }^{8}$

Tan's first composition was Eight Sketches in Hunan Accent, a suite of eight

miniatures for piano, written in 1978 as a "diary of longing" when he was homesick

and "longed for the folksongs and savored the memories of his childhood."10 In 1980,

Tan finished his first symphony, Li Sao, a work which is technically more advanced

\footnotetext{
7 Eline Flipse, “Chinese Classical Composers: Interview Tan Dun,” YouTube, accessed December 21, 2017, https://www. youtube.com/watch?v=T9WBfn1DgDo.

8 Joanna C. Lee, “Tan Dun,” Grove Music Online, accessed December 21, 2017, https://doi-org.libezproxy.hkbu.edu.hk/10.1093/gmo/9781561592630.article.42657.

9 Dun Tan, "Eight Memories in Watercolor," Tan Dun Official Website, accessed December 21, 2017, http://tandun.com/composition/eight-memories-in-watercolor.

10 Ibid.
} 
and also more personal than many of the symphonies produced by Chinese composers

of the older generations. This work was awarded a prize in the First National

Competition of Orchestra Works in $1981 .^{11}$ His Feng-Ya-Song for string quartet,

based on ancient Chinese poetry, was awarded the Weber prize in the Dresden

International Weber Chamber Music Competition in 1983, making him the first

Chinese composer to win an international prize since the start of the Communist

Revolution in $1949 .{ }^{12}$ In 1985, he wrote On Taoism for Voice, Bass Clarinet,

Contrabassoon, and Orchestra as a memorial to his grandmother's death and also to

preserve the sounds of village life in China that are slowly vanishing during the $21^{\text {st }}$

century. This is one of the most significant pieces he wrote during this period, where

he tried to "explore sound in many dimensions: microtonal, swimming among

frequencies, expanding timbres as the ink of calligraphy spreads on rice paper."13

This piece played an extremely important role in his admission into the doctoral

program at Columbia University in 1986; it also won the Bartók International

Composition Competition in 1989.

In 1986, Tan traveled to the United States and began his doctoral study at

Columbia University. He studied composition with Chou Wen-Chung and Mario

\footnotetext{
11 Ying Li, "The Research of Sorcery Colors in Tan Dun's Music" (MM diss., Shandong University, 2014).

12 “Tan Dun Biography,” Musician Guide, accessed December 21, 2017, http://www.musicianguide.com/biographies/1608003000/Tan-Dun.html.

13 Dun Tan, “On Taoism," Tan Dun Official Website, accessed December 21, 2017, http://tandun.com/composition/on-taoism.
} 
Davidovsky for three years. The first piece he wrote in the United States was also a suite of eight miniatures, Eight Colors for String Quartet, which is the composer's first exploration of the lyrical, concentrated language of Western atonality. ${ }^{14}$ Tan graduated and received his Doctoral of Musical Arts degree in composition in 1989. He did not write a large number of compositions during his doctoral study.

Since 1990, Tan has lived in New York and continues to develop his compositional and conducting career. He has had opportunity to meet many influential composers; among them, John Cage had a great impact on his musical style. Tan wrote $C-A-G-E$ for piano in 1993 , in homage to Cage. Tan was soon regarded as one of the leading living composers of China, continuing to compose with great creativity in different genres, including chamber music, orchestral works, opera, oratorio, film music, music for different media, and "organic music"—an iconic genre that he created by using the sound of natural materials like water as the main instrument of the music.

Tan's music has been recorded, performed, and commissioned by the world's leading musicians and ensembles, including Yo-Yo Ma, Lang Lang, Martin Grubinger, the Kronos Quartet, the New York Philharmonic Orchestra, the Hong Kong Philharmonic Orchestra, the Berlin Philharmonic Orchestra, the Los Angeles

\footnotetext{
14 Dun Tan, "Eight Colors for String Quartet," Tan Dun Official Website, accessed December 21, 2017, http://tandun.com/composition/eight-colors-for-string-quartet.
} 
Philharmonic, the San Francisco Symphony, the NHK Symphony Orchestra, the

Philadelphia Orchestra, the Royal Concertgebouw Orchestra, the China National

Symphony Orchestra, Netherlands Opera, Het Muziektheater, and the Metropolitan

Opera, as well as organizations including the Edinburgh International Festival,

Google, YouTube, World EXPO Shanghai, and the International Olympic Committee.

His Internet Symphony, which was commissioned by Google and YouTube, has

reached over 23 million views online. Tan's music has been recorded on labels

including Sony Classical, Deutsche Grammophon, EMI, Opus Arte, and Naxos. ${ }^{15}$

The general public became most aware of Tan's music in 2001, when he received the Academy Award for Best Original Score for the soundtrack to the film Crouching Tiger, Hidden Dragon; he is the first Chinese composer to receive this honor. ${ }^{16} \mathrm{He}$ is also a winner of other prestigious awards including a Grammy Award, Grawemeyer Award, Bach Prize, Shostakovich Award, and recently Italy's Golden Lion Award for Lifetime Achievement. As a global cultural leader, he was named the UNESCO Global Goodwill Ambassador in 2013. Other titles include "Cultural Ambassador to the World" for the World EXPO Shanghai in 2010, music director of the Beijing 2008

\footnotetext{
15 “About," Tan Dun Official Website, accessed December 23, 2017, http://tandun.com/about.

16 Oliver Chou, "How Oscar-winning composer Tan Dun is using culture to create a symphony for Hong Kong's identity," South China Morning Post, accessed December 1, 2017, http://www.scmp.com/news/hong-kong/education-community/article/2077169/how-oscar-winningcomposer-tan-dun-using-culture.
} 
Olympic Games, honorary chair of Carnegie Hall's China Advisory Council, and artistic director of the Festival Water Crossing Fire held at the Barbican Centre. ${ }^{17}$

\subsection{Piano Works of Tan Dun}

To date, Tan Dun has composed twelve works for piano. These include six works for solo piano, three solo piano concertos, and three concertos with mixed soloists that include piano. His compositional output for piano can be divided into three periods,

which are listed chronologically as follows:

First period:

Eight Memories in Watercolor (Piano Solo) (1978, rev. 2001)

A Child's Diary (Piano Solo) (1978)

Second period:

Traces (Piano Solo) (1989, rev.1992)

$C-A-G-E$ (Piano Solo) (1993)

Concerto for Pizzicato Piano and Ten Instruments (Piano and Orchestra) (1995)

Dew-Fall-Drops (Piano Solo) (2000)

Third period:

Piano Concerto "The Fire” (Piano and Orchestra) (2008)

The Banquet Concerto (Piano and Orchestra) (2010)

Martial Arts Trilogy (Violin, Cello, Piano, Chorus, and Orchestra) (2011)

The Triple Resurrection (Violin, Cello, Piano, and Orchestra) (2013)

Farewell My Concubine (Piano, Peking Opera Singer, and Orchestra) (2015)

The Fire (Piano Sonata) (Piano Solo) (2015)

During the first period, Tan only composed two piano works, both in 1978, when

he was studying at the Central Conservatory: Eight Memories in Watercolor and $A$

Child's Diary. Both works are suites of miniatures for solo piano written in traditional

17 “About," Tan Dun Official Website. 
western language that is deeply influenced by Chinese traditional music. Tan had not written any other piano music until he went to the United States.

His writing changed rapidly toward the Western avant-garde style after he arrived in the United States in 1986 . He was especially influenced by the music of John Cage. He wrote four pieces during this second compositional period: Traces, $C$ A-G-E, Dew-Fall-Drops for solo piano, and Concerto for Pizzicato Piano and Ten Instruments for solo piano and orchestra.

Traces was written in 1989 and revised in 1992. This piece includes only three pitches: A, C, and D, along with large quantities of rest. Silence plays a significant role in this piece, in which the audience members are able to hear clearly "...the sounds of the natural environment and of themselves, doesn't this sound like Cage?"18 according to Tan himself.

$C-A-G-E$ was written in 1993 and dedicated to the memory of John Cage. This piece is composed using only the four pitches $\mathrm{C}, \mathrm{A}, \mathrm{G}$, and $\mathrm{E}$ in all different registers of the piano. The entire piece is played inside the piano, not on the keys, to memorialize the music written for prepared piano by Cage. Tan applied the fingering techniques from the Chinese traditional plucked instrument pipa directly to the piano

18 Dun Tan, “Traces," Tan Dun Official Website, accessed December 23, 2017, http://tandun.com/composition/traces. 
strings, exploring nearly all possible resonances that can be produced on the piano strings. ${ }^{19}$

Tan composed an accompaniment part for his $C-A-G-E$ in 1995; this arrangement became the Concerto for Pizzicato Piano and Ten Instruments when he received a commission from the Paris Festival d'Automne. It was premiered in the same year by Ensemble Contrechamps with Margaret Leng Tan as a soloist. The concerto is structured in a variation form: the first part focuses on and develops only the pitch C; the second part, A; the third, G; and the fourth, E. Subsequently, all four pitches are mixed and varied together. Gradually these notes become rhythmically livelier, and the concerto culminates in an "exuberant, tutti expression of imaginary jazz."20

Written in 2000, Dew-Fall-Drops was commissioned by the Carnegie Hall Millenium Piano Book. This is the last piece he wrote for piano in the second period, treating the piano as if it were the Chinese traditional plucked string instrument called zheng. $^{21}$

Tan returned to writing in tonal harmonic language in his third compositional period, during which he has written six piano pieces: The Fire (Piano Sonata) for solo

\footnotetext{
19 Dun Tan, “CAGE," Tan Dun Official Website, accessed December 23, 2017, http://tandun.com/composition/c-a-g-e.

20 Dun Tan, "Concerto for Pizzicato Piano and Ten Instruments," Tan Dun Official Website, accessed December 23, 2017, http://tandun.com/composition/concerto-for-pizzicato-piano-and-ten-instruments. ${ }^{21}$ Dun Tan, "Dew-Fall-Drops," Tan Dun Official Website, accessed December 23, 2017, http://tandun.com/composition/dew-fall-drops.
} 
piano; The Fire (The Banquet Concerto) for solo piano and orchestra; Martial Arts

Trilogy, The Triple Resurrection, and Farewell My Concubine for solo piano, at least one other soloist, and orchestra.

Piano Concerto "The Fire" was commissioned by the New York Philharmonic in 2008, and was written for pianist Lang Lang. It is a very percussive piece for both the piano part and the orchestral accompaniment. Several percussion instruments, including Taiko drums, gongs, xylophone, marimba, and vibraphone are featured throughout the composition. ${ }^{22}$ A sonata version of "The Fire" was also premiered in 2015.

Following his success in winning the Academy Award for Best Original Score for the music to the martial-arts film Crouching Tiger, Hidden Dragon, Tan was invited to compose a few more martial-arts film scores in Hollywood, including Hero and The Banquet. He re-worked the music from the soundtrack of The Banquet, completing The Banquet Concerto for solo piano and orchestra in 2010.. ${ }^{23}$ In 2011, Tan combined the music from his previous martial-arts films: The Banquet Concerto; the Crouching Tiger Concerto for cello and chamber orchestra from the film soundtrack of Crouching Tiger, Hidden Dragon; and Hero Concerto for violin and

22 Dun Tan, "Piano Concerto - The Fire," Tan Dun Official Website, accessed December 23, 2017, http://tandun.com/composition/piano-concerto-the-fire.

${ }^{23}$ Dun Tan, "The Banquet Concerto," Tan Dun Official Website, accessed December 23, 2017, http://tandun.com/composition/the-banquet-concerto. 
orchestra, from the soundtrack of the film Hero. This combination became the Martial Arts Trilogy. ${ }^{24}$ In 2013, he added a newly composed movement The Triple

Resurrection for solo violin, cello, piano, and orchestra, as the fourth part to Martial Arts Trilogy. This new group became Martial Arts Cycle, a set of concerti for soloists, orchestra, and video in homage to Wagner's Ring Cycle. ${ }^{25}$

In 2015, commissioned by Guangzhou Symphony Orchestra, Tan took part in celebrating the $120^{\text {th }}$ anniversary of Peking opera master Mei Lanfang's birth, writing a double-soloist concerto, Farewell My Concubine; this work is scored for piano, Peking opera singer, and orchestra. The original Peking opera Farewell My Concubine was Mei's most celebrated Peking-opera play. It describes the love story between the warlord Xiang Yu and the beautiful Consort Yu. Tan uses the solo piano part to imitate the role of Xiang $\mathrm{Yu}$, while the Peking opera singer portrays the role of Consort Yu. ${ }^{26}$

24 Dun Tan, "Martial Arts Trilogy," Tan Dun Official Website, accessed December 23, 2017, http://tandun.com/composition/martial-arts-trilogy.

${ }^{25}$ Dun Tan, "Martial Arts Trilogy," Music Sales Classical, accessed December 23, 2017, http://www.musicsalesclassical.com/composer/work/1561/46821\#.

26 Dun Tan, "Farewell My Concubine," Tan Dun Official Website, accessed December 23, 2017, http://tandun.com/composition/concerto-for-piano-and-peking-opera-soprano-farewell-my-concubine. 


\section{CHAPTER 3}

\section{Eight Memories in Watercolor}

\subsection{Compositional Background}

The piano suite Eight Memories in Watercolor was originally entitled Eight

Sketches in Hunan Accent. Written in 1978 for solo piano, it was Tan's opus one and was written when he left Hunan to study at the Central Conservatory of Music in Beijing. At that time, the Cultural Revolution had just ended and China had just opened its doors to Western culture, including classical music. During his study at the Conservatory, Tan was immersed in studying Western classical and modern music, but he was also homesick. He describes the suite as a "diary of longing," 27 inspired by the folk songs of his culture and the recollection of his childhood, as he longed for the folksongs and savored the memories of his childhood.

In 1996, choreographers Chiang Ching and Muna Tseng set the music into a modern-dance production. ${ }^{28}$ Pianist Fou Ts'ong got to know this work through Chiang and performed four movements of the piece. ${ }^{29}$ However, the entire composition was not premiered until later.

In 2001, Tan met pianist Lang Lang at a private gathering. There Lang Lang played Floating Clouds, a movement from the piano suite, in response to requests

\footnotetext{
${ }^{27}$ Dun Tan, "Eight Memories in Watercolor," Tan Dun Official Website, accessed December 21, 2017, http://tandun.com/composition/eight-memories-in-watercolor.

${ }^{28}$ Ibid.

${ }^{29}$ Ibid.
} 
from individuals present. Tan was touched by Lang's performance and "almost thought that he had written this work for Lang, even though Lang hadn't been born yet." ${ }^{30}$ Afterward, Lang asked to premiere the complete suite in his concerts. Tan made slight revisions to the work, renaming titles, order of the pieces, and overall structure, according to Lang's suggestions. Lang premiered the revised version, entitled Eight Memories in Watercolor, at the Kennedy Center for the Performing Arts, Washington, D.C., in 2003.

Eight Sketches in Hunan Accent, the first version of Eight Memories in Watercolor, was never published under the original title. This piece was first published under the title Memories in 1987 by People's Music Publishing House in Beijing, China. In 1996, it was published again by New York-based American classical music publishing company, G. Schirmer, Inc., under the title Eight Memories in Watercolor. An informative introduction with background information about this suite was included at the beginning of this version. This work has also been included in two collections of piano music, both published in China, by People's Music Publishing House in 2001 and also by Shanghai Conservatory of Music Press in 2011. The latest version of this piece was published in China, as part of the collection A Century of Piano Solo Works by Chinese Composers, by Shanghai Music Publishing House in

30 Ibid. 
2015. Prior to this 2015 edition, the Schirmer edition (1996) had been considered the most authentic. According to the foreword in the 2015 edition, all the works included in this collection have been approved by their composers to ensure the authenticity of this edition. All the works are listed as final versions authorized by the composers. ${ }^{31}$

\subsection{General Information and Formal Structures}

Eight Memories in Watercolor is comprised of eight separate miniatures, as listed below:

1. Missing Moon 《秋月》

2. Staccato Beans《逗》

3. Herdboy's Song 《山歌》

4. Blue Nun 《听妈妈讲故事》

5. Red Wilderness 《荒野》

6. Ancient Burial 《古葬》

7. Floating Clouds 《云》

8. Sunrain 《欢》

The order of the movements has been changed in several editions. The order listed above appears in both the Schirmer edition (1996) and the final edition published by Shanghai Music Publishing House (2015). In some of the previous editions published in China, Red Wilderness and Ancient Burial appear in reverse order.

The title of each piece either describes an image or tells a story. Missing Moon makes a statement of longing, whereas Staccato Beans presents an ingenuous

\footnotetext{
31 Baolu Chen, "Tan Dun's Eight Memories in Watercolor, Op.1: Strategies for Pianists and a Version Comparison" (DMA diss., Ohio State University, 2016).
} 
childhood game. Herdboy's Song is imaginative with great freedom and Blue Nun is descriptive, like a mother telling stories. Red Wilderness pictures a quiet landscape with a sense of uncertainty, whereas Ancient Burial presents a sense of gloom.

Floating Clouds paints a picture of clouds crossing the sky and Sunrain ends the suite with a happy dance. Staccato Beans, Herdboy's Song, Blue Nun, and Sunrain were based on traditional folksongs in Hunan Province, while Tan composed the melodies of the other four pieces himself.

The pentatonic scale has been used throughout Chinese music history. The term refers to a scale of five pitches, typified by the set C-D-E-G-A, as in C major of the Western tradition. The five steps have their own names, respectively: 宫 gong (C), 商 shang (D), 角 jiao (E), 徵 $z h i(\mathrm{G})$, and 羽 $y u(\mathrm{~A})$. Each can act as tonic and form the corresponding modes; therefore, there are five Chinese pentatonic modes: gong mode, shang mode, jiao mode, zhi mode, and yu mode. Pentatonic harmonies and tonality are used throughout the suite, giving this music a characteristically Chinese sound. ${ }^{32}$

\footnotetext{
32 Jeremy Day-O'Connell, "Pentatonic," Grove Music Online, accessed February 23, 2018, https://doiorg.lib-ezproxy.hkbu.edu.hk/10.1093/gmo/9781561592630.article.21263.
} 


\subsubsection{Missing Moon 《秋月》}

Missing Moon is a lyrical piece with a singing melody in a steady tonality of $y u$ mode and shang mode. It is in binary form with an introduction and a coda. Written without barlines, the introduction and the coda are cadenzas in rubato tempo. Section A extends from mm. 2-7 and section B includes mm. 8-13. The formal structure is shown below:

\begin{tabular}{|c|c|c|c|c|}
\hline & Intro & A & B & Coda \\
\hline Theme & & $\mathrm{a} \quad \mathrm{b}$ & $a^{\prime} \quad b^{\prime}$ & \\
\hline Tonality & $\mathrm{Eb} Y u$ & Ab Shang & $\mathrm{F} \# Y u$ & $\mathrm{~Eb} Y u$ \\
\hline$m$ & 1 & 2 & 10 & 14 \\
\hline
\end{tabular}

The introduction and coda are in $y u$ mode in E-flat. The tonality modulates to shang mode in A-flat in section A and to $y u$ mode in F-sharp in section B, before moving back to $y u$ mode in E-flat in the coda. A continuous top line with floating sextuplet notes is presented above the melodies throughout sections $\mathrm{A}$ and $\mathrm{B}$. Theme a consists mostly of descending motion, while theme b starts with ascending eighth notes, followed by descending motion. Themes a' and b' are varied versions of themes $a$ and $b$, respectively.

Tan employs both major and minor seconds frequently, creating dissonance in the melodic lines. These lines eventually descend to the low register, creating a 
symbolized picture of moonlight shining down upon the earth as it spreads across the ground like flowing water.

\subsubsection{Staccato Beans 《逗》}

The Chinese title of Staccato Beans is 逗 [Amusement], which is very different from the English title. The title "beans" symbolizes children and "staccato beans" is clearly a metaphor for energetic children. The theme of this movement comes from a Hunan folk song 新舅舅 [My New Sister-in-Law], which originated in the town of

嘉禾 Jia He. ${ }^{33}$ The folk tune will be discussed more extensively in Chapter Five.

Staccato Beans is a lively piece in ternary form, mainly in $y u$ mode in D. We

find a two-measure introduction and a four-measure coda. Section A begins from mm.

3-24, where mm. 24-25 is a transition to section B; section B begins from mm. 26-43, and section A' begins from mm. 44-61. The following is the formal structure of this piece.

\begin{tabular}{|c|c|c|c|c|c|c|c|}
\hline & Intro & A & & & B & $A^{\prime}$ & Coda \\
\hline Theme & $\|:$ & $\mathrm{a}$ & $\mathrm{a}$ & & al b & a2 a2 & $: \|$ \\
\hline Tonality & $\mathrm{D} Y u$ & & & & G Yu/Bb Gong & $\mathrm{D} Y u$ & \\
\hline $\mathrm{m}$. & 1 & 3 & 13 & 23 & $26 \quad 35$ & $44 \quad 53$ & 62 \\
\hline
\end{tabular}

\footnotetext{
${ }^{33}$ Meiyue Zeng 曾美月, “谭盾《八幅水彩画的回忆》中的湖南民间音调[Hunan Folk Tunes in Tan Dun's Eight Memories in Watercolor],” 内蒙古大學藝術學院學瓡 Journal of Art College of Inner Mongolia University], no.2 (2012): 107-111.
} 
In mm. 1-24 and mm. 44-64, the tonality is $y u$ mode in D. In Section A, Theme a appears in different octaves with altered dynamics to create contrasting moods between mm. 3-12 and mm. 13-22. We see a modulation to gong mode in B-flat in transition and $y u$ mode in $\mathrm{G}$ in the right hand of $\mathrm{mm}$. 26-34. In section $\mathrm{B}, y u$ mode in $\mathrm{G}$ and gong mode in B-flat appear in the right hand and left hand, respectively, producing a sense of bitonality. Theme al is developed from section A, adding intervals instead of single-note melody. Theme $b$ is developed from the last few notes of theme a and is only presented once in the whole movement, in section B. Theme a2 is also developed from theme a. As in section A, theme a2 is placed in different octaves with varied dynamics to create contrasting moods between mm. 44-52 and mm. 53-61.

\subsubsection{Herdboy's Song 《山歌》}

Herdboy's Song is a lyrical and imitative work. It reveals a smoothly singing melody with various textures in the background. Barlines occur only occasionally; they are broken, rather than solid, contributing to a feeling that the piece should be played freely, with an improvisatory rubato. The melodies in this movement are borrowed from a love song from the Hengdong area in the eastern part of Hubei Province, which is entitled 这山望见那山高[Grass Is Greener on the Other Hill $]^{34}$

\footnotetext{
34 Ibid.
} 
Herdboy's Song is written in $y u$ mode in A. It is in strophic form, including five sections with an introduction and coda. The introduction appears in the first two measures, followed by section $\mathrm{A}$ in $\mathrm{m} .3$, section $\mathrm{B}$ in $\mathrm{m} .5$, section $\mathrm{C}$ in $\mathrm{m}$. 6 , section $\mathrm{D}$ in $\mathrm{m} .8$, section $\mathrm{E}$ in the sixth beat of $\mathrm{m} .9$, and Coda in the upbeat to $\mathrm{m}$. 11 . This formal structure is shown below:

$\begin{array}{llllllll} & \text { Intro } & \text { A } & \text { B } & \text { C } & \text { D } & \text { E } & \text { Coda } \\ \text { Theme } & & \text { a } & \text { b } & \text { c } & \text { d } & \text { e } & \text { f } \\ \text { Tonality } & \text { A Yu } & & & & & & \\ \text { (m.) } & 1 & 3 & 5 & 6 & 8 & 9 & 10\end{array}$

Themes b, c, d, and e are developed and varied from theme a. There is no time signature in this movement and each measure has a different length. Therefore, although the sections might contain only one or two measures each, they vary in duration. All melodies appear in a high register, mostly in the right hand, while the left hand presents various accompanying textures. In section A, the left hand follows the right hand. In section $\mathrm{B}, \mathrm{C}$ and $\mathrm{D}$, the left hand mostly doubles the right hand in different registers. In section E, the melody shifts to the alto voice, while the top voice provides accompaniment in syncopated rhythm. In the Coda, theme $\mathrm{f}$ is also derived from theme a, adding pentatonic arpeggiations for decoration in the middle of the phrase. 


\subsubsection{Blue Nun 《听妈妈讲故事》}

The English title of this movement in the G. Schirmer version is "Blue Nun," while the title 听妈妈讲故事 [Story Time with Mom] appears in the Chinese version published by People's Music Publishing House, Beijing, and Shanghai Conservatory of Music Press, Shanghai. The Chinese title was changed to 忧有阳的尼姑[Blue Nun] when the piece was re-published in 2015, in the collection A Century of Piano Solo Works by Chinese Composers.

Blue Nun is a lyrical and descriptive ternary-form piece in $y u$ mode in E. Like Staccato Beans and Herdboy's Song, the melody of Blue Nun is also borrowed from folk song 乡里妹子进城来 [A Girl from the Country Is Coming into Town], from Tan's hometown. ${ }^{35}$ Section A appears in mm. 1-16. Section B extends from mm. 1733. Bar 33 provides a transition from Section B back to section A' and Section A' continues from m. 34 to the end. The following is a formal diagram:

$\begin{array}{llllll} & \text { A } & & \text { B } & & \text { A' } \\ \text { Theme } & \mathrm{a} & \mathrm{a} & \mathrm{b} & \mathrm{b} & \mathrm{a} \\ \text { Tonality } & \text { E } Y u & & \text { A } Y u & & \text { E } Y u \\ \text { m. } & 1 & 9 & 17 & 25 & 33\end{array}$

Sections A and A' are in $y u$ mode in $\mathrm{E}$, while section B is in $y u$ mode in $\mathrm{A}$. Theme $\mathrm{b}$ is varied from theme $\mathrm{a}$, becoming melody in section $\mathrm{B}$. The right hand 
presents theme a at the beginning of the movement, with simple left-hand accompaniment. Canonic texture appears between the left hand and right hand in $\mathrm{mm}$. 9-16. Tan uses polyphonic writing in section B. In mm. 17-24, the right hand and left hand display similar rhythmic motion. We also see two forms of contrapuntal material: first, the right hand enters, followed by the left hand's answer; second, the right hand and left hand appear in contrary motion. The material recurs an octave higher in mm. 25-32. Canonic texture appears again between the left hand and right hand in section A.'

\subsubsection{Red Wilderness 《荒野》}

Red Wilderness is a slow and quiet piece in rounded binary form. It was written in $y u$ mode in A with some dissonant intervals throughout the movement. Section A extends from m. 1-12, followed by section B, m. 13 to the end. The tonality changes to gong mode in E from mm. 13-19 and back to $y u$ mode in A in m. 20 until the end.

Here we see the formal structure:

$\begin{array}{llll} & \text { A } & \text { B } & \\ \text { Theme } & \text { a a1 } & \text { b } & \text { a2 } \\ \text { Tonality } & \text { A } Y u & \text { E Gong } & \text { A Yu } \\ \text { m. } & 1 \quad 7 & 13 & 20\end{array}$

Section A is in $y u$ mode in A. A modulation to gong mode in E occurs in section $\mathrm{B}$, providing a dominant relationship to the home key. In $\mathrm{m}$. 20, the melody returns to 
$y u$ mode in A; however, we see ambiguities in tonality because of the harmonies in the left hand. Themes a1 and a 2 are developed from theme a in section A. The intervallic seconds in the middle voice of mm. 7-11 and mm. 19-26 create dissonance within the stable tonality. The texture gradually thickens until theme b, with seventh chords and multiple voices in section B from mm. 13-19. A simpler texture with three voices appears in theme a 2 until the end. The syncopated rhythm continues throughout the piece.

\subsubsection{Ancient Burial 《古葬》}

Tan portrays a sacrificial funeral scene in Ancient Burial, evoking profoundly sad emotions. The piece displays ternary form, with a one-measure introduction and ambiguous tonality. Measures 2-8 comprise section A; section B includes mm. 9-18, in which mm. 17-18 is transitional material; and section A' spans from m. 19 to the end. Here we see the formal structure:

$\begin{array}{llrlll} & \text { Intro } & \text { A } & \text { B } & \text { A } \\ \text { Theme } & & \text { a } & \text { b } & \\ \text { Tonality } & \text { ambiguous } & & & \text { a } \\ \text { m. } & 1 & 2 & 9 & 17 & 19\end{array}$

Theme a appears in both section A and section A.' Theme b is developed from theme a and is presented in section B. The melodies are consistently pentatonic; however, Tan applies constantly changing harmonies to create a sense of uncertain 
tonality. An ostinato in alternating major seconds occurs throughout the inner voice of Ancient Burial, invoking the feeling of a funeral march. Textures in sections A and A' are rather simple, with a top melodic line, a middle ostinato line, and a bass line. In section $\mathrm{B}$, theme $\mathrm{b}$ alternates between high and low voices, creating a much thicker texture than we see in the other sections.

\subsubsection{Floating Clouds 《云》}

With flowing sixteenth notes throughout this movement, Tan conveys the image of clouds drifting in the sky. This is a cantabile piece in binary form, with an introduction and a coda. The tonality is quite ambiguous throughout the whole movement. The first bar provides an introduction, after which section A extends from mm. 2-13. Section B includes mm. 14-24 and the coda takes us from m. 25 to the end of the piece. Below is the formal diagram:

Intro A B Coda

\begin{tabular}{lrrrrrr} 
Theme & \multicolumn{2}{c}{ a } & b & c & b & \\
Tonality & ambiguous & & & & & \\
m. & 1 & 2 & 8 & 14 & 19 & 25
\end{tabular}

We find three distinct themes (a, b, and c) in Floating Clouds. Similar to what we see in Ancient Burial, the tonal center constantly changes in this movement, making rather blurry use of the modes and occasional multi-tonal moments. The texture is fairly constant in this movement. A soaring line with running sixteenth- 
notes is presented throughout the movement. Melodic lines appear above this flowing material, perhaps suggesting moonlight "floating" on the clouds. Occasionally, Tan employs low-pitched accompaniments as well.

\subsubsection{Sunrain 《欢》}

The English title of Sunrain has a different meaning from the Chinese title 欢 [Happiness]. The title "Sunrain" is a metaphor for the Water Splashing Festival, in which people splash water on each other as an act of blessing. The melody was borrowed from a folk song 放牛歌 [Shepherd's Song] from Tan's Hunan hometown. ${ }^{36}$

Sunrain is a happy dance movement in ternary form, mainly in zhi mode in G, with an introduction and a coda. The first six bars provide the Introduction, after which section A continues from mm. 7-29, with mm. 25-29 serving as transitional material. Section B includes mm. 30-47, within which $\mathrm{mm}$. $42-47$ provide a transition back to section $\mathrm{A}^{\prime}$ in $\mathrm{m} .48$. The coda begins in $\mathrm{m} .56$ and carries us to the end of the suite. The following is the formal diagram:

\begin{tabular}{|c|c|c|c|c|c|c|c|}
\hline & Intro & A & & & B & $A^{\prime}$ & Coda \\
\hline Theme & $\|:$ & $\mathrm{a}$ & $\mathrm{a}$ & & $b$ & $\mathrm{a}$ & $: \|$ \\
\hline Tonality & G $Z h i$ & & & & ambiguous & G $Z h i$ & \\
\hline $\mathrm{m}$ & 13 & 7 & 17 & 25 & 30 & $42 \quad 48$ & 56 \\
\hline
\end{tabular}

36 Ibid. 
Theme a appears in Sections A and A.' Parallel-fourth intervals provide an important feature of this movement. In theme a, there are two parallel melodic lines presented a fourth apart. Theme b occurs in section B and is developed from theme a. The first two notes of theme a are reversed in theme b. The tonality basically stays in $\mathrm{G} z h i$ mode, except in section $\mathrm{B}$, where the tonality became ambiguous with a flavor of bitonality because of the parallel-fourth intervals in the right hand. Homophonic texture prevails in this movement, with canonic writing applied in mm. 30-37.

A tonal overview of the eight movements within Eight Memories in Watercolor reveals $y u$ modes in the first five, moving to ambiguous tonality in six and seven, and concluding with zhi mode in number eight. The following diagram shows the specifics:

$\begin{array}{ll}\text { Missing Moon } & \text { Eb yu } \\ \text { Staccato Bean } & \text { D yu } \\ \text { Herdboy's Song } & \text { A yu } \\ \text { Blue Nun } & \text { E yu } \\ \text { Red Wilderness } & \text { A yu } \\ \text { Ancient Burial } & \text { ambiguous } \\ \text { Floating Clouds } & \text { ambiguous } \\ \text { Sunrain } & \text { G zhi }\end{array}$




\section{CHAPTER 4}

\section{Chinese Cultural Influence on Eight Memories in Watercolor}

\subsection{Influenced by Chinese Traditional Custom}

The title of Missing Moon implies the traditional Chinese culture. In China, the moon represents a special metaphor related to sadness, peace, or longing. MidAutumn Festival is one of the most important Chinese traditional festivals. On that day, the moon is full, which always represents the reunion of a family. Family members will get together to celebrate by having a traditional banquet and sitting together to appreciate the moon afterwards. ${ }^{37}$ Tan spent his first Mid-Autumn Festival in Beijing during his study at the Central Conservatory of Music in 1978. It is likely he wrote Missing Moon to celebrate the festival and to express his longing for his hometown and his family. ${ }^{38}$

\subsection{Influenced by Chinese Cultural Revolution (1966-1976)}

Tan's life and the lives of millions of Chinese people were changed because of the Cultural Revolution from 1966 until 1976. It was a social and political movement dominated by the Chinese government, as chairman Mao Zedong's strict plan for social transformation attempted to reinvent China. ${ }^{39}$ During these ten years, people experienced many difficulties — and all forms of art associated with Western culture

\footnotetext{
37 Commonly shared perception among Chinese people.

38 Chen, "Tan Dun's Eight Memories in Watercolor," 14.

39 “About," Tan Dun Official Website.
} 
were banned by the government. Western musical instruments were either destroyed or sealed, and music institutions were closed. Music activities were stopped and the government allowed only a few types of music to be performed, such as the Modal opera (modified Peking opera) and some ballets that contained strong political content designed to praise Chairman Mao, the Communist Party, and the Chinese Government. New musical compositions were forbidden, unless they served a political purpose.

During these ten years, under the restrictions of government policy, most piano works were transcriptions or arrangements from traditional Chinese music. ${ }^{40}$ Under government policy, Tan was sent as a teenager to Huangjin Commune, Changshao City, in the countryside of Human province, to work in the fields with the farmers. At the same time, he got more opportunities to hear authentic folk music, especially Hunan folk tunes from the countryside. These folk melodies would become a great resource for his compositional career.

Eight Memories in Watercolor was written when the Cultural Revolution had just ended. This cataclysmic freeing of the political environment saved a whole generation of Chinese composers, including Chen Yi, Zhou Long, and Tan Dun. Many new compositional works suddenly appeared. China opened its doors to the world and

${ }^{40}$ Le Kang, "The Development of Chinese Piano Music," Asian Culture and History 1, no.2 (July 2009): 21-22. 
Western music was once again permitted. Tan entered the Central Conservatory of Music after it reopened and he immersed himself in studying Western classical and contemporary music. His career was just beginning. ${ }^{41}$

\subsection{Chinese Traditional Culture Influence in Hunan Province - Xiang-Chu}

\section{Culture and $\mathrm{Wu}$-Nuo Culture}

Tan was born and raised in Hunan province, the origin of Xiang-Chu culture, in the People's Republic of China. The Xiang-Chu culture is one of the unique regional cultures in China, arising from the vast and fertile land of Hunan province. "Xiang" [湘] is the abbreviation of Hunan. “Chu” [楚] represents the Chu state [楚国] in ancient China, located in the Hunan area nowadays, which can be traced back to 1115-223 B.C.E. At that time, ancient China was comprised of several states, of which $C h u$ state was one of the biggest, having a large population, long history, and rich cultural resources. The king of $C h u$ state attached great importance to developing music and set up a music office to manage music affairs. Chu music is well-developed and became an essential part of $C h u$ Culture. The music enriches many activities, especially celebrations and rituals. The most prominent feature of $C h u$ music is the trinity of vocal music, dance, and instrumental music. This form was also borrowed by Tan in his compositions, such as Nine Songs, which is written for performance

41 “About,” Tan Dun Official Website. 
with dance, music, and drama. Vocal music can be better embodied in the

characteristics of $C h u$ music. It took a large proportion in $C h u$ music. Its style was

fulfilled with religion and witchcraft. ${ }^{42}$

Chu culture is romantic, whimsical, and full of ghosts. By nature, the root of the

$C h u$ culture is the belief in all things. Tan said: "The most important part that touched

me a lot in the Chu culture is that there are some things that can be perceived and that

also can speak to nature. ${ }^{\prime 43}$ In his music, everything has life. Water can talk with

birds; stone can talk with wind; all things could have conversations with each other.

This concept is well-integrated in his compositions, including Water Concerto for

Water Percussion and Orchestra, Paper Concerto for Paper Percussion and

Orchestra, and Earth for Ceramic Instruments and Orchestra. Tan described Xiang-

$C h u$ Culture in an interview, saying that "Xiang-Chu culture is my root and my

understanding comes from the most primitive culture. I will never give up pursuing

the original culture. This is a modern process, which I often learn to create through

preserving the old." 44

"Memory of my childhood, people, water, is very deep in my mind and

\footnotetext{
42 Yingying Chen 陈莹莹, “八幅水彩画的回忆的民族特征及演奏分析[Eight Memories in Watercolor: Artistic Characteristics and Analysis of Piano Performance]," (MM diss., Jiangxi Normal University, 2013), 5.

43 Zichao Yang 杨子超，“谭盾音乐的多元化因素探索[Exploring the diversified factors in Tan Dun's music],” Radio \& TV Journal no.7 (2015): 222-226.

44 Guozhong Ouyang 欧阳国忠, and Haiyan Jian 简海燕, “谭盾-用湘楚之锤敲响世界大锣[Tan Dun-Ring the World with the Xiang-Chu hammer,” 高中生[High Schooler] no.7 (2015): 14-15.
} 
inerasable. It's in my blood. ${ }^{\circ 5}$ Tan was born and raised in a rural Hunan village, where millennia-old shamanistic traditions still survived. ${ }^{46}$ When he was young, he lived close to the graveyard, where funerals happened every day. ${ }^{47} \mathrm{~A}$ funeral ritual was organized by a shaman and accompanied by funeral music. From day to day, Tan was influenced and interested in this shamanistic culture, which led him to think of being a shaman in the future. ${ }^{48}$ When he plays or conducts music, he is a shaman, where the theatre is an altar, and the music performance is a religious ritual.

Tan said during an interview: "No matter how I organize a language, how to design a structure according to a theme, there is one thing that I may never be able to get rid of in my mind, that is $\mathrm{Wu}-\mathrm{Nuo}$ culture [巫倠文化], deep-rooted on my mind. ${ }^{49} \mathrm{Wu}-\mathrm{Nuo}$ is an ancient primitive culture that now provides an important part of Chinese tradition. It is mainly located in the southwestern region of China, which includes Hunan province. Nuo drama [倠戏] was a Chinese opera drama, which was formed on the basis of sacrificial funeral ritual and was usually accompanied by singing and dancing. Tan employs the spirit of $\mathrm{Wu}-\mathrm{NuO}$ culture and emotions of $\mathrm{NuO}$

\footnotetext{
45 Opera Philadelphia, "Get to Know Composer Tan Dun" [filmed February 2010], YouTube video, 4:06, posted [February 2010], https://youtu.be/-m2TizGwOp8.

46 “About," Tan Dun Official Website.

${ }^{47}$ Fafen Zheng 郑发奋, “游走于东西方文化艺术之间[Walking between Eastern and Western Cultures and Arts]," Musical Works no.4 (2010): 107-109.

${ }^{48}$ Guozhong Ouyang, Haiyan Jian, "Ring the World with the Xiang-Chu hammer," 14-15.

${ }^{49}$ Boji Sheng 盛伯䩀, “矢于艺术思想的真实记录-- 《根籁一谭盾与家乡的对话》编后感[About the True Record of Artistic Thought__ After Dialogue between Tan Dun and His Hometown]," 当代 电视[Modern Television] no.2 (2002): 64-65.
} 
drama in Ancient Burial. He portrays a mysterious sacrificial funeral scene by using a constant change of harmonies and uncertain tonality. The steady rhythmic pulse and the ostinato in alternating major seconds occurs throughout the inner voice, invoking the feeling of a funeral march and conveying a sense of solemnity (see Figure 1).

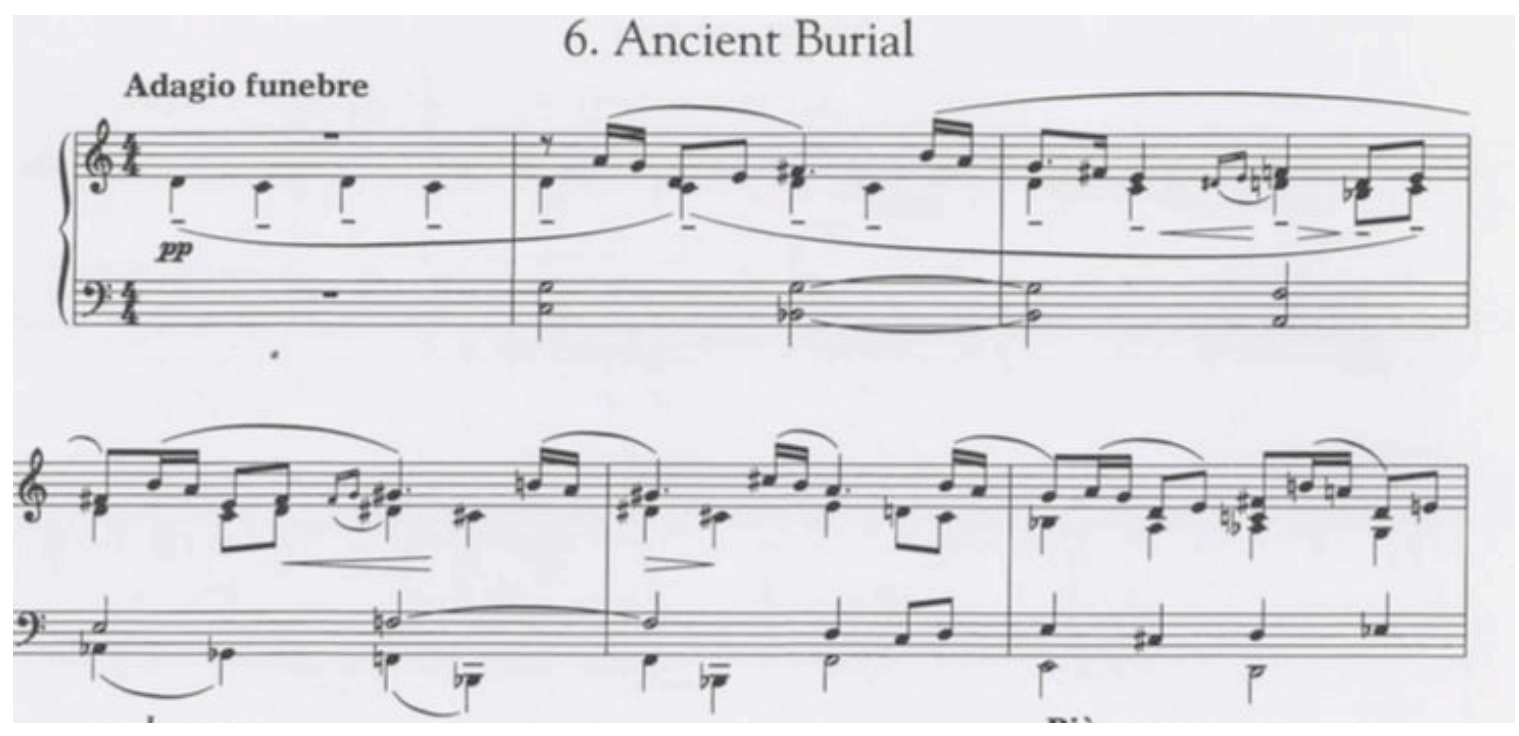

Figure 1 Ancient Burial, mm.1-6

EIGHT MEMORIES IN WATERCOLOR

By Tan Dun

Copyright $@ 1996$ by G. Schirmer, Inc. (ASCAP)

International Copyright Secured. All Rights Reserved.

Used by Permission.

Warning: Unauthorized reproduction of this publication is prohibited by Federal Law and is subject to criminal prosecution.

Tan has more than once indicated that Xiang-Chu culture is located in the deepest part of his heart and that it is the foundation for his compositional life. He wrote not only Eight Memories in Watercolor, but also many other compositions under the influence of the Xiang-Chu culture, such as the multi-media production The Map Concerto for Cello, Video and Orchestra, the string quartet Feng-Ya-Song, the 
music ritual and performance Nine Songs, and chamber music Concerto for Six. 


\section{CHAPTER 5}

\section{Application of Chinese Musical Elements in Eight Memories in Watercolor}

\subsection{Use of Chinese Pentatonic Scales}

Pentatonic scale forms were used and developed throughout Chinese music

history. The Chinese pentatonic scale refers to a scale of five pitches, typified by the set $\mathrm{C}-\mathrm{D}-\mathrm{E}-\mathrm{G}-\mathrm{A}$, as compared to $\mathrm{C}$ major in Western tradition. The five steps have their own names, respectively：宫 gong (C), 商 shang (D), 角 jiao (E), 徵 zhi (G), and 羽 $y u(\mathrm{~A})$. The intervals between pitches are changeless: they are major second, major second, minor third, and major second, respectively (see Figure 2).

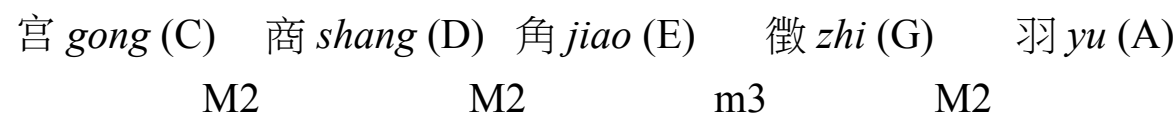

Figure 2 Intervals of pentatonic scale

Each of the five notes can act as the home tone (equivalent to the tonic note of a Western scale) and form corresponding modes. Therefore, there are five Chinese pentatonic modes: gong mode, shang mode, jiao mode, zhi mode, and $y u$ mode (see Figure 3). Pentatonic harmonies and tonality are used throughout Eight Memories in Watercolor, giving this piece a characteristically "Chinese" quality. ${ }^{50}$

\footnotetext{
50 Jeremy Day-O’Connell, "Pentatonic," Grove Music Online, accessed February 23, 2018, https://doiorg.lib-ezproxy.hkbu.edu.hk/10.1093/gmo/9781561592630.article.21263.
} 

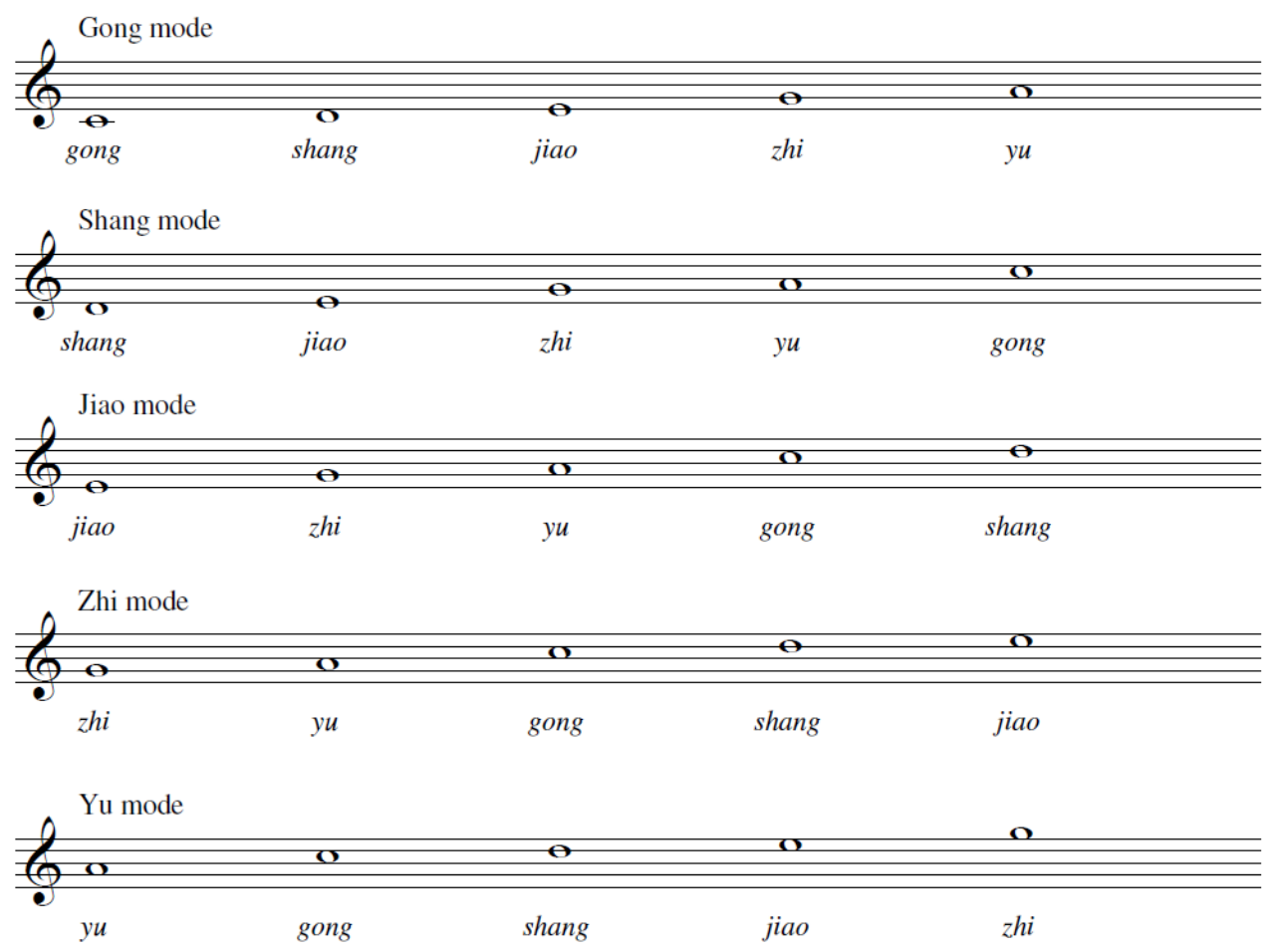

Figure 3 Five Chinese pentatonic modes

The pentatonic scale derives from consecutive intervals of perfect fifth, for

example, C-G-D-A-E; these tones can be rearranged as C-D-E-G-A. The major-third interval from gong to jiao (C to E) is the main clue to confirming which note is gong, defining the key and mode in the corresponding passage.

For example, in mm. 1-12 of Staccato Beans, the main notes are D-F-G-A-C. In these notes, $\mathrm{F}$ to $\mathrm{A}$ forms a major-third interval with a main note of $\mathrm{D}$, so we know it is in $y u$ mode in D (see Figure 4). 


\section{Staccato Beans}

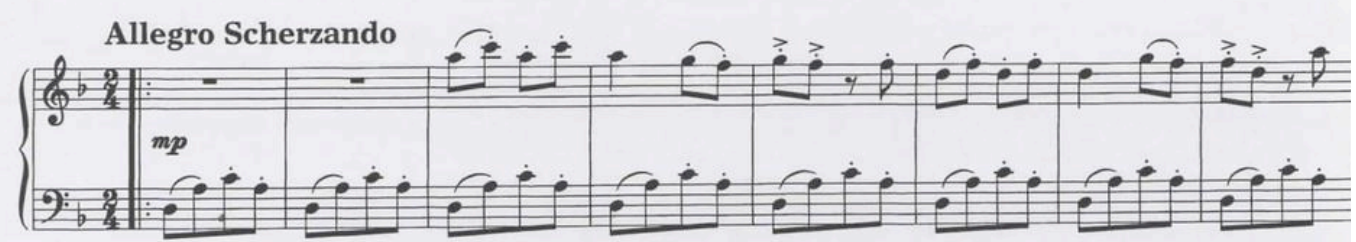

(the second time faster)

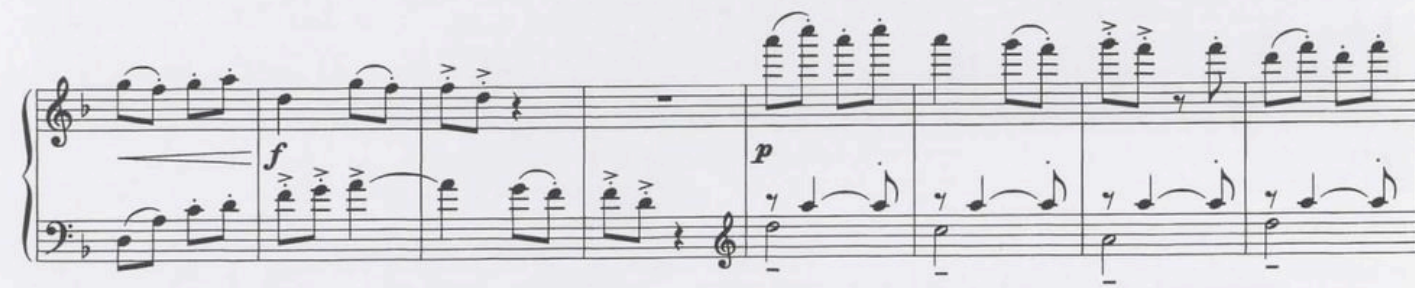

Figure 4 Staccato Beans, mm. 1-16, showing yu mode

\section{EIGHT MEMORIES IN WATERCOLOR}

By Tan Dun

Copyright $(\mathcal{} 1996$ by G. Schirmer, Inc. (ASCAP)

International Copyright Secured. All Rights Reserved.

Used by Permission.

Warning: Unauthorized reproduction of this publication is prohibited by Federal Law and is subject to criminal prosecution.

Tan also applied multi-tonal concepts in Eight Memories in Watercolor, for

example, in Floating Clouds (see Figure 5). First, in mm. 5-6, the notes in the highest

voice are C, E-flat, F, G, B-flat, with E-flat being the main note. In this situation, E-

flat to $\mathrm{G}$ forms a major third; thus, this material is in gong mode in E-flat, particularly

since the E-flat is emphasized on the downbeats of mm. 6-7. Second, from m. 4

through the first two beats of m. 5, the middle voice displays four notes, C, E-flat, F,

and A-flat. In these notes, A-flat to $\mathrm{C}$ forms a major-third interval; the emphasis on $\mathrm{C}$

confirms that this material is in jiao mode in C. Similarly, the middle voice from the

last two beats of m. 5 to m. 6 is in zhi mode in B-flat. As a whole, in mm. 4-6 we see

multiple modes, which are gong mode in E-flat, jiao mode in C, and zhi mode in B- 
flat.
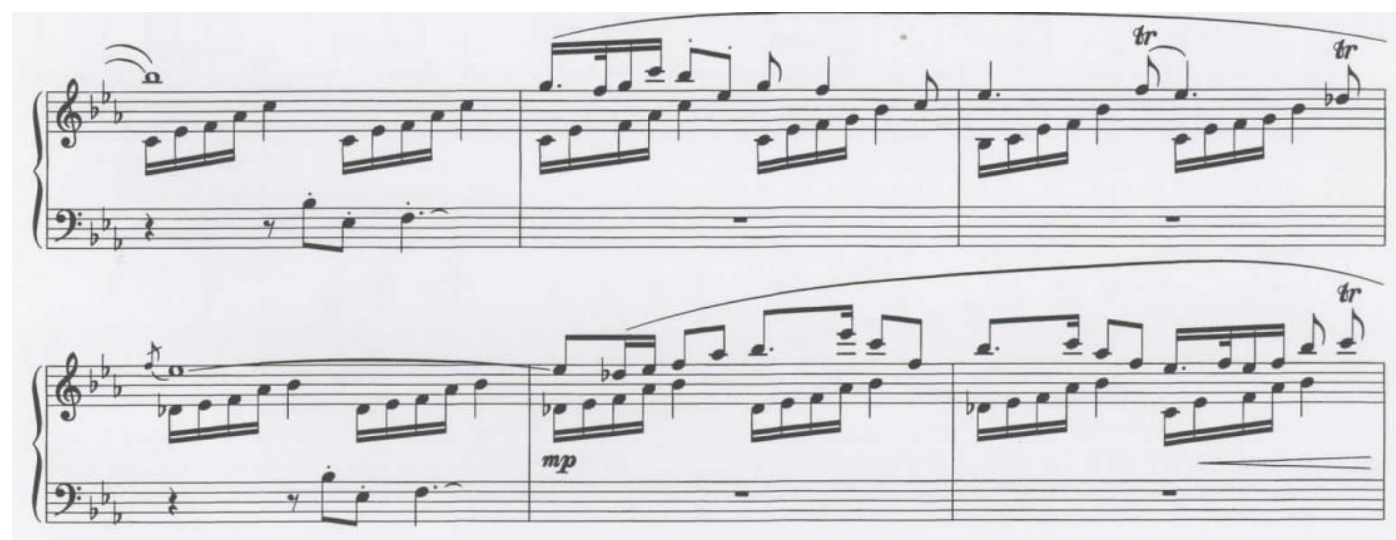

Figure 5 Floating Clouds, mm. 4-9

\section{EIGHT MEMORIES IN WATERCOLOR}

By Tan Dun

Copyright $(1996$ by G. Schirmer, Inc. (ASCAP)

International Copyright Secured. All Rights Reserved.

Used by Permission.

Warning: Unauthorized reproduction of this publication is prohibited by Federal Law and is subject to criminal prosecution.

\subsection{Neutral Tone}

"Neutral tone" [中立音] is a phenomenon in Chinese traditional by which some notes are slightly raised to form quartertones within Chinese pentatonic scales. The term was coined by Chinese musicologist Mei $\mathrm{Li}^{51}$ who defined neutral tone as "a special interval called neutral tone in the traditional folk music in China, which is between a major interval and a minor interval. For example, a neutral-tone third is the interval between a major third and a minor third." ${ }^{, 52}$ Neutral-tone is a special feature

51 Translated by the author Qian Xu.

Mei Li 李玫, “中立音赖以存在的民间乐器机制(上)[Special Physical Features of Folk-Music Instruments as Prerequisites for Neutral-Tone],” Musicology In China no.1 (2001): 19-31.

52 Translated by the author Qian Xu.

Mei Li 李玫, “民间音乐中中立音现象的律学分析(上)[An Analysis of the Neutral-Tone Phenomenon in Folk Music]," Journal of the Central Conservatory of Music no.3 (2000): 28. 
and part of the character of Huagu dance [花鼓戏], in Hunan province. ${ }^{53}$ In Huagu dance, the shang note and zhi note of the pentatonic scale are usually raised by a quartertone, becoming C-D $-\mathrm{E}-\mathrm{G}^{+}-\mathrm{A} .{ }^{54}$

Since quartertones cannot be played by the piano, which is a chromatic equaltempered instrument, Tan replaced the quarter-interval neutral note with a chromatic note. For instance, in mm. 35-41 of "Staccato Beans," the right-hand chord includes Bb-D-F\#-G. The right hand is in gong mode in B-flat in this section; therefore, the "correct" pentatonic structure should be Bb-C-D-F-G. The F-sharp cannot be explained by this pentatonic harmony; however, it would be reasonable to conclude that the F, as the fourth note of B-flat gong mode, should actually be a neutral note, implied here by a chromatic note F-sharp, as shown below (see Figure 6).

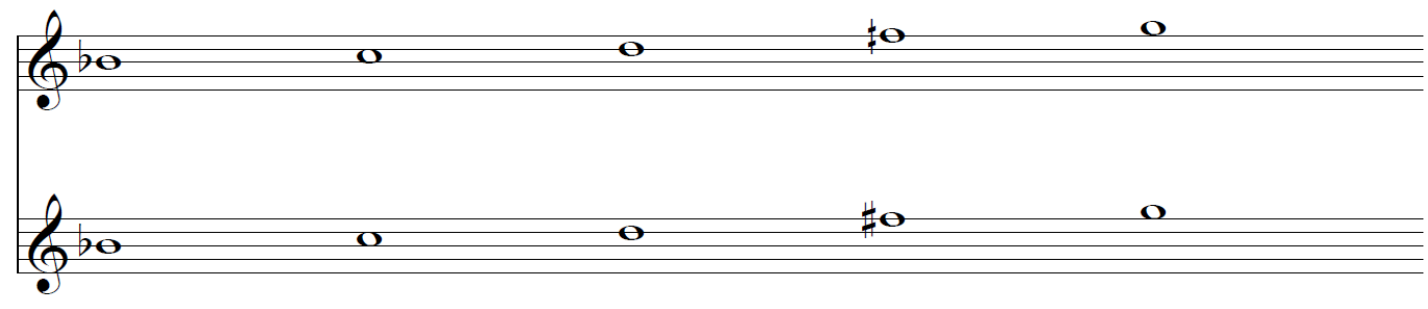

Figure 6 F-sharp replacement of neutral tone F in Staccato Beans

Other examples can be found in Herdboy's Song. It is written in $y u$ mode in A throughout this movement, with only two exceptions, the dissonances G sharp and D

\footnotetext{
53 Caiyun Zhang 张彩云, “谭盾钢琴组曲《八幅水彩画的回忆》创作研究[Researching on Tan Dun's Piano Suite Eight Memories in Watercolor].” (MM diss., Southwestern University, 2009). 54 The symbol "+" indicates a quarter-sharp.
} 
sharp. These represent the neutral notes of $y u$ mode in A, if we consider them as

chromatic replacements for G-quarter-sharp and D-quarter-sharp in m. 2 (see Figure

7), m. 5 (see Figure 8), and m.10 (see Figure 9). The scale of $y u$ mode in A with

neutral tone is also shown below (see Figure 10).

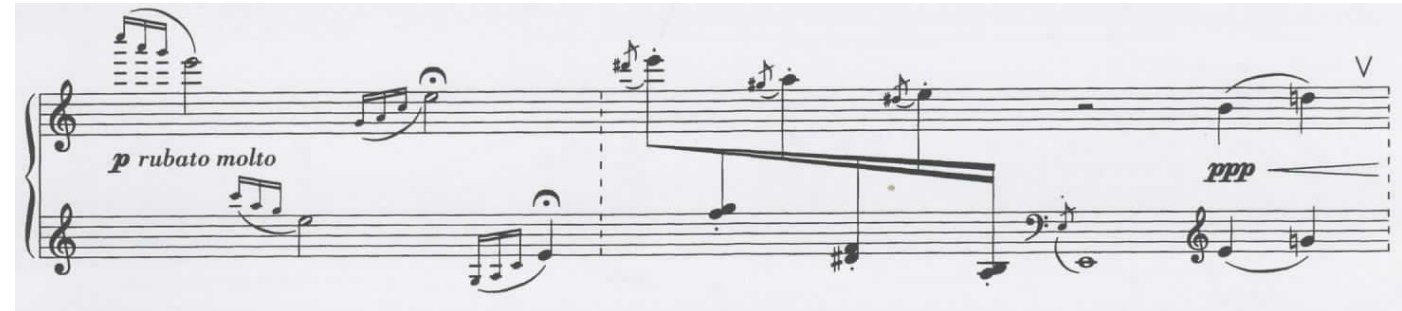

Figure 7 Herdboy's Song, mm. 1-2

\section{EIGHT MEMORIES IN WATERCOLOR}

By Tan Dun

Copyright (C 1996 by G. Schirmer, Inc. (ASCAP)

International Copyright Secured. All Rights Reserved.

Used by Permission.

Warning: Unauthorized reproduction of this publication is prohibited by Federal Law and is subject to criminal prosecution.

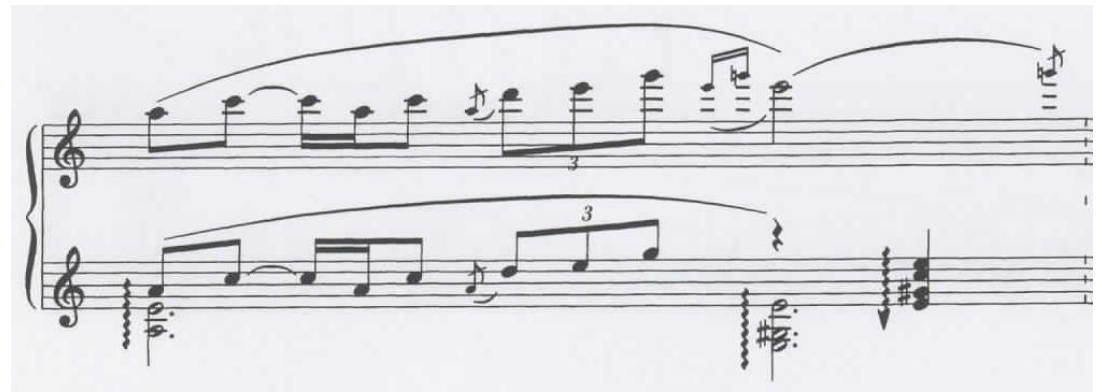

Figure 8 Herdboy's Song, m.5

\section{EIGHT MEMORIES IN WATERCOLOR}

By Tan Dun

Copyright (C 1996 by G. Schirmer, Inc. (ASCAP)

International Copyright Secured. All Rights Reserved.

Used by Permission.

Warning: Unauthorized reproduction of this publication is prohibited by Federal Law and is subject to criminal prosecution. 


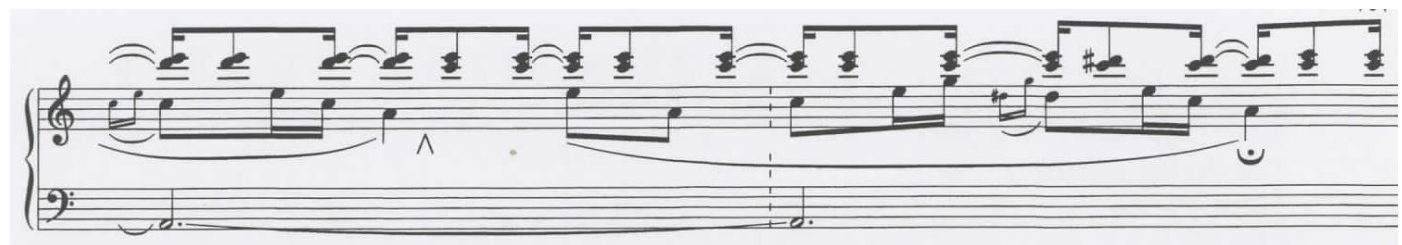

Figure 9 Herdboy's Song, m.10

\section{EIGHT MEMORIES IN WATERCOLOR}

By Tan Dun

Copyright (C) 1996 by G. Schirmer, Inc. (ASCAP)

International Copyright Secured. All Rights Reserved.

Used by Permission.

Warning: Unauthorized reproduction of this publication is prohibited by Federal Law and is subject to criminal prosecution.

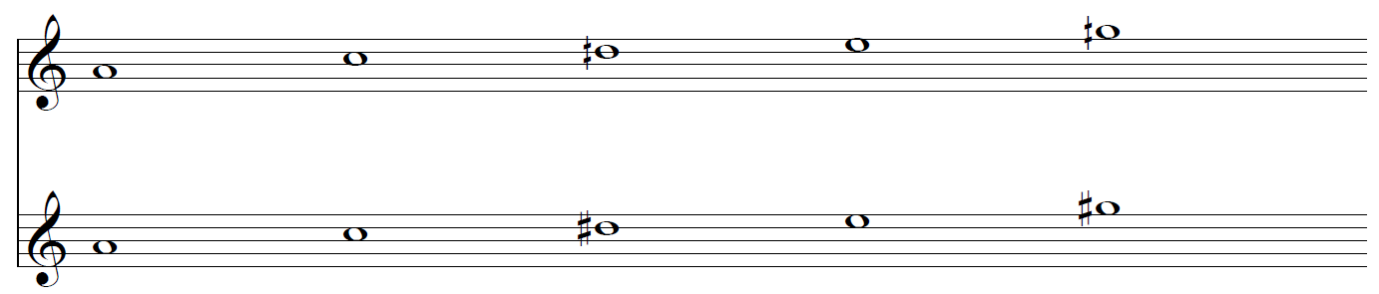

Figure 10 D-sharp and G-sharp replacements of neutral tones D and G respectively in Herdboy's Song

\subsection{Use of Folk Tunes}

Tan said in an interview, "Many of my compositions were based on Hunan folk music and authentic Hunan language." ${ }^{55}$ In Eight Memories in Watercolor, there are four movements which directly cite folk songs. They are Staccato Beans, Herdboy's Song, Blue Nun, and Sunrain, respectively.

55 Translated by the author Qian Xu.

Maochun Liang 梁茂春, “是报效祖国的时候了”-写在”谭盾交响音乐会”之前[It Is Time to Serve the Motherland - Written Before the "Tan Dun Symphony Concert]," 人民音乐[People's Music] no.1 (1994): 13-17. 


\section{$\underline{\text { 5.3.1 Staccato Beans }}$}

Tan borrows the melody of 新媹嬇 [My New Sister-in-Law] (see Figure 11) ${ }^{56}$ as the main theme of Staccato Beans.

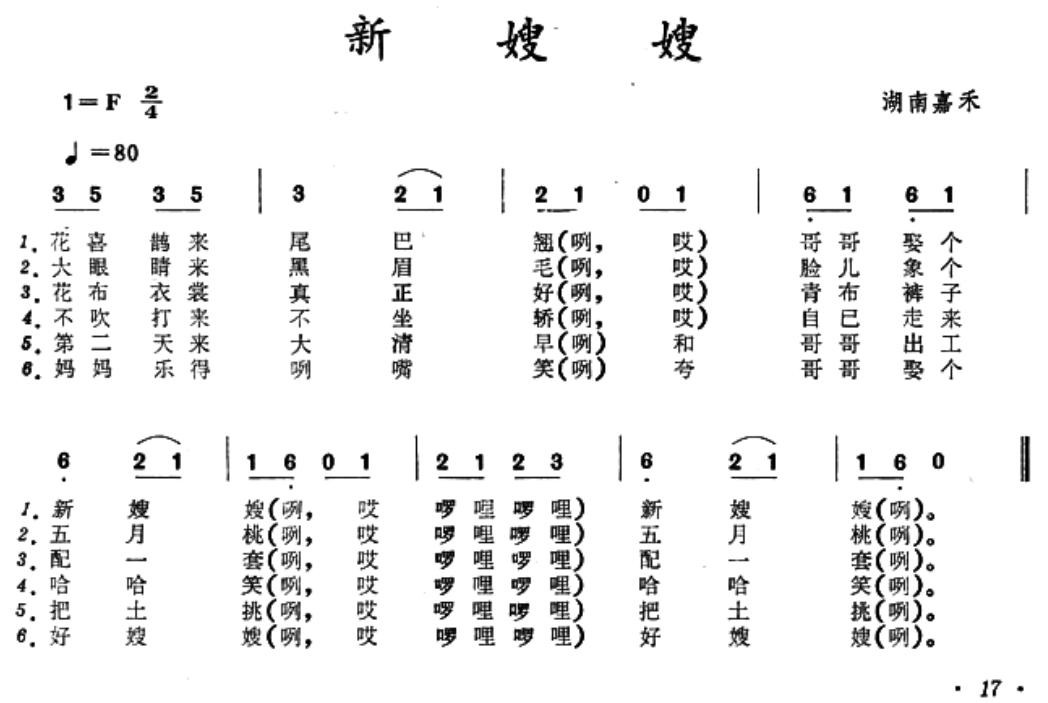

Figure 11 My New Sister-in-Law

My New Sister-in-Law is a Hunan folk song, originating from Jiahe [嘉禾], under the administration of Chenzhou, in Hunan Province. This piece consists of six stanzas and emanates a joyful atmosphere. The lyrics praise a new sister-in-law for her beauty, industriousness, and thriftiness in managing a household. My New Sister-inLaw and Staccato Beans are both in 2/4 meter and in the same pentatonic yu mode in D. Both are lively pieces with a relatively fast tempo. Tan directly cites the melody from My New Sister-in-Law in Staccato Beans, as shown below (see Figure 12 and

\footnotetext{
56 “新嫂舅 My New Sister-in-Law],” 中国曲谱网[Chinese Score Web], accessed March 30, 2018, http://www.qupu123.com/shaoer/sanzi/p314585.html.
} 
Figure 13).

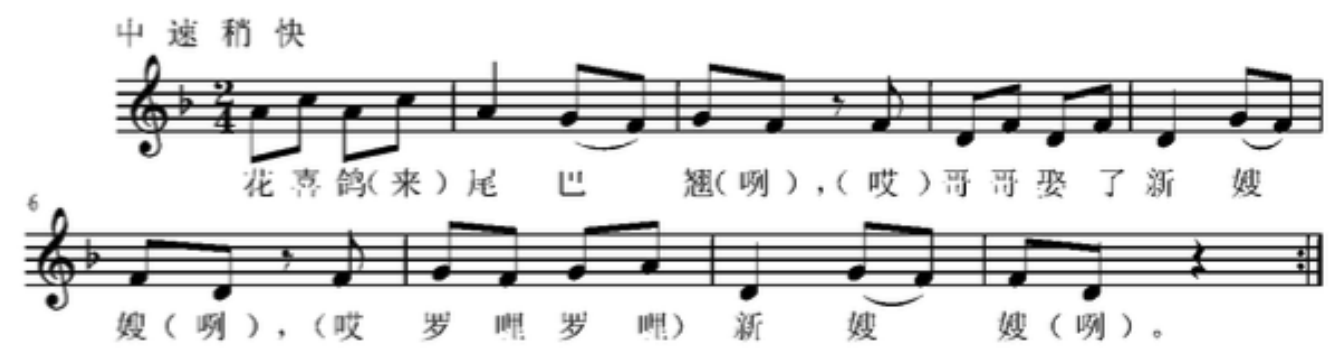

Figure 12 My New Sister-in-Law

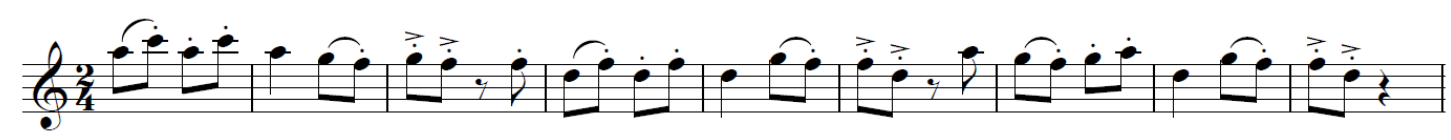

Figure 13 Staccato Beans, melody

In Staccato Beans, Tan applies frequent inflections to decorate the theme

depicting the lively children. For example, he indicates accent on the staccatos in $\mathrm{m}$.

5, m. 8, and m. 11, which makes these notes more energetic (see Figure 14). 


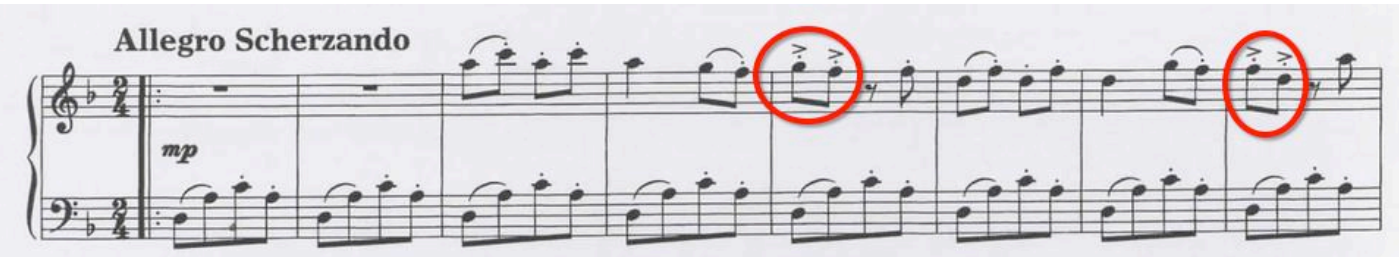

(the second time faster)

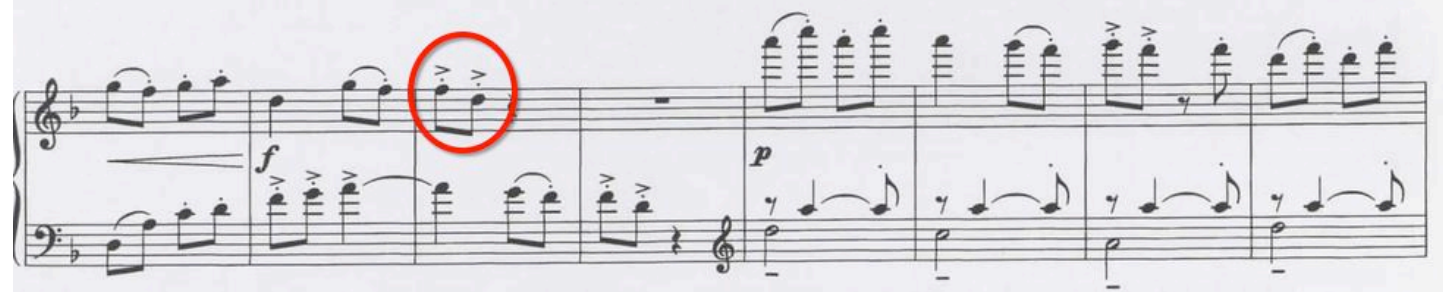

Figure 14 Staccato Beans, mm. 1-16

\section{EIGHT MEMORIES IN WATERCOLOR}

By Tan Dun

Copyright $(1996$ by G. Schirmer, Inc. (ASCAP)

International Copyright Secured. All Rights Reserved.

Used by Permission.

Warning: Unauthorized reproduction of this publication is prohibited by Federal Law and is subject to criminal prosecution.

\subsubsection{Herdboy's Song}

In “Herdboy’s Song,” Tan borrows some ideas from 这山望见那山高 [Grass Is

Greener on the Other Hill], a love song from Hengdong (see Figure 15). ${ }^{57}$

57 Zeng, "Hunan Folk Tone in Tan Dun's Memories of the Eight Watercolor Paintings," 109. 


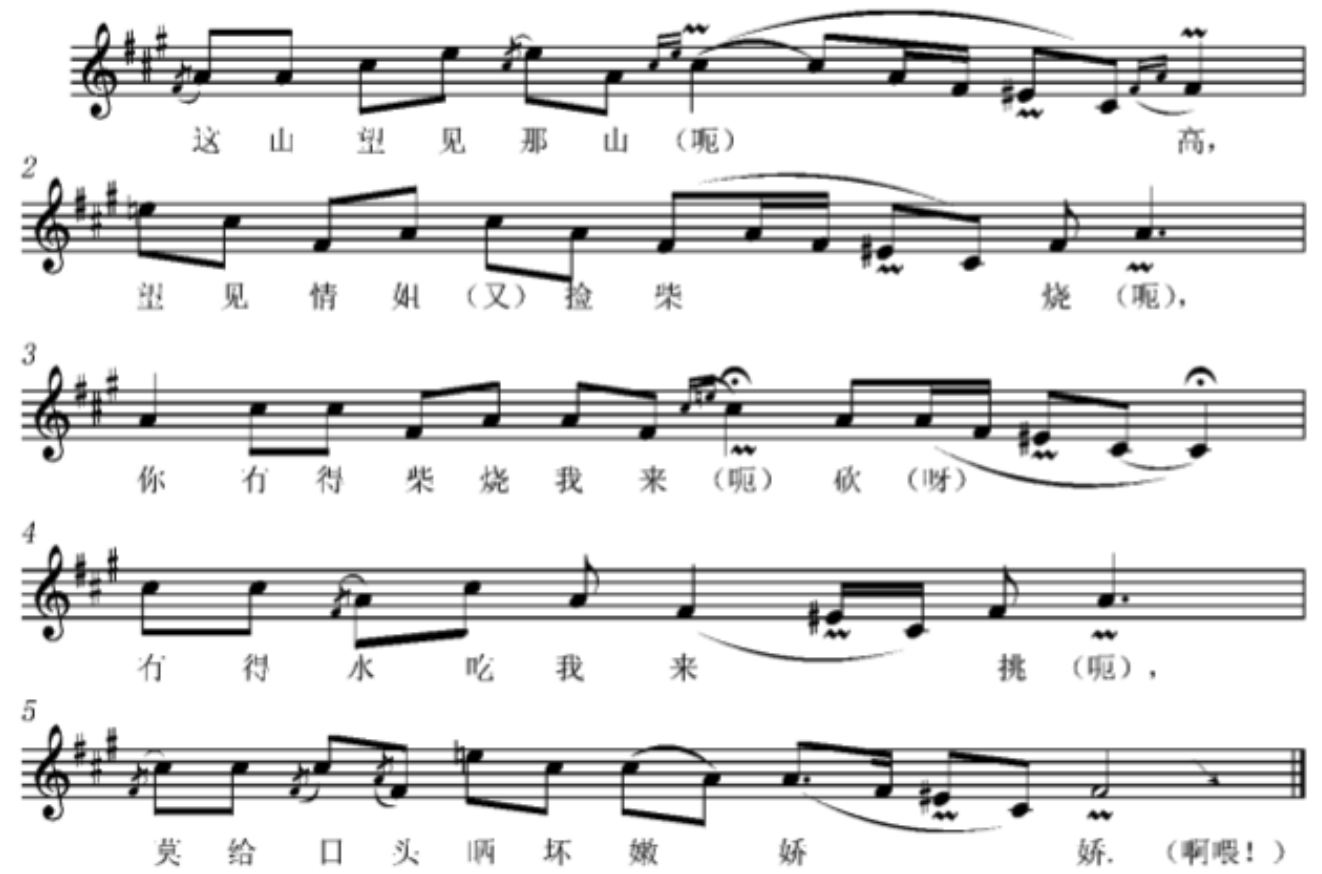

Figure 15 Grass is Greener on the Other Hill

Herdboy's Song and Grass Is Greener on the Other Hill are similar in the

structure. Both consist of five stanzas, while Herdboy's Song includes an introduction and a coda; they are both to be played freely with rubato. The structure features the Chinese Shan Ge Style [五句子山歌], which means mountain song, a genre of Chinese traditional folk music sung in villages. This genre originated at least 2000 years ago and was famous in the Hunan area. It usually consists of five stanzas as one section, with lyrics about love. Although Tan did not cite the entire melody of Grass Is Greener on the Other Hill directly in Herdboy's Song, they are similar in their melodic gestures (see Figure 16 and Figure 17). 


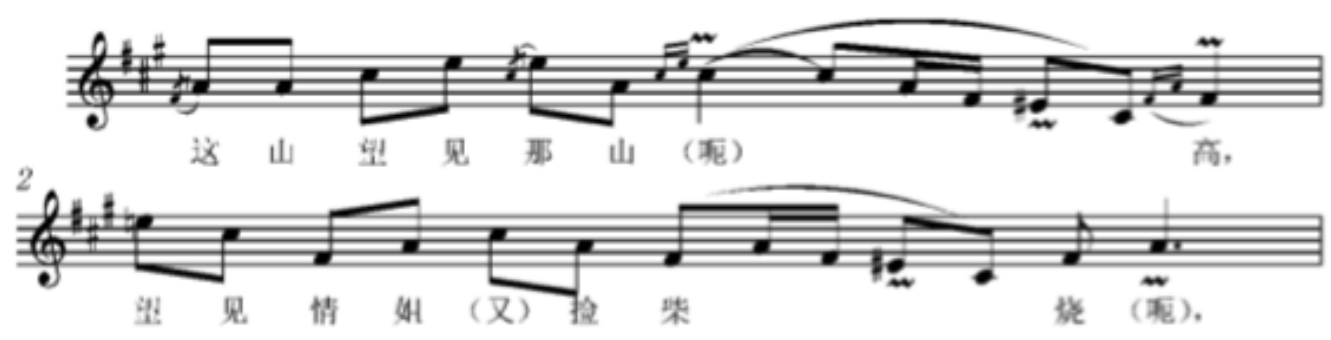

Figure 16 Grass is Greener on the Other Hill

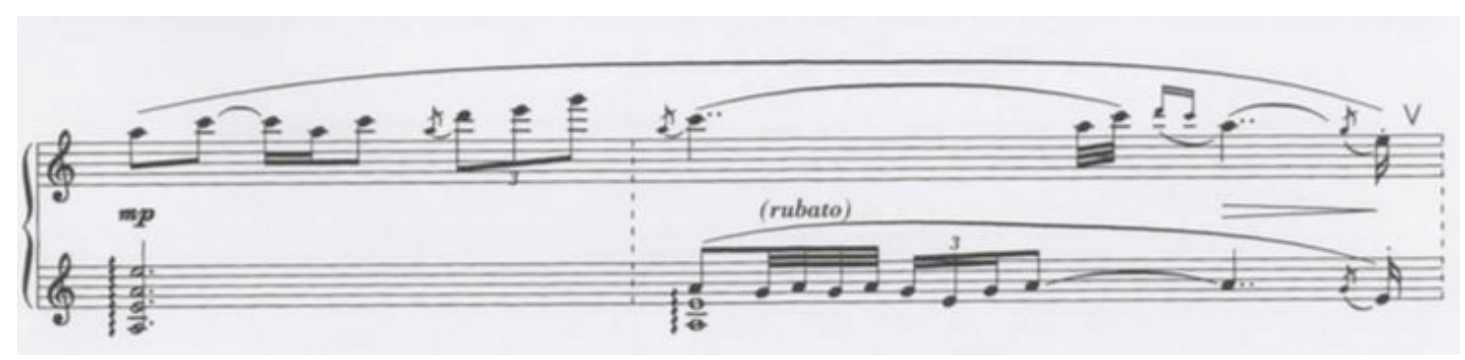

Figure 17 Herdboy's Song, mm. 3-4

\section{EIGHT MEMORIES IN WATERCOLOR}

By Tan Dun

Copyright $(1996$ by G. Schirmer, Inc. (ASCAP)

International Copyright Secured. All Rights Reserved.

Used by Permission.

Warning: Unauthorized reproduction of this publication is prohibited by Federal Law and is subject to criminal prosecution.

\subsubsection{Blue Nun}

The melody of the main theme in Blue Nun was borrowed from 乡里妹子进城

来 [A Girl from the Country is Coming into Town], a popular folk song from

Shaodong [邵东] in Hunan Province (see Figure 18). ${ }^{58}$

58 “乡里妹子进城来 A Girl from the Country is Coming into Town], ”找歌谱[Find Music], accessed March 30, 2018, http://www.zhaogepu.com/jianpu/79890.html. 


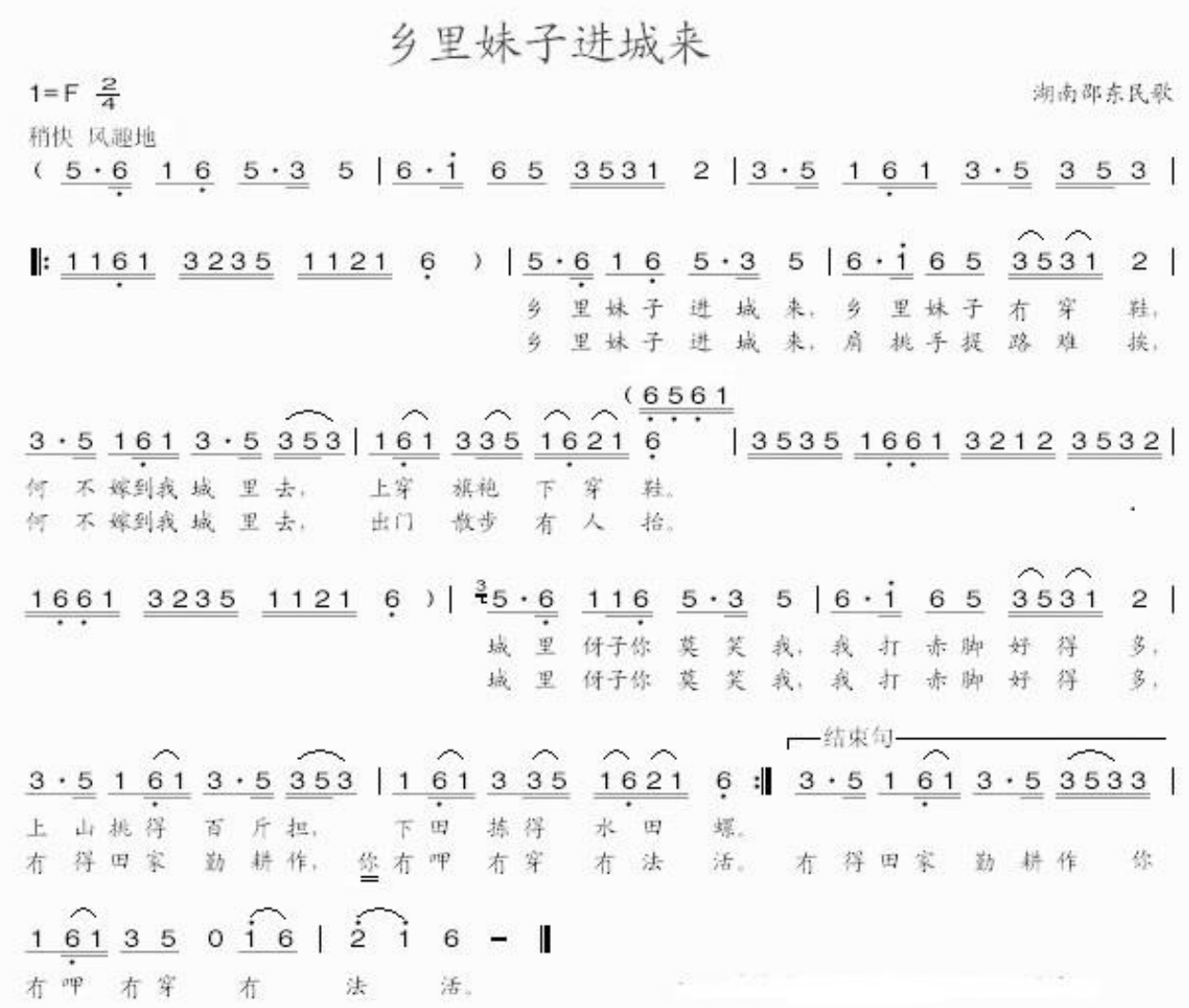

Figure 18 A Girl from the Country is Coming into Town

A Girl from the Country is Coming into Town was famous in the 1970s in the

Hunan area and was widely spread orally. It tells a story about a man from town who tempted a country girl to marry him, and the song describes the character of a pure, simple, and confident country girl. This piece was originally a duet sung in Hunan dialect. Tan does not cite the entire melody of $A$ Girl from the Country is Coming into Town in Blue Nun, but the two pieces display similarities in harmonic progression, melodic contour, and rhythmic gestures. Compared to A Girl from the Country Is Coming into Town (see Figure 19), ${ }^{59}$ Tan borrows the basic harmonic and melodic

59 Zeng, "Hunan Folk Tone," 110. 
contour, but simplifies the rhythm in Blue Nun (see Figure 20 and Figure 21).

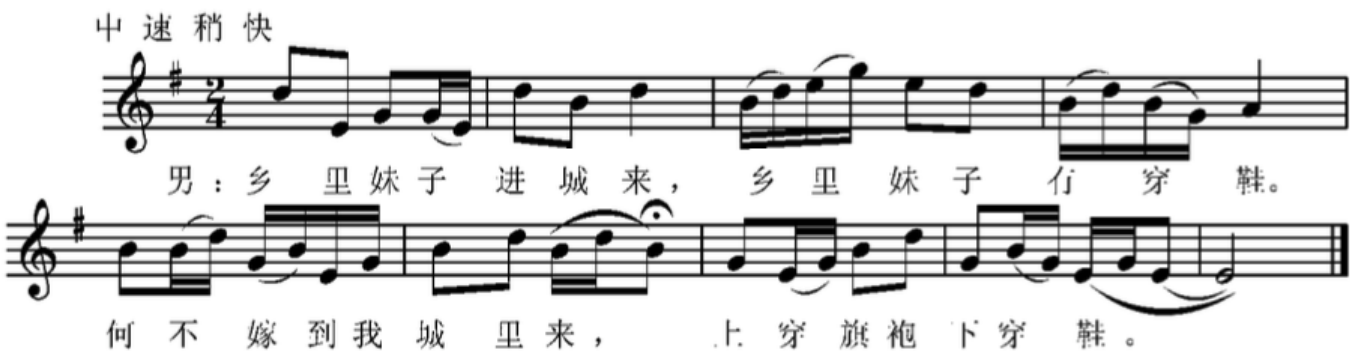

Figure 19 A Girl from the Country is Coming into Town

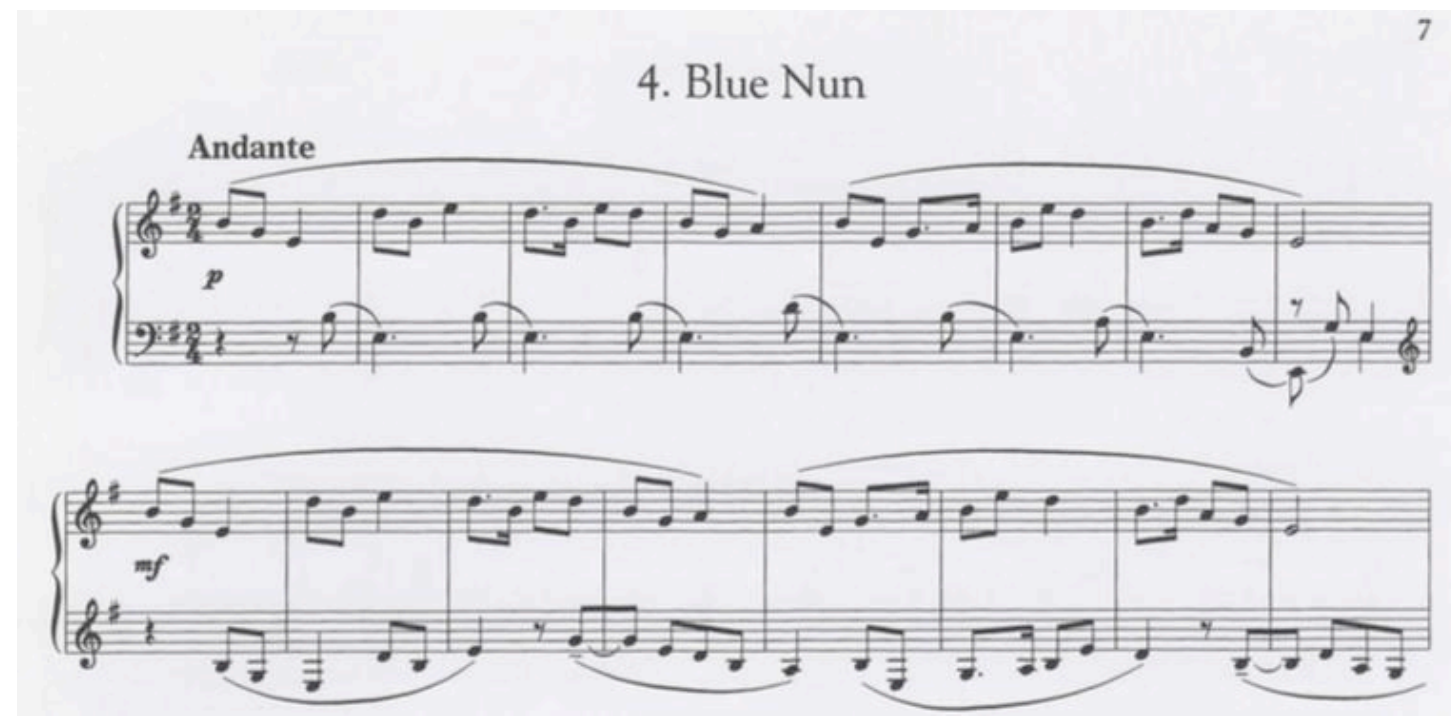

Figure 20 Blue Nun, mm. 1-16

\section{EIGHT MEMORIES IN WATERCOLOR}

By Tan Dun

Copyright $\odot 1996$ by G. Schirmer, Inc. (ASCAP)

International Copyright Secured. All Rights Reserved.

Used by Permission.

Warning: Unauthorized reproduction of this publication is prohibited by Federal Law and is subject to criminal prosecution. 


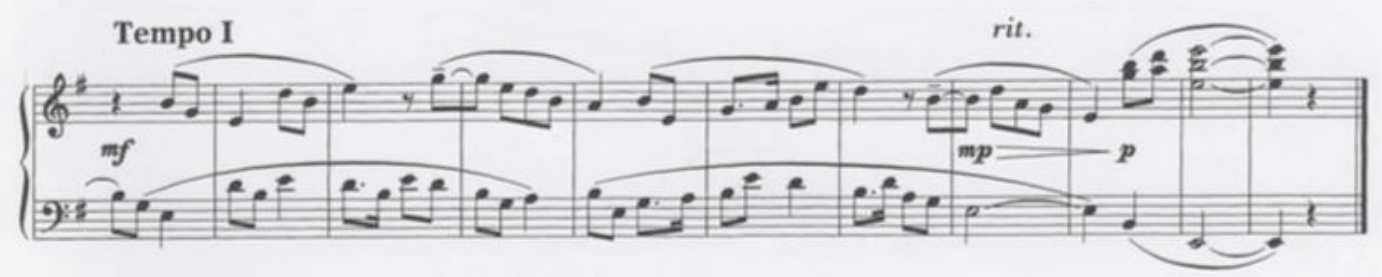

Figure 21 Blue Nun, mm. 33-44

\section{EIGHT MEMORIES IN WATERCOLOR}

By Tan Dun

Copyright $(1996$ by G. Schirmer, Inc. (ASCAP)

International Copyright Secured. All Rights Reserved.

Used by Permission.

Warning: Unauthorized reproduction of this publication is prohibited by Federal Law and is subject to criminal prosecution.

\section{$\underline{\text { 5.3.4 Sunrain }}$}

The melody of Sunrain is based on a children's song 放牛歌 [Shepherd's Song], from Tan's hometown in Hunan (see Figure 22). ${ }^{60}$

\section{中国民歌}

\begin{tabular}{|c|c|c|c|c|c|c|c|c|}
\hline $1=0$ & G $\frac{2}{4}$ & & & & & & & 湖 南 \\
\hline 21 & 21 & 1 & 1 & $5 \longdiv { 5 6 }$ & 5 & 2 & 5 & 2 \\
\hline $\begin{array}{l}\text { 1. 太 阳 } \\
\text { 2, 哥 哥 }\end{array}$ & $\begin{array}{l}\text { 出 来 } \\
\text { 骑 }\end{array}$ & （㖓 & $\begin{array}{l}\text { 路) } \\
\text { 咚) }\end{array}$ & 一点 & $\begin{array}{l}\text { 红, } \\
\text { 海, }\end{array}$ & $\begin{array}{l}\text { (哬 } \\
(\text { 㭻 }\end{array}$ & 喂 & 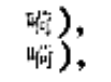 \\
\hline $\begin{array}{ll}5 & 5 \\
\end{array}$ & 25 & & & 21 & $\begin{array}{ll}21 \\
\end{array}$ & 5 & & 5 \\
\hline $\begin{array}{l}\text { 哥 㮣 } \\
\text { 姝 妹 }\end{array}$ & 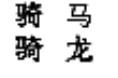 & $\begin{array}{l}\text { (小䶸 } \\
\text { (小睡 }\end{array}$ & 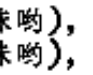 & $\begin{array}{l}\text { 虯骑 } \\
\text { 怔 }\end{array}$ & $\begin{array}{l}\text { 龙 (哪 } \\
\text { 㽞 }\end{array}$ & $\begin{array}{l}\text { 咚 } \\
\text { 略 }\end{array}$ & & $\begin{array}{l}\text { 降)。 } \\
\text { 咚)。 }\end{array}$ \\
\hline
\end{tabular}

Figure 22 Shepherd's Song

60 “放牛歌[Shepherd's Song],”中国词曲网[Chinese Song Network], accessed March 30, 2018, http://www.ktvc8.com/article/article_566730_1.html. 
This is a game song for when children ride on a bamboo horse. It depicts a joyful and exciting festive scene. In Sunrain, Tan also conveys a ceremonial impression by imitating a Chinese gong at the beginning (see Figure 23).

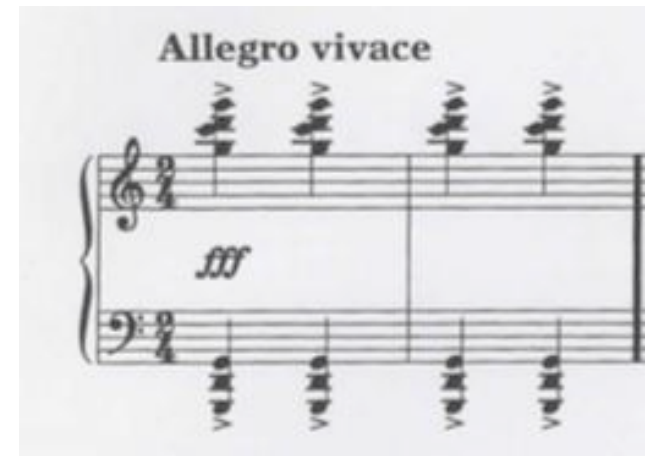

Figure 23 Sunrain, mm. 1-2

\section{EIGHT MEMORIES IN WATERCOLOR}

By Tan Dun

Copyright $(1996$ by G. Schirmer, Inc. (ASCAP)

International Copyright Secured. All Rights Reserved.

Used by Permission.

Warning: Unauthorized reproduction of this publication is prohibited by Federal Law and is subject to criminal prosecution.

The main theme features bitonality because of the parallel-fourth motion in the right hand. The alto voice has basically the same melody as Shepherd's Song (see

Figure 24 and Figure 25). ${ }^{61}$

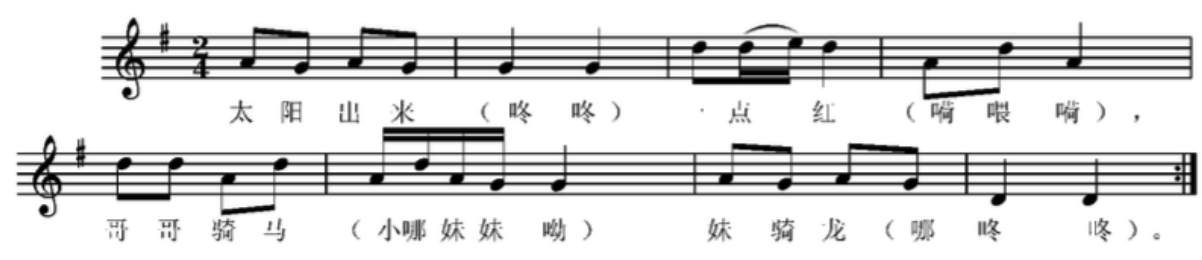

Figure 24 Shepherd's Song

61 Zeng, "Hunan Folk Tone," 110. 

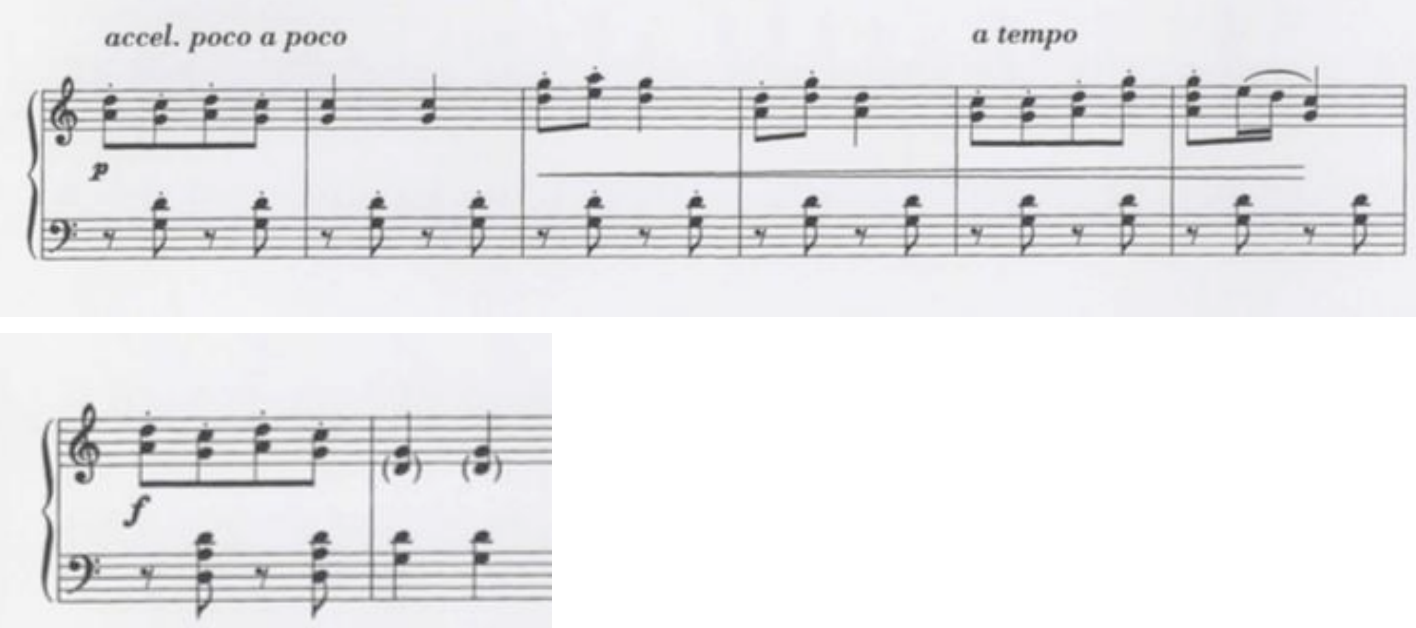

Figure 25 Sunrain, mm. 7-14

\section{EIGHT MEMORIES IN WATERCOLOR}

By Tan Dun

Copyright $(1996$ by G. Schirmer, Inc. (ASCAP)

International Copyright Secured. All Rights Reserved.

Used by Permission.

Warning: Unauthorized reproduction of this publication is prohibited by Federal Law and is subject to criminal prosecution.

\subsection{Imitation of Chinese Instruments}

\subsubsection{Imitation of zheng}

Zheng (see Figure 26) is a traditional plucked-string instrument with movable

bridges. It is considered one of the principal Chinese zither instruments, with a history spanning more than 2500 years. The modern zheng usually has 21 strings, with a large resonant cavity made from wood. There are a number of methods for playing the zheng to produce a variety of sounds; examples include flicking, tapping, shaking, pulling, strumming, lifting, stroking, sliding, wiggling, or chopping the strings. It is played by both hands. Usually the right hand plucks the notes and the left hand 
sometimes changes the pitch by tapping the string or produces vibrato by shaking the string. ${ }^{62}$ Tan evokes the zheng in Eight Memories in Watercolor by imitating its sound, conveying a particularly Chinese atmosphere.

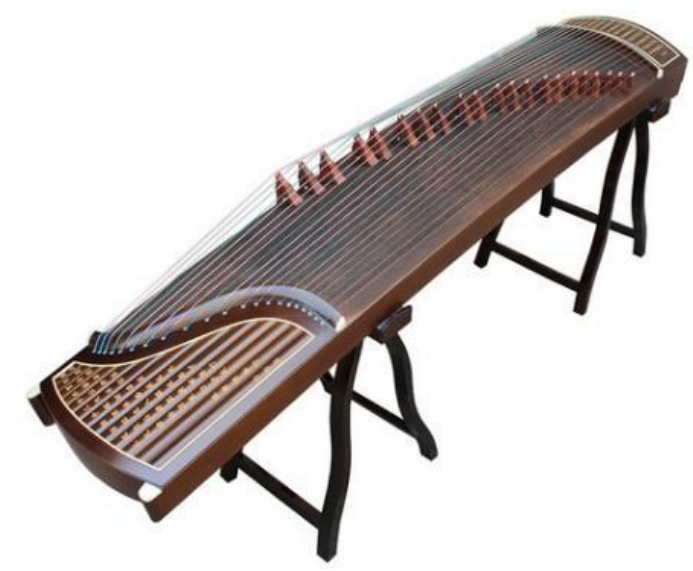

Figure 26 Zheng

\subsubsection{Imitation of right hand playing of zheng}

At the beginning of Missing Moon, the four descending grace notes (Gb-Eb-Db$\mathrm{Bb})$ in the left hand imitate the plucking sound of the right hand playing the zheng (see Figure 27).

${ }^{62}$ Mei Han, "Zheng," Oxford Music Online, accessed March 16, 2018, http://www.oxfordmusiconline.com/subscriber/article/grove/music/46543. 


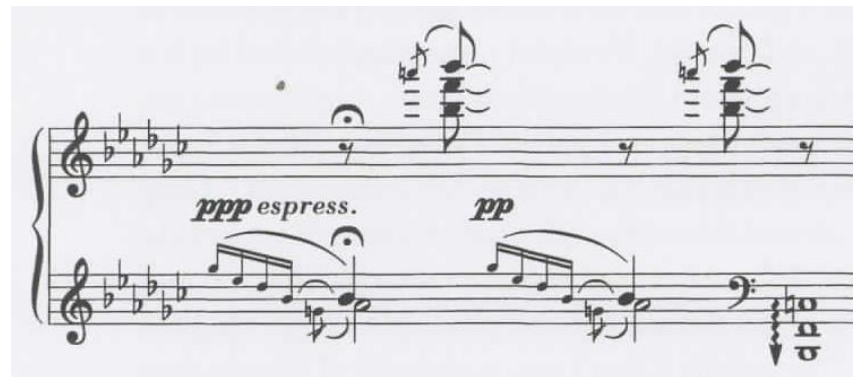

Figure 27 Missing Moon, m.1

\section{EIGHT MEMORIES IN WATERCOLOR}

By Tan Dun

Copyright (C) 1996 by G. Schirmer, Inc. (ASCAP)

International Copyright Secured. All Rights Reserved.

Used by Permission.

Warning: Unauthorized reproduction of this publication is prohibited by Federal Law and is subject to criminal prosecution.

Another example can be found in $\mathrm{m} .1$ of Red Wilderness. The grace notes (A-G-

E) imitate the plucking sound of the right hand playing the zheng (see Figure 28).

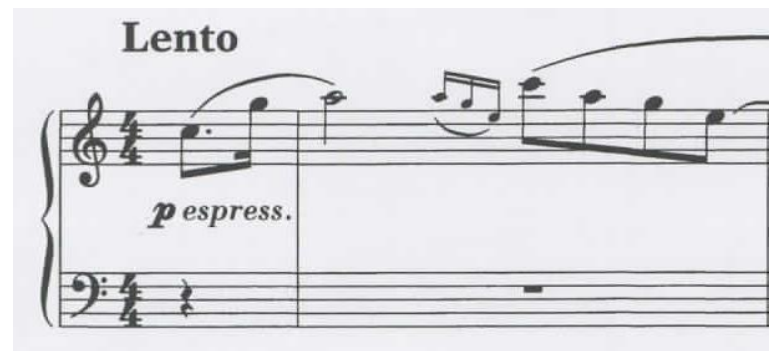

Figure 28 Red Wilderness, m.1

\section{EIGHT MEMORIES IN WATERCOLOR}

By Tan Dun

Copyright $\odot 1996$ by G. Schirmer, Inc. (ASCAP)

International Copyright Secured. All Rights Reserved.

Used by Permission.

Warning: Unauthorized reproduction of this publication is prohibited by Federal Law and is subject to criminal prosecution.

\subsubsection{Imitation of left hand playing of zheng}

By pressing on a string of the zheng, the left hand can increase the tension and

raise the pitch, "bending" the pitch upward as much as a minor second. From the end 
of the introduction to m. 4 of Missing Moon, the pianist's left hand imitates this effect

by adding a lower minor-second grace note before the melodic notes (see Figure 29).

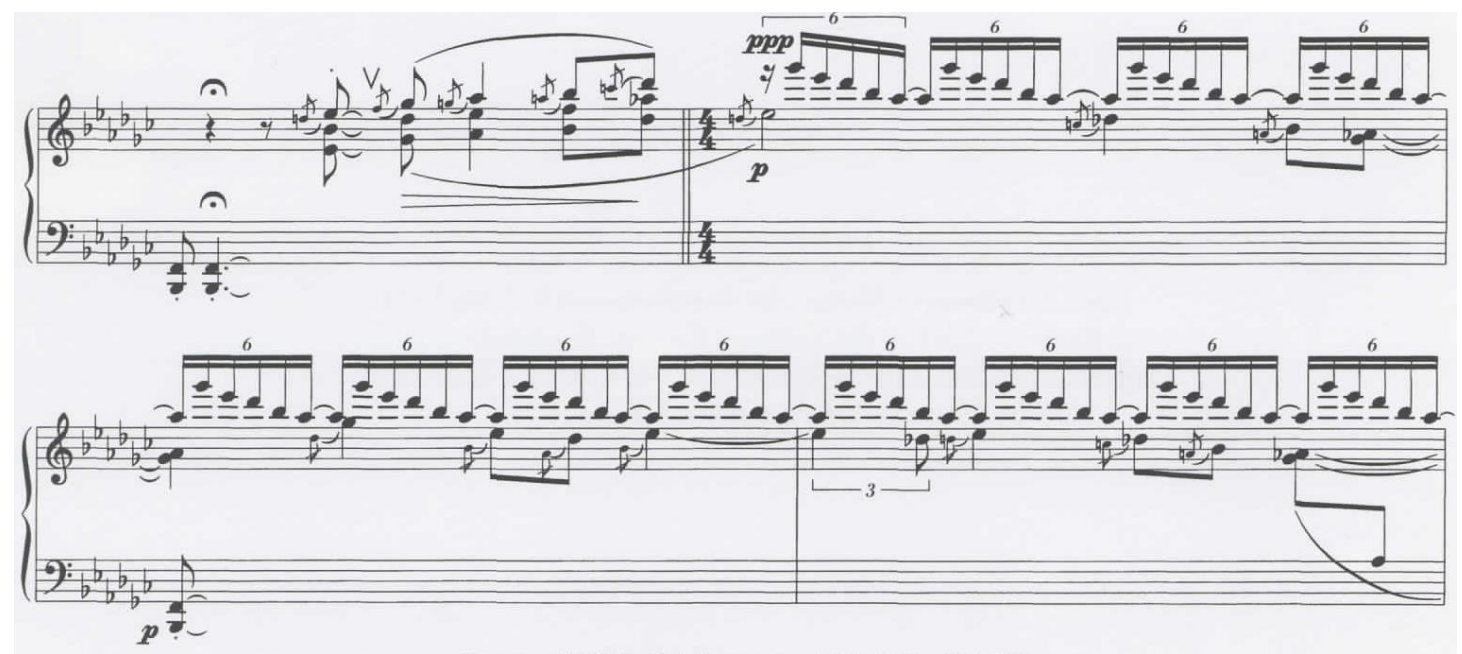

Figure 29 Missing Moon, mm. 1-4

\section{EIGHT MEMORIES IN WATERCOLOR}

By Tan Dun

Copyright (C) 1996 by G. Schirmer, Inc. (ASCAP)

International Copyright Secured. All Rights Reserved.

Used by Permission.

Warning: Unauthorized reproduction of this publication is prohibited by Federal Law and is subject to criminal prosecution.

Another example appears in the right hand of m. 2 of Herdboy's Song. The grace notes move up a half step to imitate the bending effect of zheng (see Figure 30). 


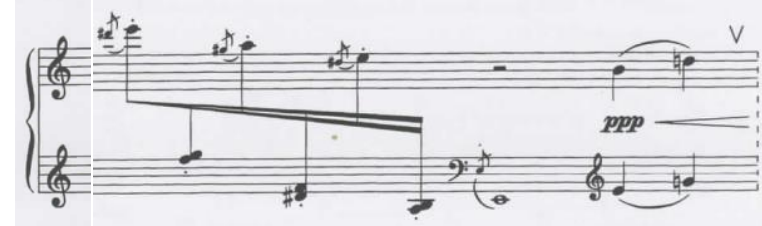

Figure 30 Herdboy's Song, m.2

\section{EIGHT MEMORIES IN WATERCOLOR}

By Tan Dun

Copyright (C) 1996 by G. Schirmer, Inc. (ASCAP)

International Copyright Secured. All Rights Reserved.

Used by Permission.

Warning: Unauthorized reproduction of this publication is prohibited by Federal Law and is subject to criminal prosecution.

\subsubsection{Imitation of glissando playing of zheng}

Glissando on zheng is produced by quickly sliding across the strings. In m. 14 of Missing Moon, the grace notes approaching the lowest note provide a clear example (see Figure 31).

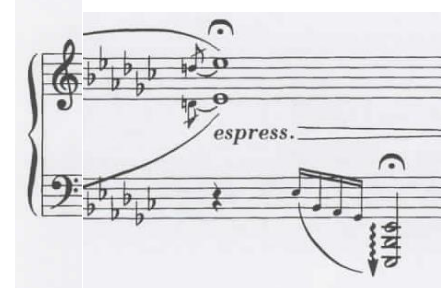

Figure 31 Missing Moon, m.14

\section{EIGHT MEMORIES IN WATERCOLOR}

By Tan Dun

Copyright $(1) 1996$ by G. Schirmer, Inc. (ASCAP)

International Copyright Secured. All Rights Reserved.

Used by Permission.

Warning: Unauthorized reproduction of this publication is prohibited by Federal Law and is subject to criminal prosecution.

Another example appears in m. 11 of Herdboy's Song, where the eight-note glissando patterns repeat and accelerate (see Figure 32). 


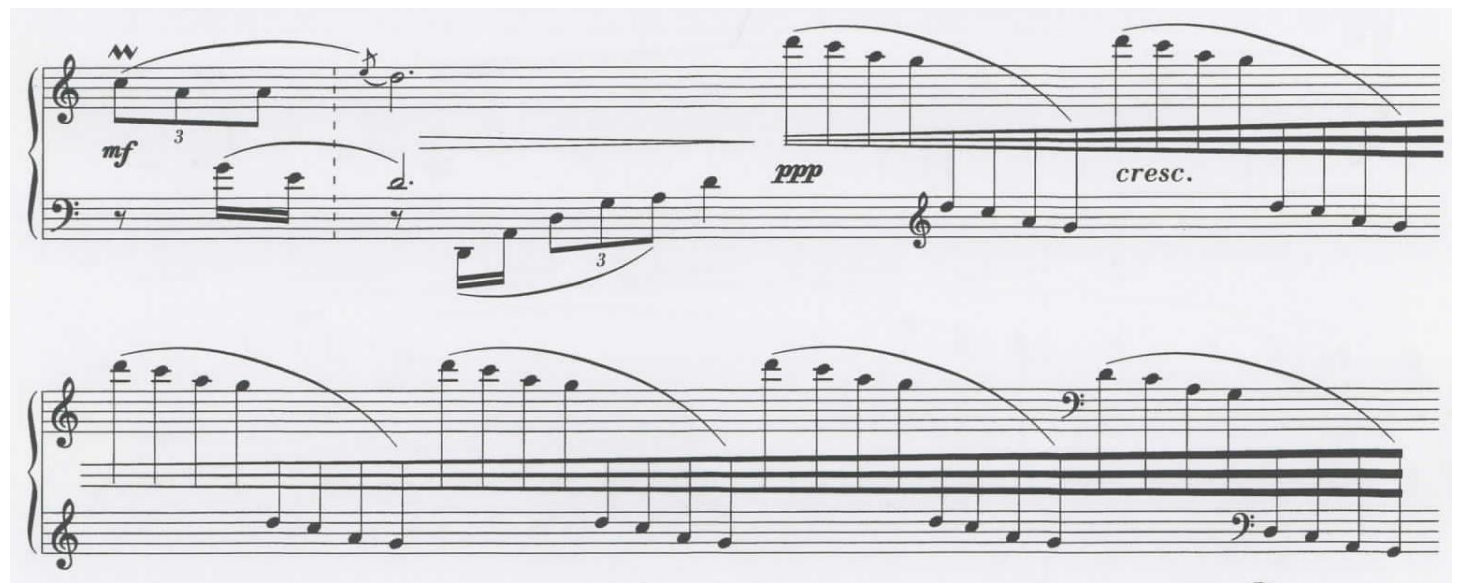

Figure 32 Herdboy's Song, m. 11

\section{EIGHT MEMORIES IN WATERCOLOR}

By Tan Dun

Copyright $(1996$ by G. Schirmer, Inc. (ASCAP)

International Copyright Secured. All Rights Reserved.

Used by Permission.

Warning: Unauthorized reproduction of this publication is prohibited by Federal Law and is subject to criminal prosecution.

\subsubsection{Imitation of Chinese gong and drums}

Chinese gong (see Figure 33) and drums (see Figure 34) are the most frequently used instruments in Chinese folk music, especially in the south and among Chinese minority peoples. They are always used as a set by at least two persons and are played on significant occasions, such as festivals, banquets, weddings, and funerals. By hitting different spots on the drums and gong, players can change the timbre and pitch of the resulting sound. 


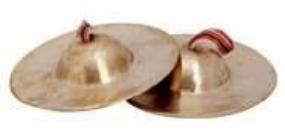

Figure 33 Chinese gong

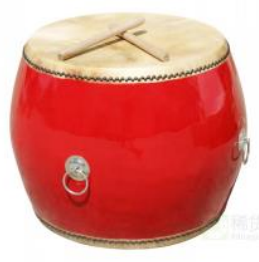

Figure 34 Chinese drum

In the introduction of Sunrain, right hand and left hand imitate the sound of the gong and drum, respectively. A major-second interval is presented in the right hand throughout this section, imitating the natural cluster sound from the Chinese gong (see Figure 35). Perfect intervals are presented in the left hand in mm. 1-2, imitating the resonant sounds of the drums (see Figure 35). In mm. 3-6, the moving bass line in the left hand imitates the different pitches and sounds the drummers create by hitting different spots on the drums (see Figure 35). The resulting combined sonority of the right hand and left hand evokes a scene of joyful festivities. 


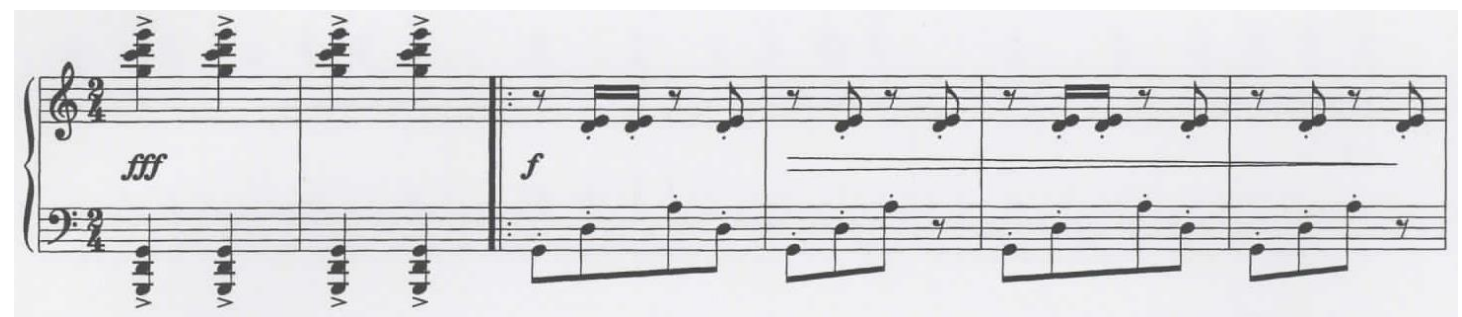

Figure 35 Sunrain, mm. 1-6

\section{EIGHT MEMORIES IN WATERCOLOR}

By Tan Dun

Copyright (C) 1996 by G. Schirmer, Inc. (ASCAP)

International Copyright Secured. All Rights Reserved.

Used by Permission.

Warning: Unauthorized reproduction of this publication is prohibited by Federal Law and is subject to criminal prosecution.

\subsubsection{Imitation of sheng}

Sheng (see Figure 36) is a mouth-blown free reed instrument and is also regarded

as the mouth organ of the Han Chinese. It is one of the earliest Chinese instruments,

mentioned as early as the fourteenth century B.C.E. The instrument is constructed of a

bowl-shaped wind chest of wood or metal (or gourd in ancient times), with a blow-

pipe extending out from one side. Shengs appear in various types and sizes, ranging

from 13 reeds (traditional sheng), 32 reeds (modern keyed chromatic sheng), to 53

reeds (keyboard sheng). It was used at important Chinese occasions such as weddings,

funerals, and sacrifices. The sheng can also be used to accompany singing and

dance. ${ }^{63}$

${ }^{63}$ Alan R. Thrasher, “Sheng," Oxford Music Online, accessed March 16, 2018, https://doi-org.lib-
ezproxy.hkbu.edu.hk/10.1093/gmo/9781561592630.article.25623. 


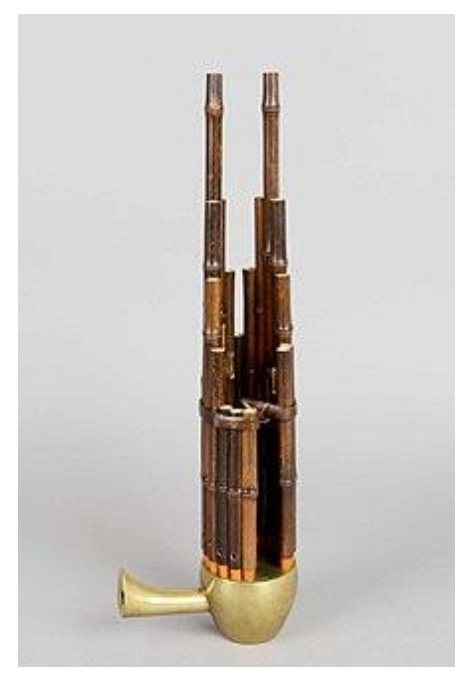

Figure 36 Sheng

In mm. 31-37 of Sunrain, each hand canonically presents parallel fourths,

conveying a scene of two sheng players chasing each other (see Figure 37 ).

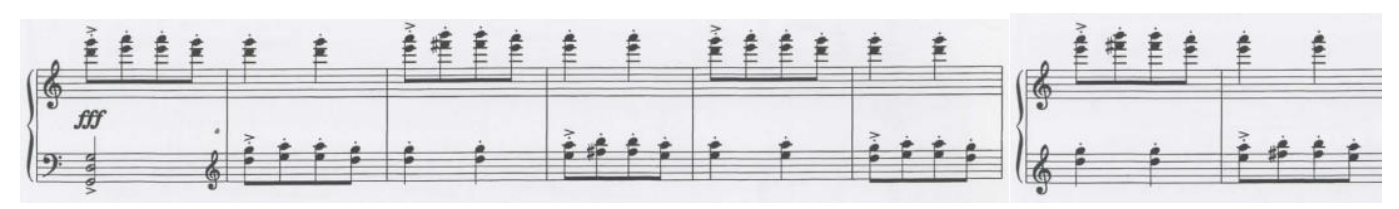

Figure 37 Sunrain, mm. 30-37

\section{EIGHT MEMORIES IN WATERCOLOR}

By Tan Dun

Copyright $(1996$ by G. Schirmer, Inc. (ASCAP)

International Copyright Secured. All Rights Reserved.

Used by Permission.

Warning: Unauthorized reproduction of this publication is prohibited by Federal Law and is subject to criminal prosecution.

\subsubsection{Imitation of bianzhong}

Bianzhong [编钟] (see Figure 38) is an ancient Chinese percussion instrument consisting of a set of bell-chimes made from bronze. The earliest found artefacts of bianzhong were dated between 6000 and 5000 B.C.E. In ancient times it was an 
important instrument for large-scale outdoor rituals. ${ }^{64}$

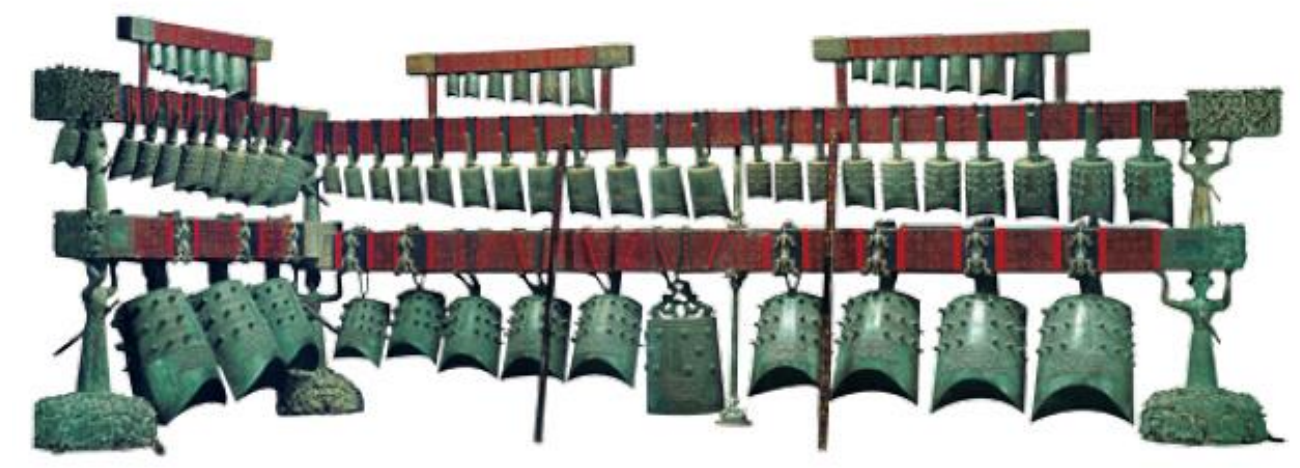

Figure 38 Bianzhong

In Ancient Burial, a middle voice consisting of a D-C-D-C pattern imitates the playing of bianzhong (see Figure 39).

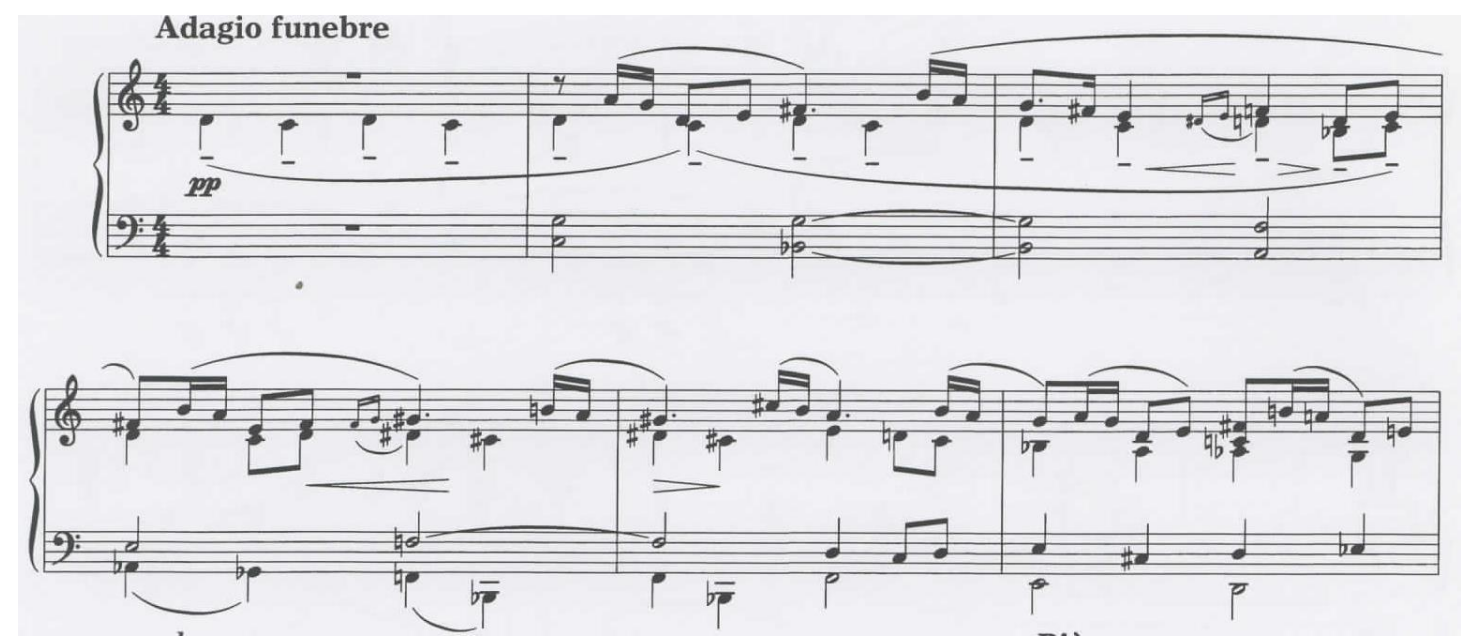

Figure 39 Ancient Burial, mm. 1-6

\section{EIGHT MEMORIES IN WATERCOLOR}

By Tan Dun

Copyright (C 1996 by G. Schirmer, Inc. (ASCAP)

International Copyright Secured. All Rights Reserved.

Used by Permission.

Warning: Unauthorized reproduction of this publication is prohibited by Federal Law and is subject to criminal prosecution.

64 Alan R. Thrasher, "Musical instruments," Oxford Music Online, accessed March 16, 2018, https://doi-org.lib-ezproxy.hkbu.edu.hk/10.1093/gmo/9781561592630.article.43141. 


\subsection{Tuo Qiang}

Tuo qiang [拖腔] is a melismatic singing style in Chinese traditional folk songs.

A syllable, usually a one-syllable word, is sung through several different notes in

succession. The performance style of tuo qiang varies among areas and genres. It is

common practice in Hunan folk songs for the last note of a phrase to be scooped up to

a high note. ${ }^{65}$

An example can be found in m. 5 of Herdboy's Song. The final grace note G is an imitation of the scooped-up tuo qiang after the last note $\mathrm{E}$ of the phrase (see Figure 40).

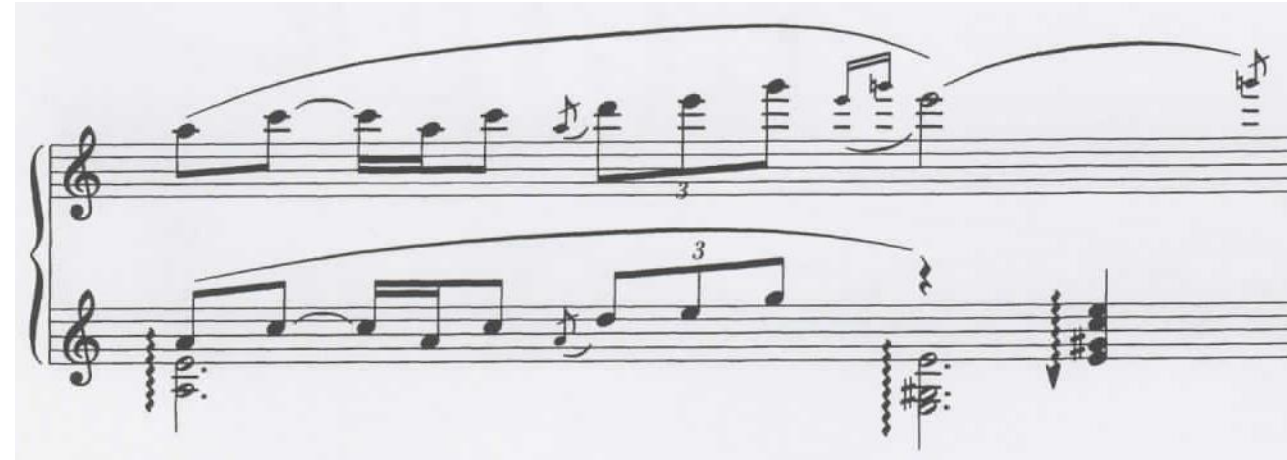

Figure 40 Herdboy Song, m.5

\section{EIGHT MEMORIES IN WATERCOLOR}

By Tan Dun

Copyright (C) 1996 by G. Schirmer, Inc. (ASCAP)

International Copyright Secured. All Rights Reserved.

Used by Permission.

Warning: Unauthorized reproduction of this publication is prohibited by Federal Law and is subject to criminal prosecution.

65 Baolu Chen, Tan Dun's Eight Memories in Watercolor p.28 


\section{CHAPTER 6}

\section{Conclusion}

Through this study of Eight Memories in Watercolor I have gained a deeper understanding of this beautiful piece of music. I hope that the reader also can enjoy the ways that Tan Dun merges Western compositional technique with Chinese musical elements in his writing style. This awareness can give us a better grasp of Tan's musical language and can help us appreciate the Chinese cultural influences revealed in his other compositional genres as well. Appreciating these connections can also help to inform the interpretive decisions by pianists who want to perform Eight Memories in Watercolor or other pieces in similar style, whether by Tan or by any other composer.

The musical language Tan developed in the Eight Memories in Watercolor, especially his use of Chinese musical and cultural elements, continues to be part of his personal compositional style in his later works. Xiang-Chu culture and $\mathrm{Wu}-\mathrm{NuO}$ culture, now steeped in mystery for modern observers, are deeply rooted in Tan's other musical compositions such as Nine Songs, dedicated to the memory of the great Chinese poet Qu Yuan, who lived in the state of Chu during the "Warring State" period of ancient China, from 340 to 278 B.C.E. The work is non-narrative, based on Qu Yuan's ancient poems of the same name. Nine Songs was composed in 1989 for performance with dance, music, and drama. This piece is a representative example of 
Tan's music that is filled with the beauty of nature and the mysteries of shamanistic ritual, deeply influenced by Xiang-Chu culture and Wu-Nuo culture. ${ }^{66}$

In Eight Memories in Watercolor, Tan conveys a particularly Chinese sound palette by imitating traditional instruments such as zheng, Chinese gong and drums, sheng, and bianzhong. He also applies similar techniques in his later compositions, exploring more ways to bring the flavor of Chinese traditional instruments into his music. A good example is $C-A-G-E$, written in 1993 and dedicated to the memory of John Cage. In $C-A-G-E$, Tan applies directly to the piano strings the fingering techniques of the traditional Chinese plucked instrument called pipa. Similarly, within Eight Memories in Watercolor he evokes the characteristic sound of zheng in Missing Moon, Red Wilderness, and Herdboy's Song.

In Staccato Beans and Herdboy's Song, Tan uses chromatic notes to replace the "neutral tones" (quartertones) which are a special characteristic of Huagu dance in Hunan province. Borrowing from Chinese traditional dance or opera also occurs in his later compositions; for example, the opera Marco Polo incorporates style elements of Peking Opera. The historical story of Marco Polo describes a journey from the West to the East. Through his treatment of this material, Tan achieves a cultural blending through a twenty-first-century form of opera that incorporates multiple languages,

\footnotetext{
66 Dun Tan, "Nine-Songs," Tan Dun Official Website, accessed March 31, 2018, http://tandun.com/composition/nine-songs.
} 
cultures, time periods, Eastern and Western operatic traditions, and varied musical styles to create an authentically international genre. ${ }^{67}$

Eight Memories in Watercolor is Tan's Opus 1. He composed the work when he was only 19 years old, during his undergraduate study at Beijing's Central Conservatory. This piece is representative of his early period of composition, already indicating his exceptional talent. He builds his personal style from deep Chinese traditional roots with the addition of skillful Western techniques of composition. The influence of Chinese culture and Chinese music continues in his later works.

In Tan's piano pieces, we observe changes in his compositional style, which begins with traditional Western language that is greatly influenced by Chinese traditional music. He has also written Western avant-garde music and returned to tonal harmonic language.

Tan's compositional style and repertoire are constantly expanding and his music reveals more and more variety in multiple genres. These are the branches that have sprung from the deep cultural roots that he first explored in Eight Memories in

\section{Watercolor.}

67 Dun Tan, “Marco Polo," Tan Dun Official Website, accessed March 31, 2018, http://tandun.com/composition/marco-polo. 


\section{BIBLIOGRAPHY}

\section{Dissertations}

Chen, Baolu. "Tan Dun's Eight Memories in Watercolor, Op.1: Strategies for Pianists and a Version Comparison." DMA diss., Ohio State University, 2016.

Chen, Yingying 陈莹甞. “八幅水彩画的回忆的民族特征及演奏分析 [Eight

Memories in Watercolor: Artistic Characteristics and Analysis of Piano

Performance].” MM diss., Jiangxi Normal University, 2013.

Li, Ying. "The Research of Sorcery Colors in Tan Dun's Music.” MM diss., Shandong University, 2014.

Shao, Yutong. "A study on Chinese Modal Operas." PhD diss., Northeast Normal University, 2007.

Zhang, Caiyun 张彩云. “谭盾钢琴组曲《八幅水彩画的回忆》创作研究

[Researching on Tan Dun's Piano Suite Eight Memories in Watercolor].” MM diss., Southwestern University, 2009.

\section{Journal Articles}

Kang, Le. "The Development of Chinese Piano Music." Asian Culture and History 1, no.2 (July 2009): 21-22.

Li, Mei 李玫. “中立音赖以存在的民间乐器机制(上) [Special Physical Features of Folk-Music Instruments as prerequisites for Neutral-Tone (First half)].”中国音乐学 [Musicology in China] no. 1 (2001): 19-31.

Li, Mei 李玫.”民间音乐中中立音现象的律学分析(上)[Musical Temperament Analysis of Neutral-Tone in Chinese Traditional Music].” 中央音乐学院学报 [Journal of the Central Conservatory of Music] no.3 (2000): 28-35.

Liang, Maochun 梁茂春. “是报效祖国的时候了”-写在-谭盾交响音乐会-之前[It Is Time to Serve the Motherland - Written Before the "Tan Dun Symphony Concert]." 人民音乐[People's Music] no.1 (1994): 13-17.

Ouyang, Guozhong 阳国忠, and Jian, Haiyan 简海燕. “谭盾-用湘楚之锤敲响世界 大锣[Tan Dun—Ring the World with the Xiang-Chu hammer.” 高中生[High Schooler] no.7 (2015): 14-15. 
Sheng, Boji 盛伯骥. “关于艺术思想的真实记录-- 《根籁一谭盾与家乡的对话》编 后感[About the True Record of Artistic Thought_—After Dialogue between Tan Dun and His Hometown." 当代电视[Modern Television] no.2 (2002): 64-65.

Yang, Zichao 杨子超 . “谭盾音乐的多元化因素探索[Exploring the diversified factors in Tan Dun's music].” Radio \& TV Journal no.7 (2015): 222-226.

Zeng, Meiyue 曾美月. “谭盾《八幅水彩画的回忆》中的湖南民间音调[Hunan Folk Tone in Tan Dun's Eight Memories in Watercolor].” 内蒙古大學藝術學院學報 [Journal of Art College of Inner Mongolia University], no.2 (2012): 107-111.

Zheng, Fafen 郑发奋. “游走于东西方文化艺术之间[Walking between Eastern and Western Cultures and Arts].” Musical Works no.4 (2010): 107-109.

\section{Sheet Music}

Tan, Dun. Eight Memories in Watercolor. New York: G. Schirmer, Inc. (ASCAP), 1996

\section{Music Reference Works}

Day-O'Connell, Jeremy. "Pentatonic." Grove Music Online. Accessed February 23, 2018. https://doi-org.libezproxy.hkbu.edu.hk/10.1093/gmo/9781561592630.article.21263.

Han, Mei. "Zheng.” Oxford Music Online. Accessed March 16, 2018. http://www.oxfordmusiconline.com/subscriber/article/grove/music/46543.

Lee, Joanna C. “Tan Dun.” Grove Music Online. Accessed December 21, 2017. https://doi-org.lib-ezproxy.hkbu.edu.hk/10.1093/gmo/9781561592630.article.42657.

Lüderwaldt, Andreas, and Köhn, Thomas Sebastian. "Sámi music." Grove Music Online. Accessed December 21, 2017. https://doi-org.libezproxy.hkbu.edu.hk/10.1093/gmo/9781561592630.article.24461.

Thrasher, Alan R. "Musical Instruments." Oxford Music Online. Accessed March 16, 2018. https://doi-org.libezproxy.hkbu.edu.hk/10.1093/gmo/9781561592630.article.43141. 
Thrasher, Alan R. "Sheng.” Oxford Music Online. Accessed March 16, 2018.

https://doi-org.lib-ezproxy.hkbu.edu.hk/10.1093/gmo/9781561592630.article.25623

\section{Newspaper}

Chou, Oliver. "How Oscar-winning composer Tan Dun is using culture to create a symphony for Hong Kong's identity." South China Morning Post. Accessed

December 1, 2017. http://www.scmp.com/news/hong-kong/educationcommunity/article/2077169/how-oscar-winning-composer-tan-dun-using-culture.

\section{Interviews}

Flipse, Eline. "Chinese Classical Composers: Interview Tan Dun.” YouTube. Accessed December 21, 2017. https://www. youtube.com/watch?v=T9WBfn1DgDo.

Opera Philadelphia. "Get to Know Composer Tan Dun”. Filmed [February 2010]. YouTube video, 4:06. Posted [February 2010]. https://youtu.be/-m2TizGwOp8.

\section{Websites}

“About.” Tan Dun Official Website. Accessed December 23, 2017.

http://tandun.com/about.

“Martial Arts Trilogy.” Music Sales Classical. Accessed December 23, 2017.

http://www.musicsalesclassical.com/composer/work/1561/46821\#.

"Piano 2017\&2018, Grade 5 Piano." Associated Board of the Royal Schools of Music. Accessed December 20, 2017.

https://gb.abrsm.org/fileadmin/user_upload/syllabuses/piano0517.pdf.

"Syllabus." Standard Grade Examination Committee of the Central Conservatory of Music. Accessed December 20, 2017.

http://wap.kjwyh.ccom.edu.cn/index/index/textbook.

“Tan Dun Biography.” Musician Guide. Accessed December 21, 2017.

http://www.musicianguide.com/biographies/1608003000/Tan-Dun.html.

Tan, Dun. “CAGE.” Tan Dun Official Website. Accessed December 23, 2017.

http://tandun.com/composition/c-a-g-e.

Tan, Dun. "Concerto for Pizzicato Piano and Ten Instruments." Tan Dun Official Website. Accessed December 23, 2017. http://tandun.com/composition/concerto-forpizzicato-piano-and-ten-instruments. 
Tan, Dun. "Dew-Fall-Drops.” Tan Dun Official Website. Accessed December 23, 2017. http://tandun.com/composition/dew-fall-drops.

Tan, Dun. "Eight Colors for String Quartet." Tan Dun Official Website. Accessed December 21, 2017. http://tandun.com/composition/eight-colors-for-string-quartet.

Tan, Dun. "Eight Memories in Watercolor." Tan Dun Official Website. Accessed December 21, 2017. http://tandun.com/composition/eight-memories-in-watercolor.

Tan, Dun. "Farewell My Concubine." Tan Dun Official Website. Accessed December 23, 2017. http://tandun.com/composition/concerto-for-piano-and-peking-operasoprano-farewell-my-concubine.

Tan, Dun. "Marco Polo.” Tan Dun Official Website. Accessed March 31, 2018. http://tandun.com/composition/marco-polo.

Tan, Dun. "Martial Arts Trilogy." Tan Dun Official Website. Accessed December 23, 2017. http://tandun.com/composition/martial-arts-trilogy.

Tan, Dun. "Nine-Songs.” Tan Dun Official Website. Accessed March 31, 2018. http://tandun.com/composition/nine-songs.

Tan, Dun. “On Taoism.” Tan Dun Official Website. Accessed December 21, 2017. http://tandun.com/composition/on-taoism.

Tan, Dun. "Piano Concerto - The Fire." Tan Dun Official Website. Accessed December 23, 2017. http://tandun.com/composition/piano-concerto-the-fire.

Tan, Dun. "The Banquet Concerto.” Tan Dun Official Website. Accessed December 23, 2017. http://tandun.com/composition/the-banquet-concerto.

Tan, Dun. “Traces.” Tan Dun Official Website. Accessed December 23, 2017. http://tandun.com/composition/traces.

“新舅娸 $M y$ New Sister-in-Law].” 中国曲谱网[Chinese Score Web]. Accessed March 30, 2018. http://www.qupu123.com/shaoer/sanzi/p314585.html. 
“乡里妹子进城来 A Girl from the Country is Coming into Town].”找歌谱[Find Music]. Accessed March 30, 2018. http://www.zhaogepu.com/jianpu/79890.html.

“放牛歌[Shepherd's Song].”中国词曲网[Chinese Song Network]. Accessed March 30, 2018. http://www.ktvc8.com/article/article 566730 1.html. 


\section{APPENDIX}

\section{Score with Annotations by the Author}

2

\section{EIGHT MEMORIES IN WATERCOLOR}

1. Missing Moon
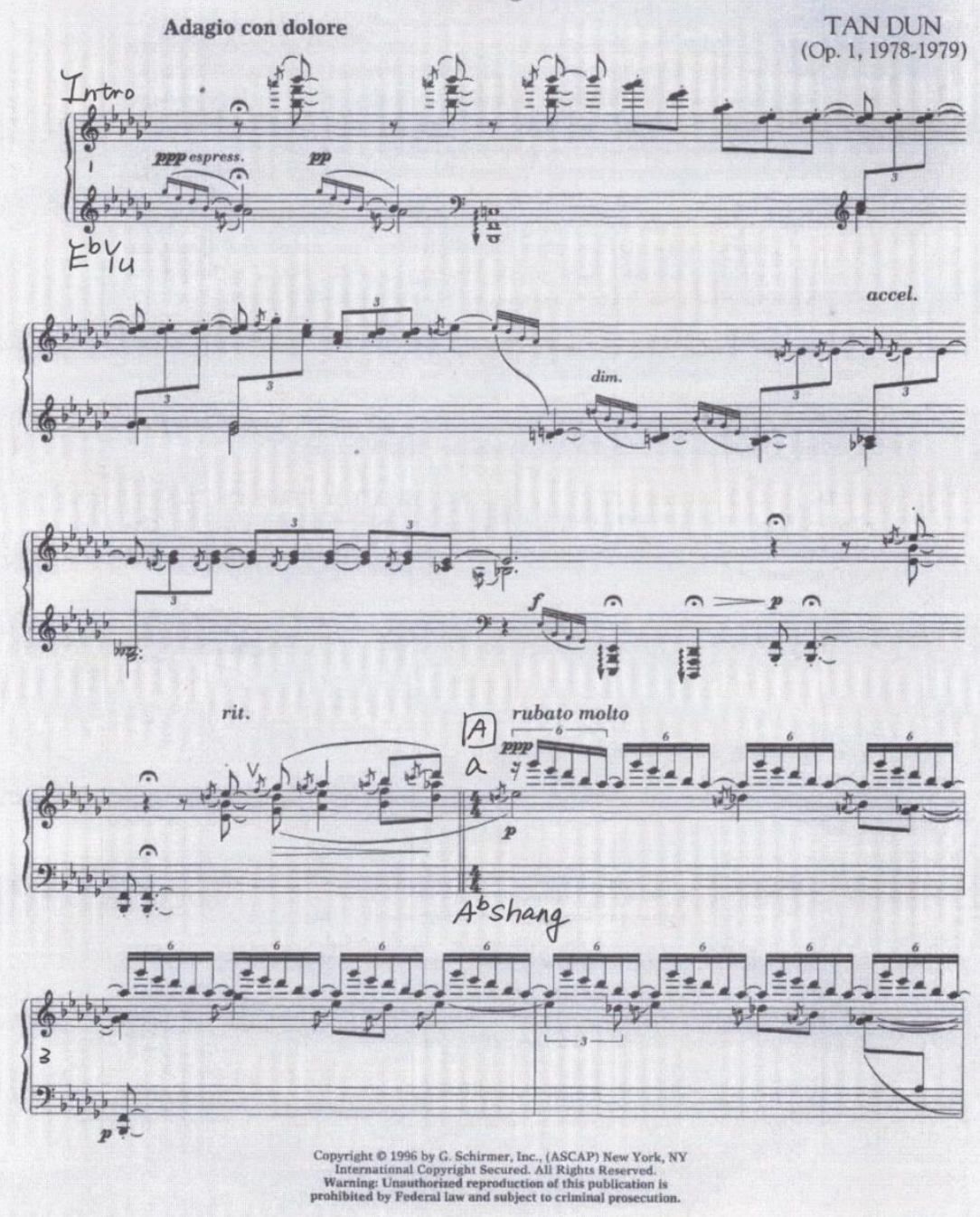

\section{EIGHT MEMORIES IN WATERCOLOR}

By Tan Dun

Copyright $(1996$ by G. Schirmer, Inc. (ASCAP)

International Copyright Secured. All Rights Reserved.

Used by Permission.

Warning: Unauthorized reproduction of this publication is prohibited by Federal Law and is subject to criminal prosecution. 

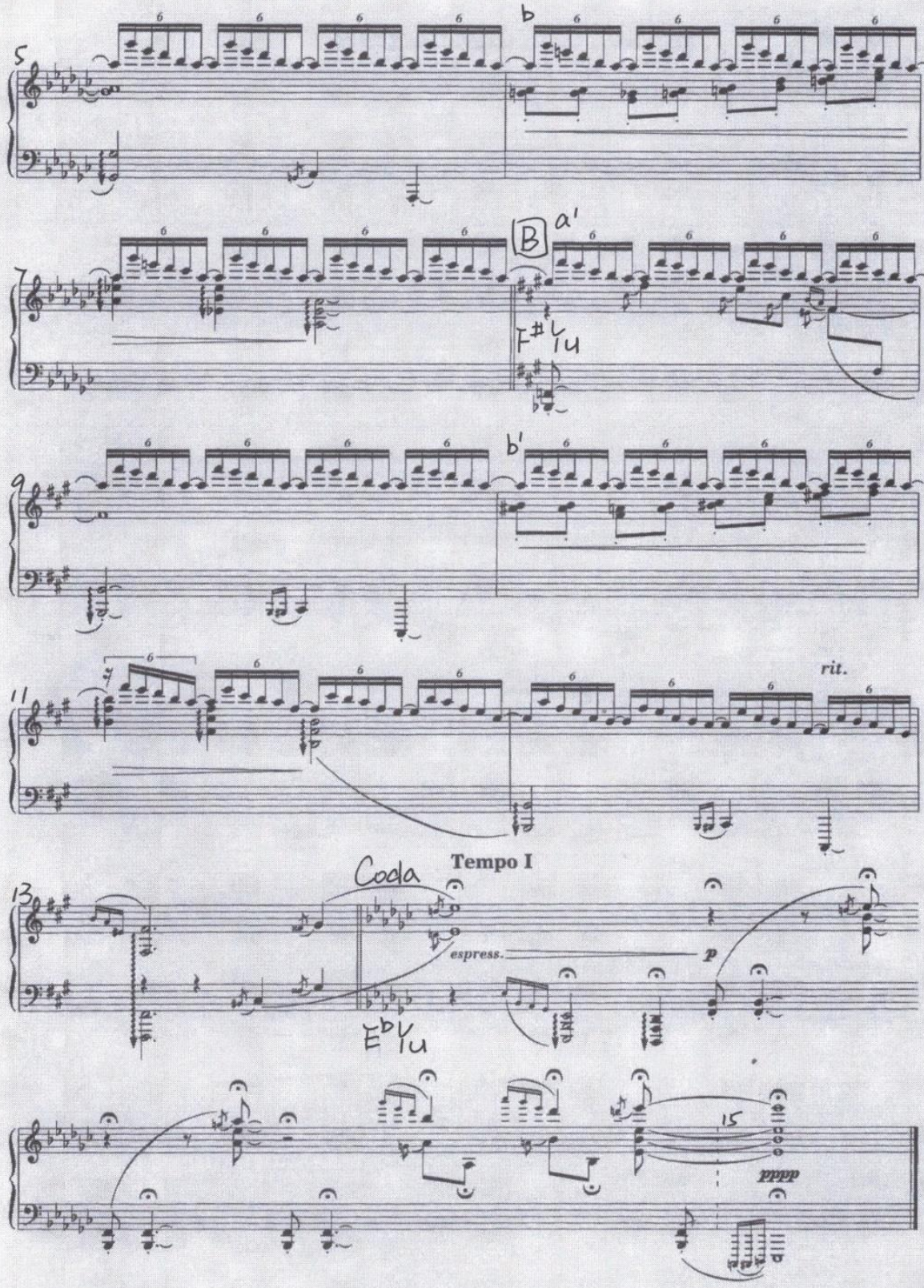

\section{EIGHT MEMORIES IN WATERCOLOR}

By Tan Dun

Copyright (C) 1996 by G. Schirmer, Inc. (ASCAP)

International Copyright Secured. All Rights Reserved.

Used by Permission.

Warning: Unauthorized reproduction of this publication is prohibited by Federal Law and is subject to criminal prosecution. 


\section{Staccato Beans}
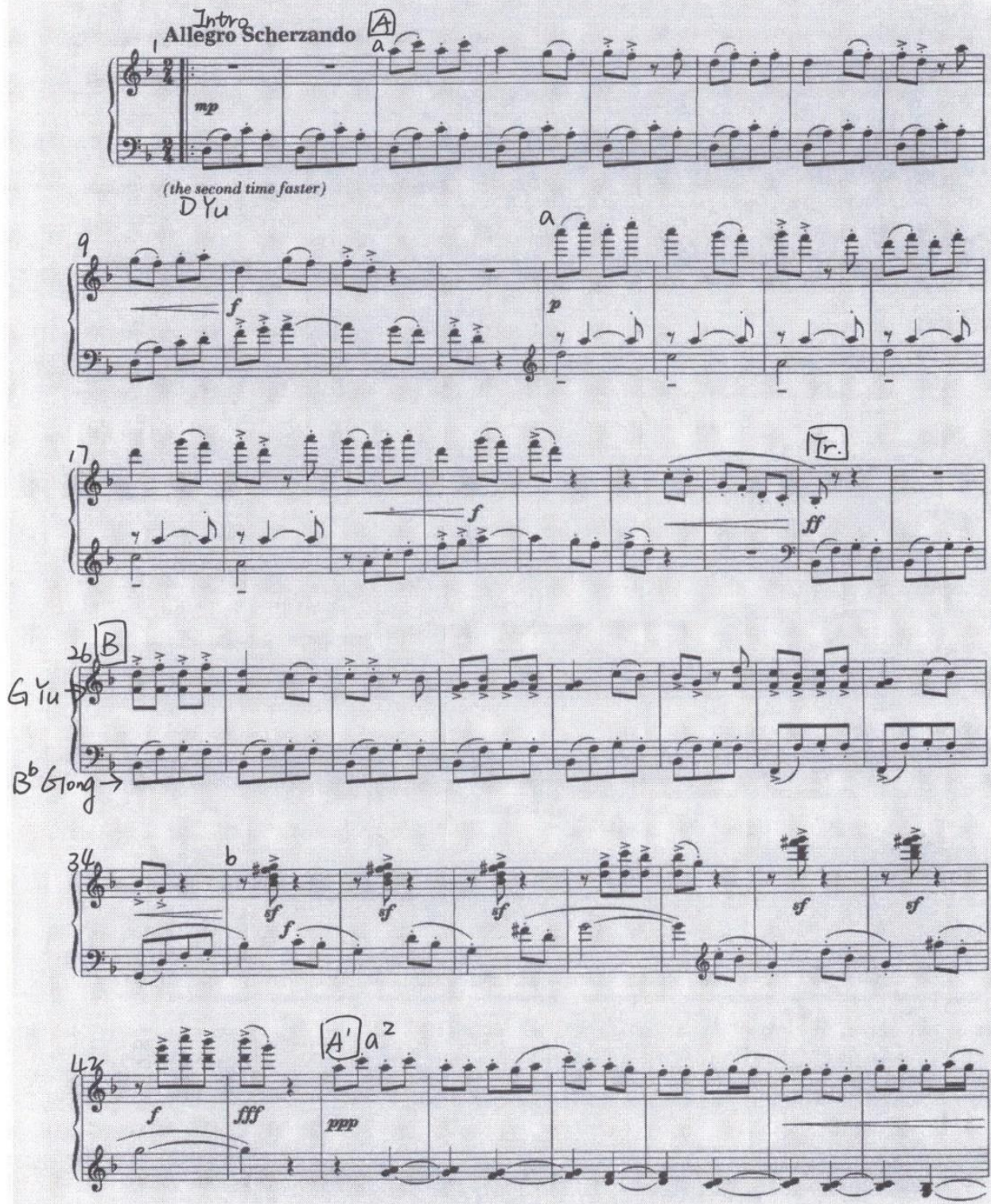

\section{EIGHT MEMORIES IN WATERCOLOR}

By Tan Dun

Copyright $(1996$ by G. Schirmer, Inc. (ASCAP)

International Copyright Secured. All Rights Reserved.

Used by Permission.

Warning: Unauthorized reproduction of this publication is prohibited by Federal Law and is subject to criminal prosecution. 

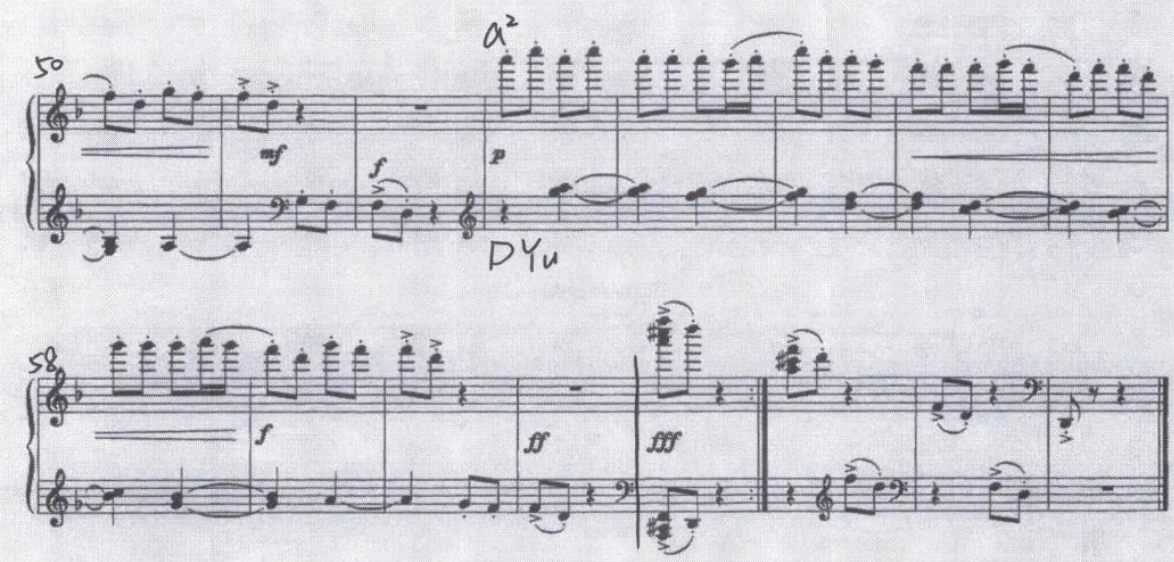

\section{Herdboy's Song}
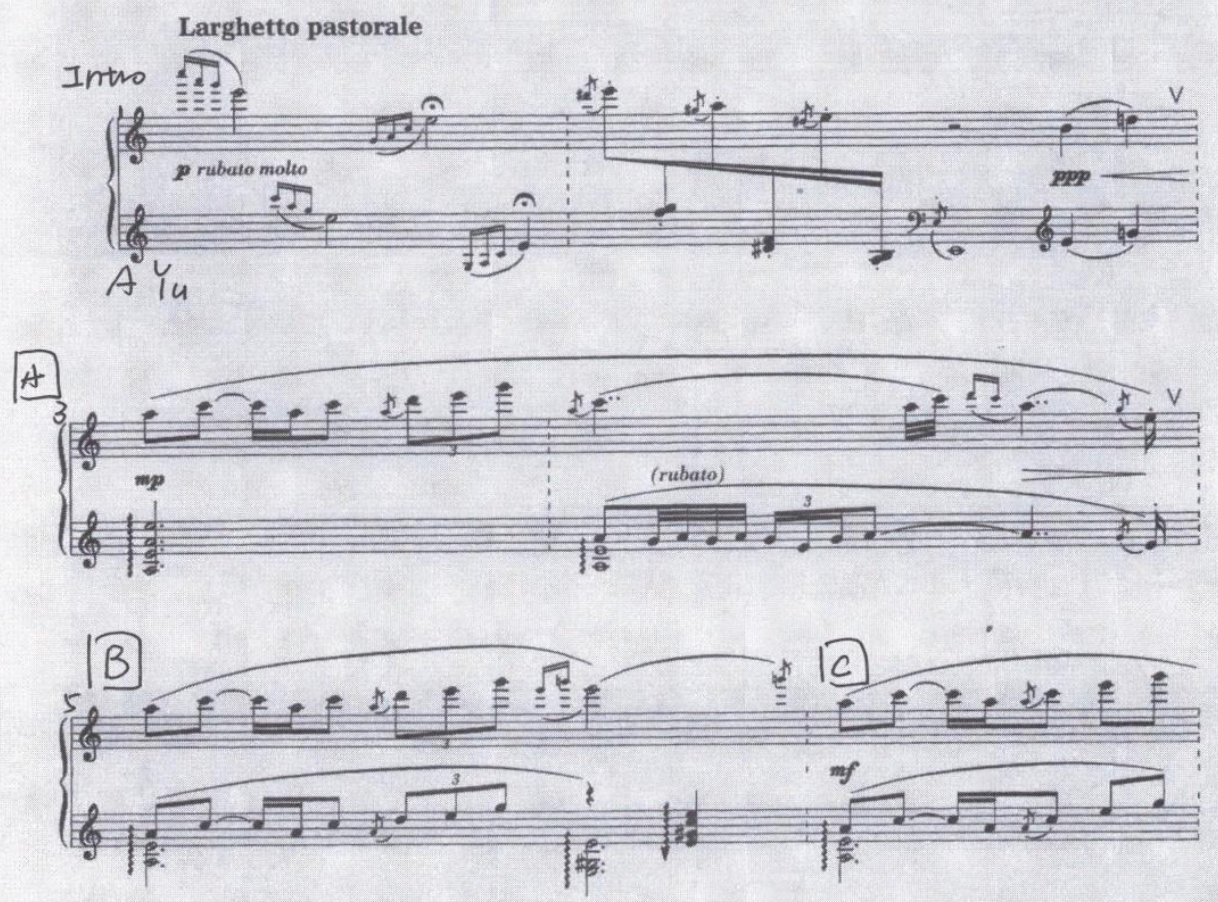

\section{EIGHT MEMORIES IN WATERCOLOR}

By Tan Dun

Copyright (C) 1996 by G. Schirmer, Inc. (ASCAP)

International Copyright Secured. All Rights Reserved.

Used by Permission.

Warning: Unauthorized reproduction of this publication is prohibited by Federal Law and is subject to criminal prosecution. 

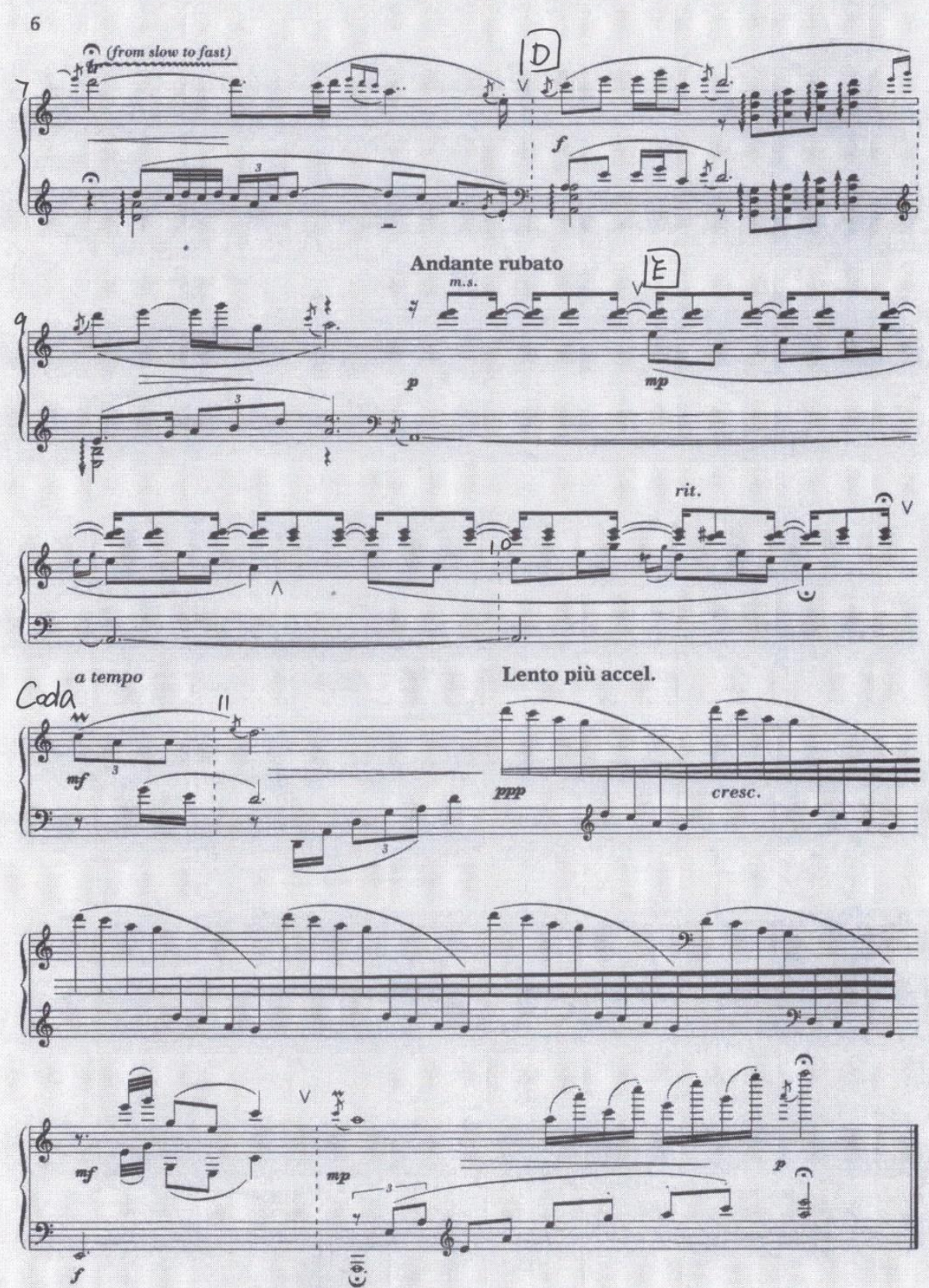

\section{EIGHT MEMORIES IN WATERCOLOR}

By Tan Dun

Copyright (C) 1996 by G. Schirmer, Inc. (ASCAP)

International Copyright Secured. All Rights Reserved.

Used by Permission.

Warning: Unauthorized reproduction of this publication is prohibited by Federal Law and is subject to criminal prosecution. 
A Andante 4. Blue Nun
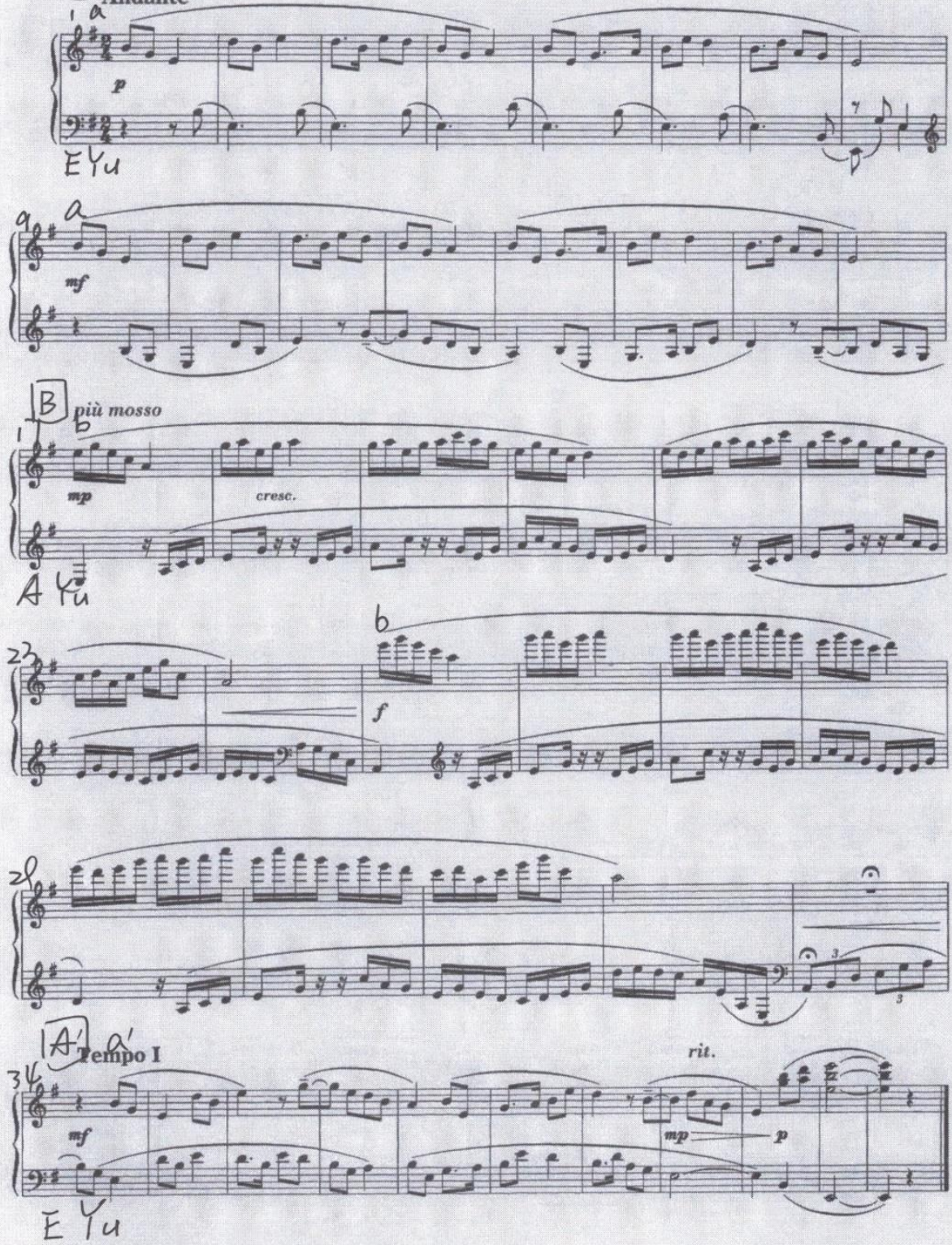

\section{EIGHT MEMORIES IN WATERCOLOR}

By Tan Dun

Copyright (C) 1996 by G. Schirmer, Inc. (ASCAP)

International Copyright Secured. All Rights Reserved.

Used by Permission.

Warning: Unauthorized reproduction of this publication is prohibited by Federal Law and is subject to criminal prosecution. 


\section{Red Wilderness}

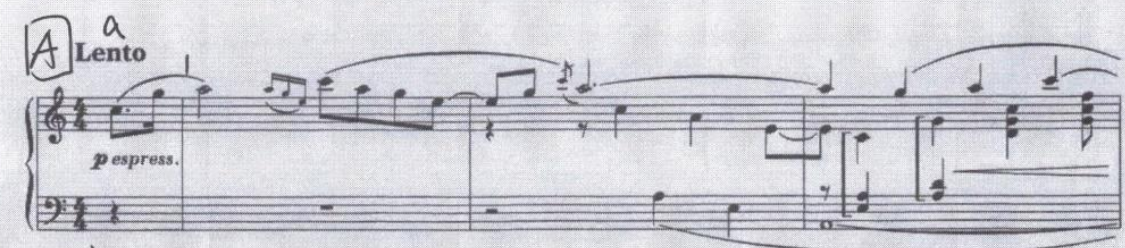

$A Y_{u}$
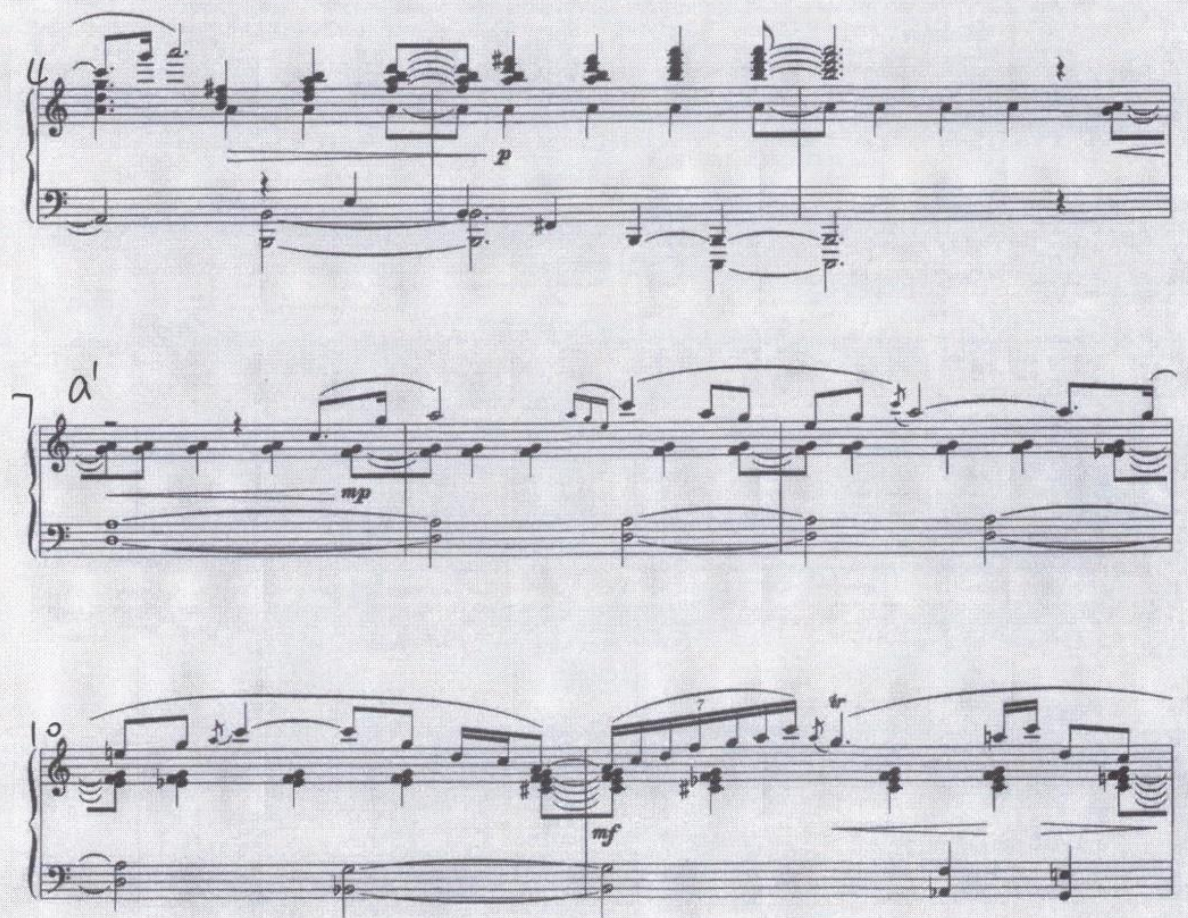

\section{EIGHT MEMORIES IN WATERCOLOR}

By Tan Dun

Copyright $(1996$ by G. Schirmer, Inc. (ASCAP)

International Copyright Secured. All Rights Reserved.

Used by Permission.

Warning: Unauthorized reproduction of this publication is prohibited by Federal Law and is subject to criminal prosecution. 


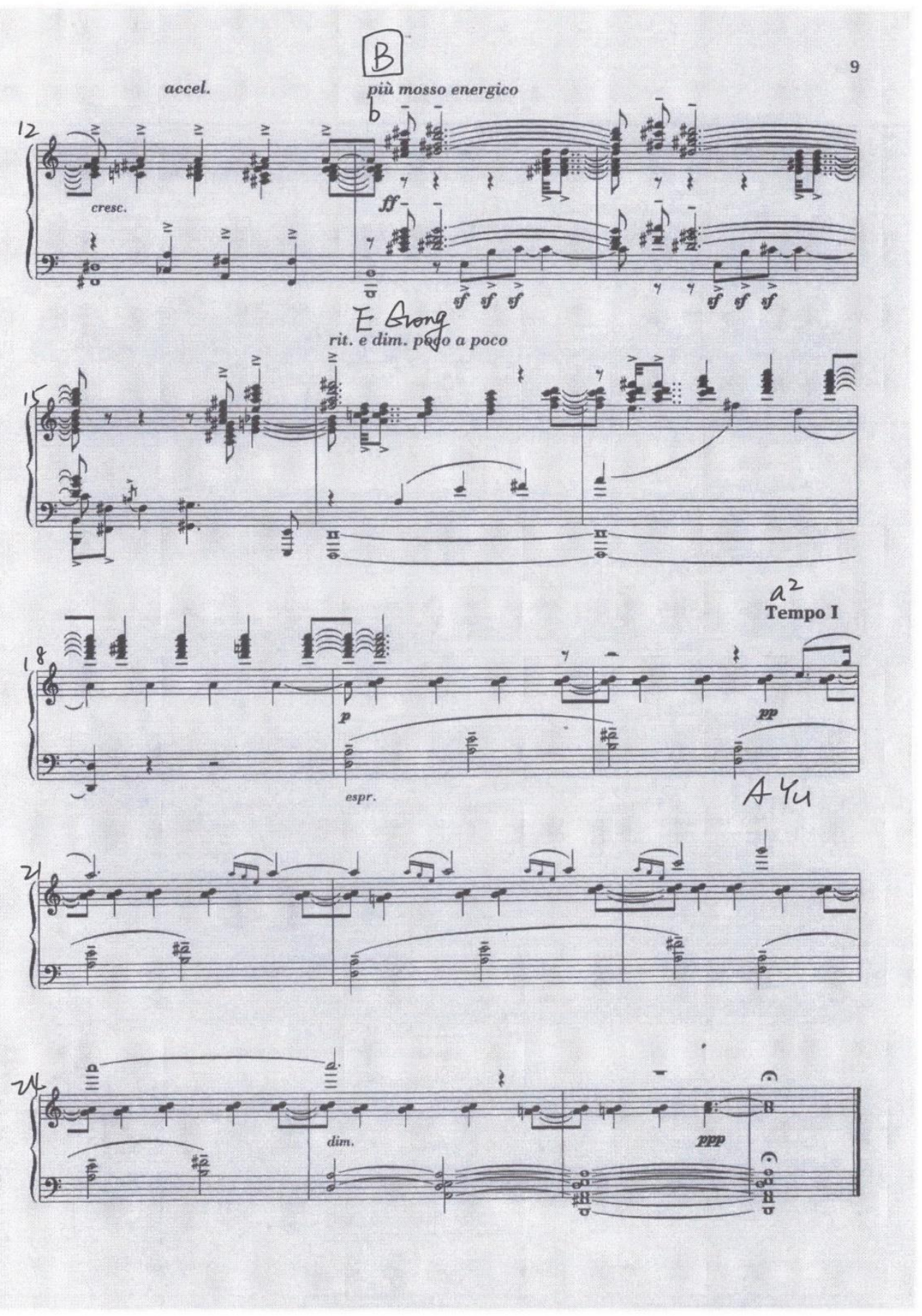

\section{EIGHT MEMORIES IN WATERCOLOR}

By Tan Dun

Copyright $(1996$ by G. Schirmer, Inc. (ASCAP)

International Copyright Secured. All Rights Reserved.

Used by Permission.

Warning: Unauthorized reproduction of this publication is prohibited by Federal Law and is subject to criminal prosecution. 
10
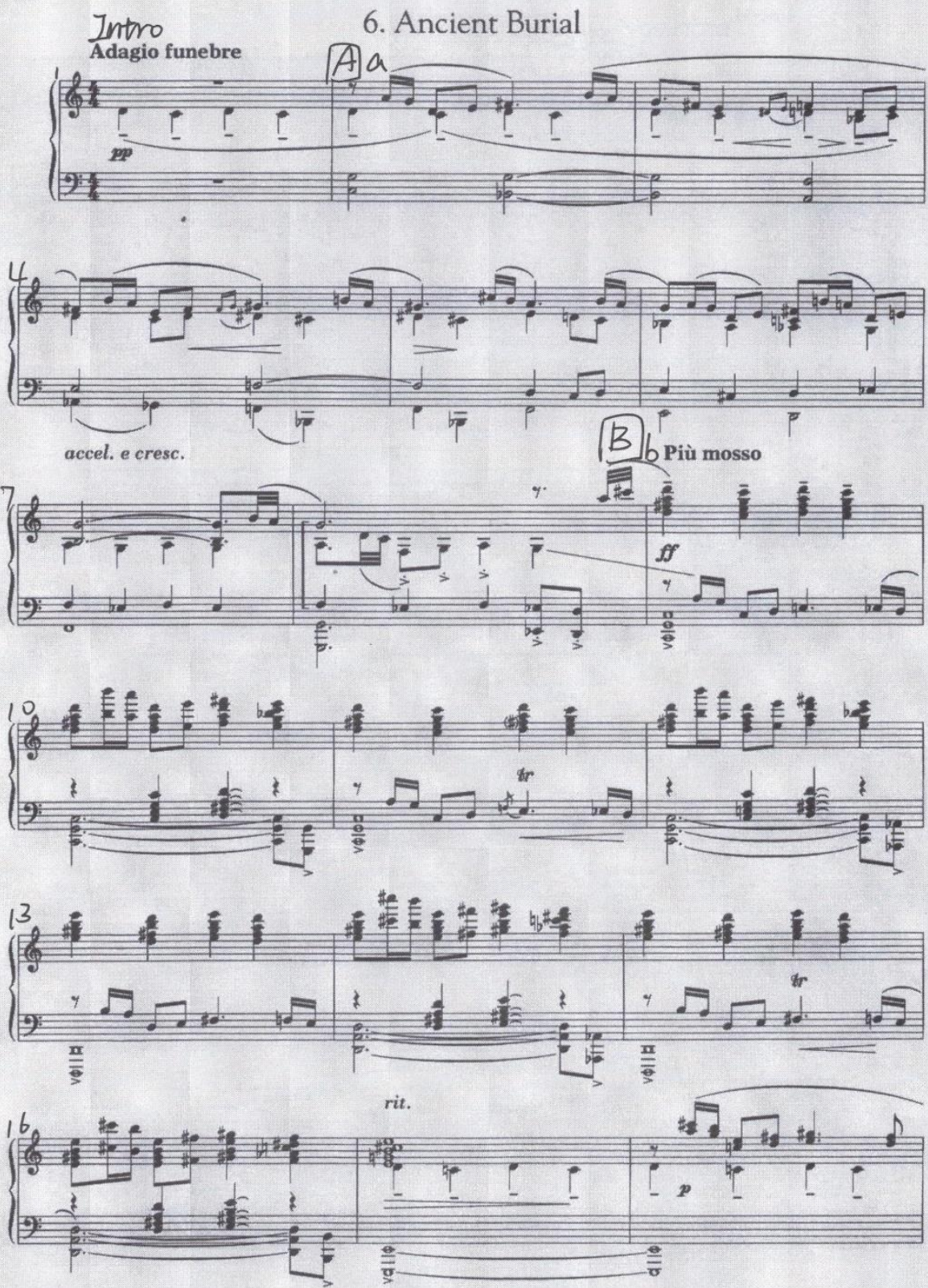

\section{EIGHT MEMORIES IN WATERCOLOR}

By Tan Dun

Copyright $(1996$ by G. Schirmer, Inc. (ASCAP)

International Copyright Secured. All Rights Reserved.

Used by Permission.

Warning: Unauthorized reproduction of this publication is prohibited by Federal Law and is subject to criminal prosecution. 


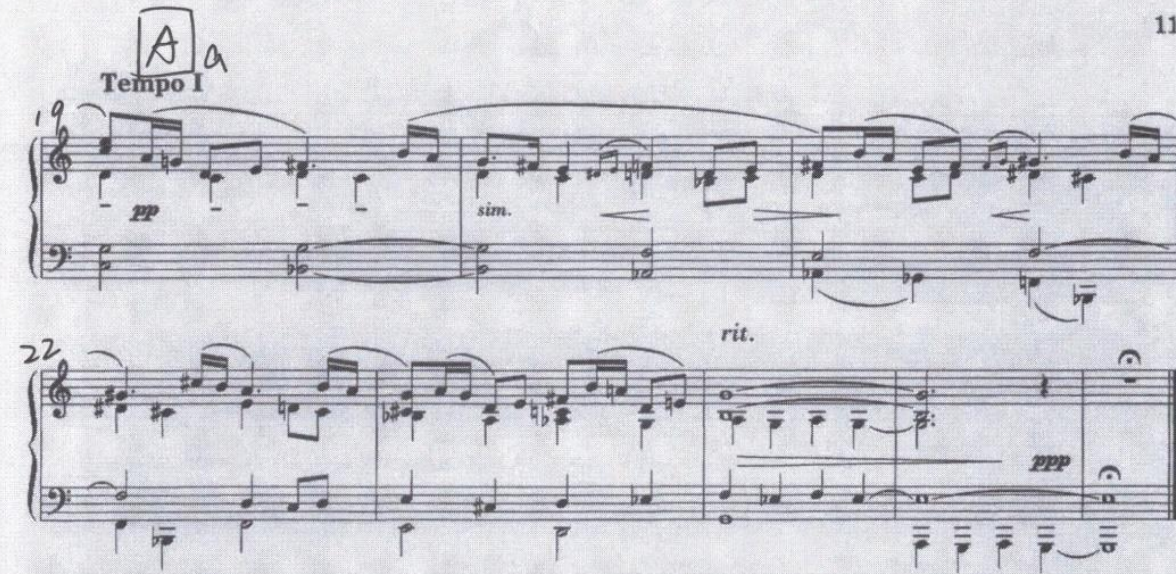

7. Floating Clouds
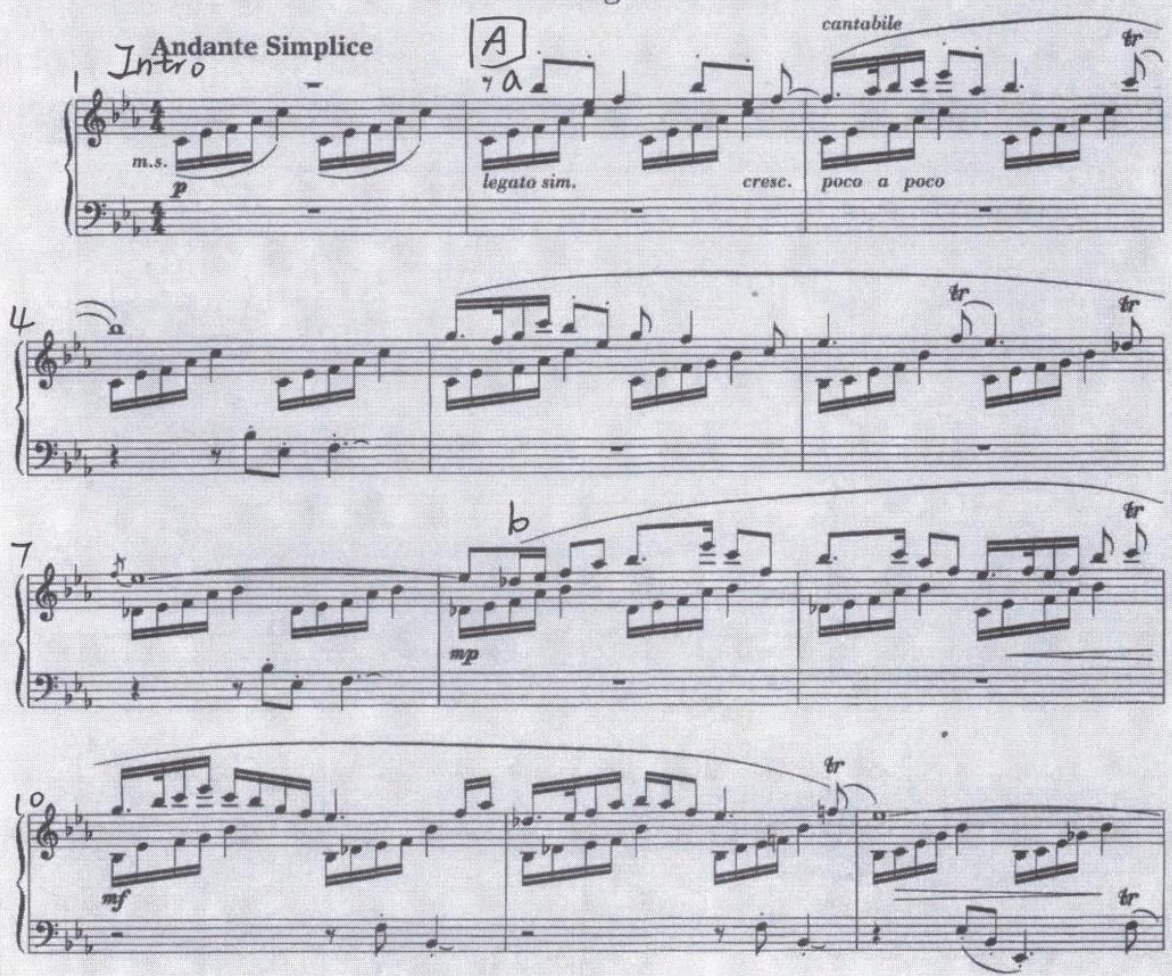

\section{EIGHT MEMORIES IN WATERCOLOR}

By Tan Dun

Copyright (C) 1996 by G. Schirmer, Inc. (ASCAP)

International Copyright Secured. All Rights Reserved.

Used by Permission.

Warning: Unauthorized reproduction of this publication is prohibited by Federal Law and is subject to criminal prosecution. 

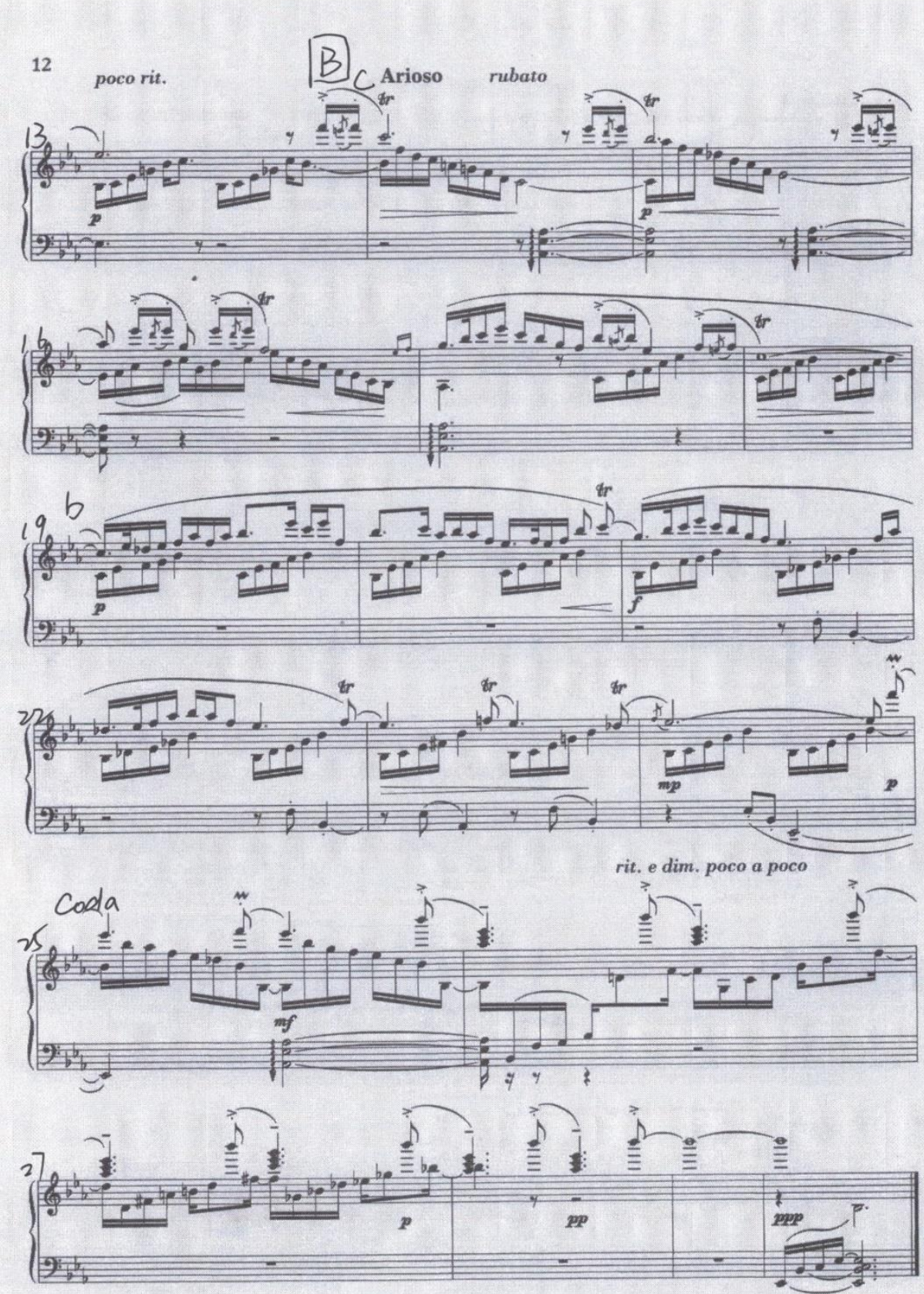

\section{EIGHT MEMORIES IN WATERCOLOR}

By Tan Dun

Copyright (C) 1996 by G. Schirmer, Inc. (ASCAP)

International Copyright Secured. All Rights Reserved.

Used by Permission.

Warning: Unauthorized reproduction of this publication is prohibited by Federal Law and is subject to criminal prosecution. 
8. Sunrain

Intro
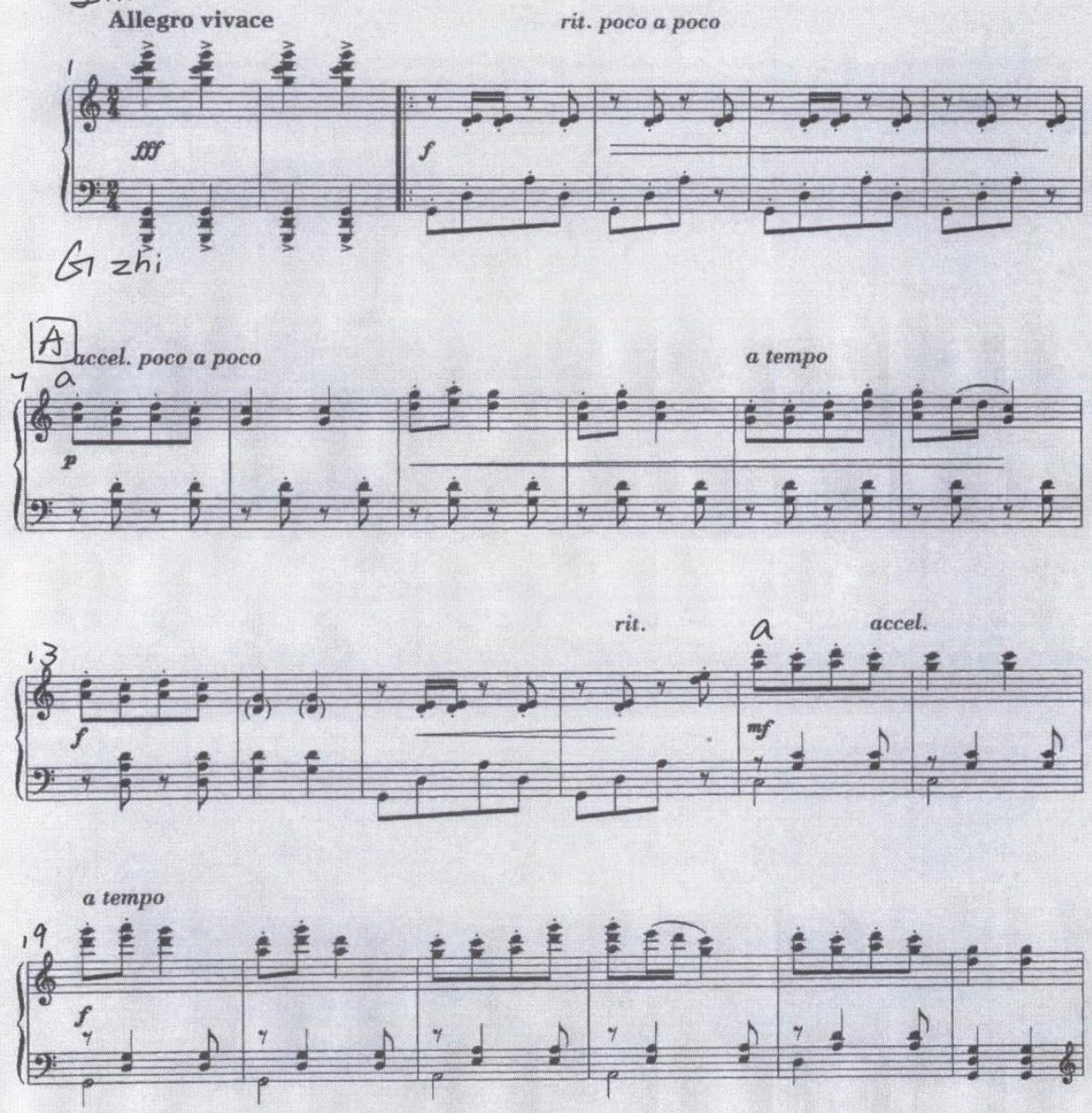

Tran.

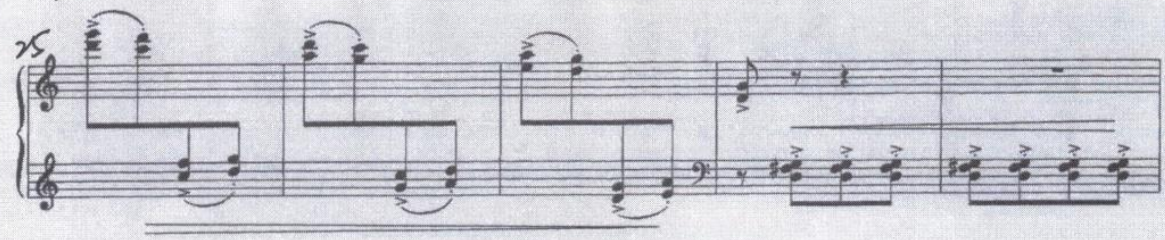

\section{EIGHT MEMORIES IN WATERCOLOR}

By Tan Dun

Copyright (C) 1996 by G. Schirmer, Inc. (ASCAP)

International Copyright Secured. All Rights Reserved.

Used by Permission.

Warning: Unauthorized reproduction of this publication is prohibited by Federal Law and is subject to criminal prosecution. 

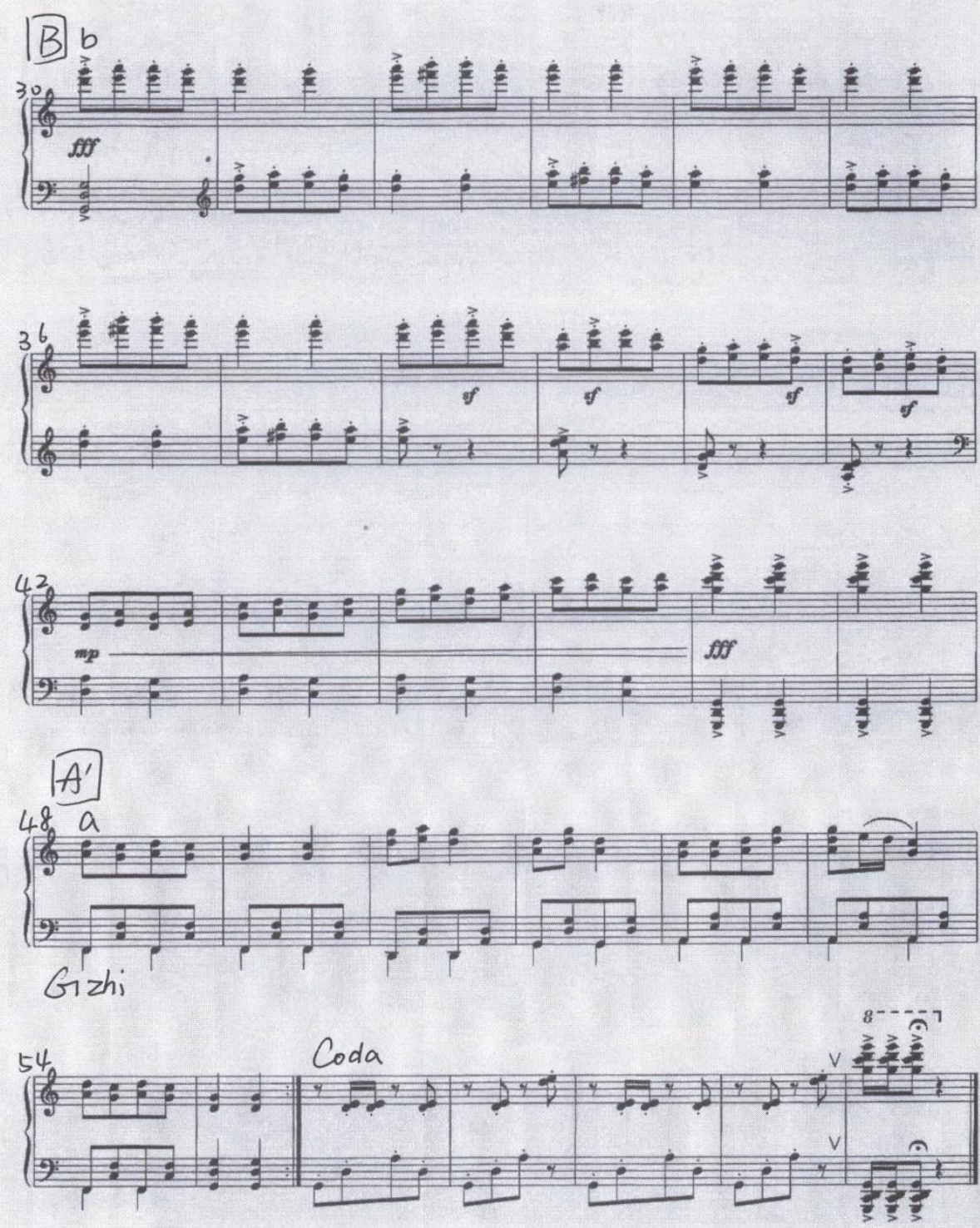

\section{EIGHT MEMORIES IN WATERCOLOR}

By Tan Dun

Copyright $(1996$ by G. Schirmer, Inc. (ASCAP)

International Copyright Secured. All Rights Reserved.

Used by Permission.

Warning: Unauthorized reproduction of this publication is prohibited by Federal Law and is subject to criminal prosecution. 